\title{
NOBODY OWNS WATER: \\ TE TIRITI, TE WAI AND CHANGING PĀKEHĀ
}

by

James Graham

A thesis submitted to the Victoria University of Wellington in fulfilment of the

requirements for the degree of

Master of Environmental Studies

Victoria University of Wellington

2015 
Within the harbour, a white obelisk commemorating the ferocious battle between the Europeans and the Filipinos offers two sharply varying accounts of those events. One face presents the European point of view: 'Here on $27^{\text {th }}$ April 1521 the great Portuguese navigator Hernanado de Magallances in the service of the King of Spain was slain by native Filipinos.' Another face portrays the conflict from the Filipino perspective: 'Here on this spot the great chieftain Lapu repelled an attack by Ferdinand Magellan, killing him and sending his forces away.' (Bergreen, 2003, p. 283) 


\begin{abstract}
Colonisation has been described as being at least in part about securing and controlling natural resources and the history of relationships between indigenous people and subsequent settlers as largely representing a battle for control over those resources (Kahn, 1999). A current example is the contest between Māori and the Crown over access to and control over fresh water resources in Aotearoa/New Zealand, part of a wider assertion of Māori rights under the Treaty of Waitangi (Ruru, 2012; Mikaere, 1997; Wikaira 2010). The Ministry for the Environment reports that Māori assertions of water ownership should be addressed before any changes to water management can occur (Ministry for the Environment, 2005).

Pākehā responses to Māori interests in water are critical to future outcomes for both Pākehā and Māori. How Pākehā views about the Treaty have changed and how they might change in the future will determine how Pākehā respond to Māori claims of rights and interests in water. The views of Pākehā are important because, as the culturally and numerically dominant group in Aotearoa/New Zealand they exert considerable political power.
\end{abstract}

This research investigates how and why Pākehā views about the Treaty of Waitangi, particularly in regard to water, have changed and how and why they may change in the future. A qualitative approach was taken, using a constructionist theoretical lens. Semi-structured interviews with purposively selected Pākehā research participants who had demonstrated knowledge of the Treaty, provided the primary data source. Review of relevant literature provided a secondary data source. The data was analysed thematically to reveal any patterns, themes and contexts of the interview participants' views.

The literature and interviews outlined considerable change in Pākehā views since the 1950s, indicating a growing acceptance that Māori have a special status as tangata whenua and that the Treaty gives specific rights to Māori. This is seen in the acceptance of Māori cultural practices at official functions, limited resourcing of Māori input to resource management decisions, increasing acceptance of te reo in the media, Pākehā adoption of Māori practices and perhaps most significantly acceptance of historic injustice and Crown compensation to iwi through the Treaty settlement process. Empirical evidence from successive surveys by the Human Rights Commission indicate a growing general knowledge and interest in the Treaty of Waitangi. However dominant group 'myth making' remains and resistance to change is evident. 
Pākehā change has occurred in response to external influences like the American civil rights movement, womens' movement, and progressive church anti-racism ideas but critical influences were Māori protests including the 1975 land march, Whāingaroa (Raglan Golf Course), Takaparawhau (Bastion Point) and Pākaitore (Moutoa Gardens). Television made these protests more visible to Pākehā in the 1960s and increased contact between Pākehā and Māori as Māori moved from rural areas to cities from the 1950s were factors. Significant decisions made by the Waitangi Tribunal, government attempts to include the Treaty into policy, the concientising effect of the Springbok rugby tour in 1981 and Treaty education all contributed to changing Pākehā views. Barriers to changing Pākehā views were identified as the unrecognised bias which derives from Pākehā values, their position of dominance and biased media.

The participants foresaw Pākehā becoming more informed, through on going contact with Māori and Māori organisations resulting in increased resourcing of Māori input to resource management decisions and slow devolution of greater authority over resources to Māori authorities. From this it was hoped that Pākehā might develop a greater understanding of the power relationship that exists between Pākehā and Māori resulting in greater sharing of that power.

The interviewees indicated that change would occur if Pākehā could see the benefits that would accrue to them as a group and to Aotearoa/New Zealand, suggesting that this could occur if Pākehā were properly and fully informed. They considered that Pākehā had a responsibility to work with Pākehā and highlighted the importance of Treaty education.

A pattern of three phases of Pākehā change emerged from the interviews. The first was an understanding and acceptance of historic injustice that had led to the Treaty settlement process. The second is development of an understanding of Māori tino rangatiratanga as expressed in Article Two of the Treaty, the first stages of which were being seen in Treaty settlements over natural resources with co-management or co-governance provisions, particularly where they relate to water. The third step, not widely seen in Pākehā society is an acceptance within Aotearoa/New Zealand of a Māori world view. It was expressed that if the second and third steps are to follow the first, considerable further change must occur in Pākehā thinking.

Key words: Te Tiriti o Waitangi, water, tino rangatiratanga, Pākehā views 


\section{Acknowledgements}

I wish to acknowledge the considerable assistance I have received throughout the preparation and writing of this thesis from my supervisor Dr Jessica Hutchings and the ever present encouragement and support of my partner Suzanne Miller. 


\section{Preface}

Many groups in our society hold ideas, attitudes and positions about the world around them which differ depending on their place in society. The roots of these positions are much deeper and more complex that we suspect. Bergreen (2004) in his depiction of Magellan's unsuccessful attempt to circumnavigate the globe notes that in the Philippines today Magellan is portrayed as an invader and murderer, not a courageous explorer. His killer in a battle at Matane, Lapu Lapu is celebrated in a large statue in Mactan Harbour overlooking the Pacific and engraved on a white obelisk within the harbour, two accounts of the battle are recorded. One from the perspective of the Europeans, that the great navigator Magellan in the service of the King of Spain was slain by native Filipinos. The other from the local perspective, that the great chieftain Lapu Lapu repelled Magellan's attack, killing him and sending his forces away. Bergreen (2004) shows how differently conflict and history can be viewed by the protagonists, as relevant in twenty first century Aotearoa/New Zealand as it was when Magellan arrived in the Philippines.

Fernando-Armesto (2006) points out that by the time European sailors had developed the knowledge and technology to enter the Atlantic Ocean and begin exploring south along the African coast some 700 years ago, the extraordinary Polynesian exploration of the Pacific which began more than a thousand years previous, was drawing to a close.

Vaka Moana, Voyages of the Ancestors (Howe, 2006), recounts the discovery and settlement of the Pacific and how Polynesian navigators used the stars, wave patterns, bird sightings and other information to sail cleverly designed ocean going canoes between and beyond the islands in the vast Pacific. Oral traditions provided information, facilitating a complex network of societies, successfully travelling and trading. Eventually these Pacific seafarers settled in what Europeans would call New Zealand.

It must have been a paradise. Geoff Park's Ngā Uruora, The Groves of Life (Park, 1995) and Environmental Histories of New Zealand (Pawson \& Brooking, 2002), paint a picture of the Aotearoa/New Zealand landscape, before any people arrived, where birds in enormous numbers inhabited dense forests which cloaked the mainland and islands in an almost naive existence, oblivious to the destruction which would arrive from the sea.

These two books describe the impact of Māori, the loss of forests and species at their hands and the wholesale destruction of much of what remained in Te Ika a Maui (North Island) and 
to a lesser extent in Te Wai Pounamu (South Island) when English settlers arrived to transform Aotearoa/New Zealand into the place they thought it should be.

The Trial of the Cannibal Dog, Captain Cook in the South Seas (Salmond, 2003) and Bligh, William Bligh in the South Seas (Salmond, 2011) are both insightful explorations of the early interactions and cultural clashes between the societies of the Pacific and the tentacles of European exploration, highlighting the difficulty that each culture found in understanding the motivations, responses and behaviour of the other and exposing the colonising motivations of the Europeans. The dislocation and devastation that European explorers brought to the Pacific, laid the foundations for their goal of establishing colonies, none more so than in Aotearoa/New Zealand.

Joan Druett's book, Tupaia, The Remarkable Story of Captain Cooks Polynesian Navigator (Druett, 2011), challenges the view that explorers from Europe sailed into the unknown. Tupaia, a Tahitian high priest, drew Cook a map showing many Pacific Islands and guided Cook to Aotearoa/New Zealand. When in Aotearoa/New Zealand, Tupaia was able to communicate with Māori, who acknowledged his considerable mana, making him indispensable as an interpreter for Cook.

Harry Evison's Te Wai Pounamu (Evison, 1993), a history of the alienation of South Island Māori from their whenua recalls in detail the events, the people, the agreements, the lies, the abuses and the terrible reality of how English colonisers wrested the land, resources, and means of survival from Ngāi Tahu living in Te Wai Pounamu.

Jared Diamond's Guns, Germs and Steel (Diamond, 1998), provides some explanation of how natures accidents allowed Europeans to develop the tools which would give them an advantage in historical causation, a key to the European belief in their own superiority, sense of entitlement and conviction that they had a right to exploit and colonize the people and lands they encountered.

These books, and others provide an education about the country we live in. Who was here, how they got here and what they have done. But they also provide clues to why we view the world the way we do.

In 2007, I was working for a government ministry which provided me with an opportunity to visit many small Māori communities and marae in Northland and the East Cape. It also allowed me to consider the way in which the Crown engages with Māori communities, expresses the 
concept of 'partnership' under te Tiriti and how little contact there was between those making government decisions and those who were affected by those decisions.

On one occasion, I was involved in interviewing candidates for a District Health Board position. One candidate, who was Māori, when asked about Te Tiriti o Waitangi, put his hand on his heart and said words to the effect that for him, the Treaty was in here, in his heart, it was a part of him. This would not be a universal Māori view and many Māori would not respond to Te Tiriti in this way. Yet for this person it seemed appropriate. He was comfortable and genuine. But it was not a Pākehā response. I couldn't imagine a Pākehā making that response to the question.

Since then I have thought and re-thought this response. Why is there a difference between Māori and Pākehā when it comes to questions about Te Tiriti? Why does Te Tiriti seem to be more important to Māori than Pākehā and what role does, or could, te Tiriti play in the relationship between these two peoples?

It is the books above that have paved the path that led me to the research questions in this thesis and it is these questions that form the foundation of my research.

But of course I do not come to this research with a totally objective view. My background affects my position as a researcher. I am Pākehā, I am male, middle aged and employed in a professional capacity in the water quality area. Subsequently I am also relatively affluent. My ancestors are Welsh, English and French. None of my grandparents were born in Aotearoa/New Zealand. I am embedded in the group that colonized Aotearoa/New Zealand and these circumstances have provided to me, opportunities for success that other New Zealanders may have not had. This position necessarily affects my response to any research about te Tiriti.

I do however, accept that Māori are tangata whenua in Aotearoa/New Zealand and that this fact provides them with some specific rights and authorities. I agree that colonisation by Europeans has been devastating for Māori and that the Crown has a responsibility to provide redress and compensation to Māori. I also believe that Pākehā have a responsibility to actively learn about the colonial history of Aotearoa/New Zealand and to create change toward decolonisation. A fundamental change in their positioning. I suspect that te Tiriti o Waitangi is the most significant document, not only in Aotearoa/New Zealand's past, but also in the present and for the future.

It is my hope that this research can assist in creating this kind of change for Pākehā. 


\section{Table of Contents}

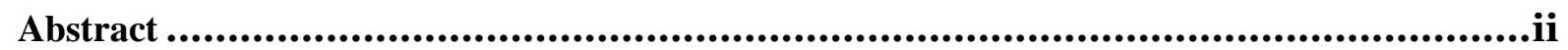

Acknowledgements ....................................................................................... iv

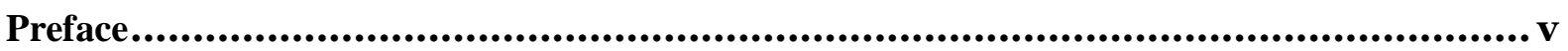

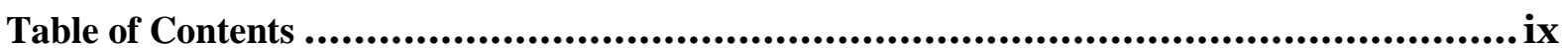

1. Introduction ...................................................................................... 1

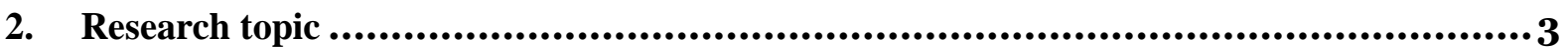

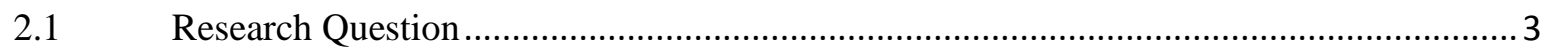

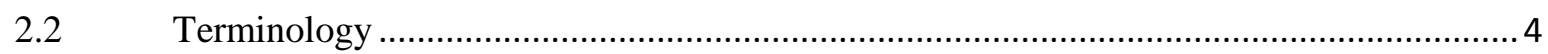

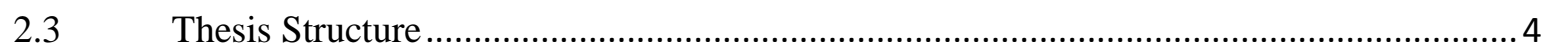

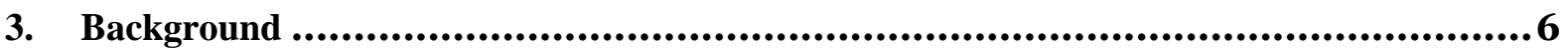

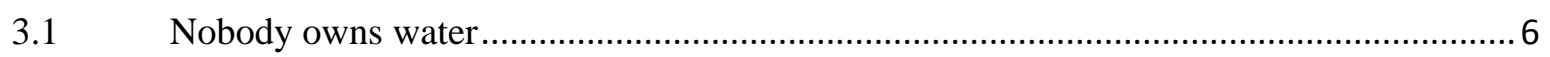

3.2 European 'discovery’ of Aotearoa/New Zealand .............................................................. 7

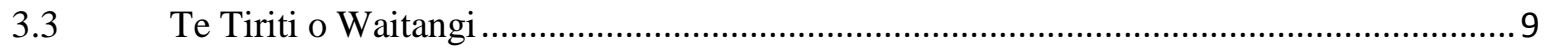

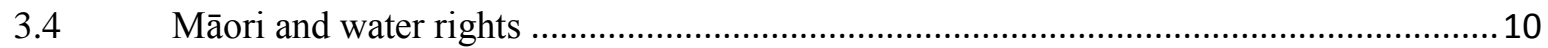

4. Literature Review: Māori, Pākehā, te wai and te Tiriti....................................... 12

4.1 Historical changes in perceptions of te Tiriti............................................................. 14

4.2 Indigeneity: Who are we and who belongs?........................................................... 17

4.3 What does the empirical evidence tell us about what we think? ......................................21

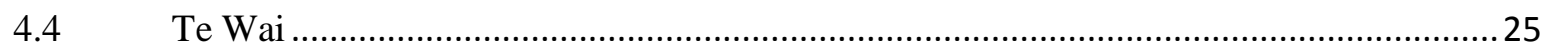

4.5 Inequality, power relationships and Treaty settlements. ................................................ 30

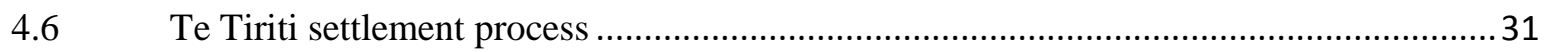

4.7 Pākehā opposition to the realisation of Māori rights ...................................................... 34

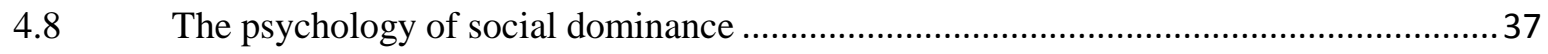

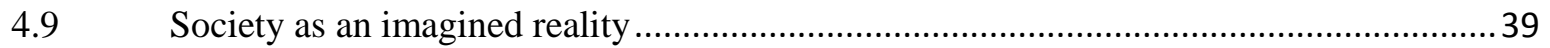

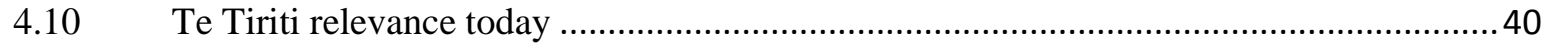

4.11 Making progress: Tiriti education and Pākehā as allies? ............................................... 42

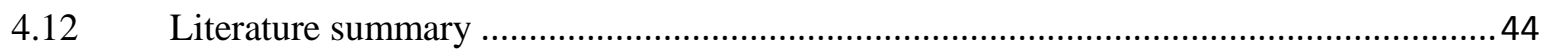

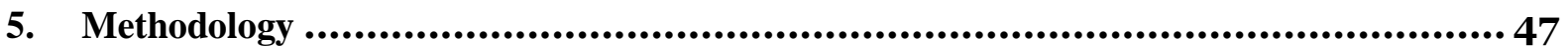

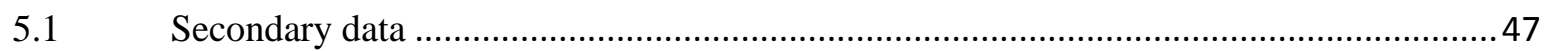

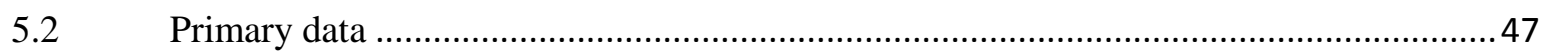

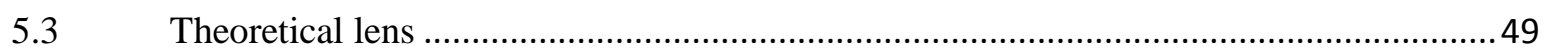

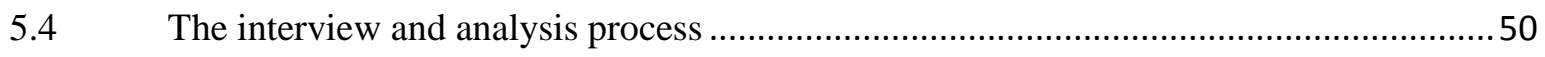


6. Results - "It's up to us to commit to the process" "............................................52

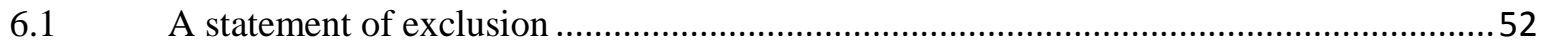

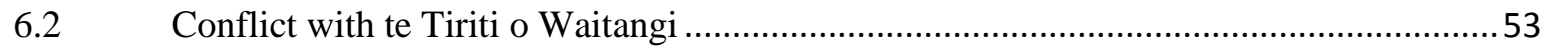

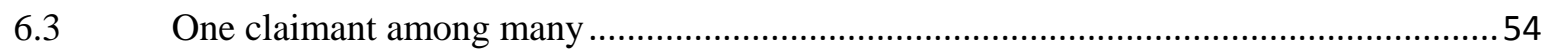

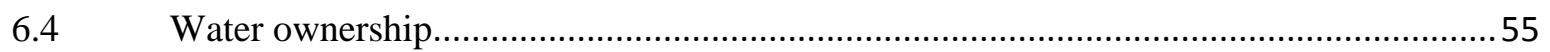

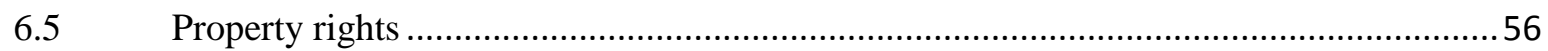

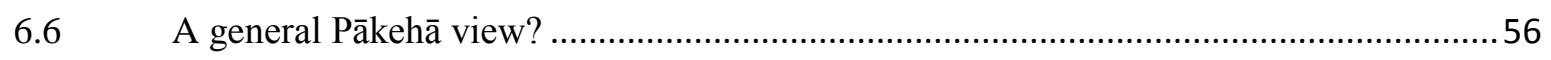

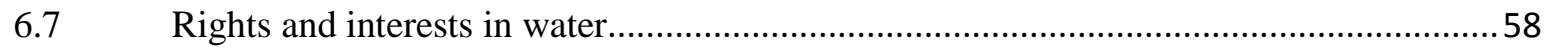

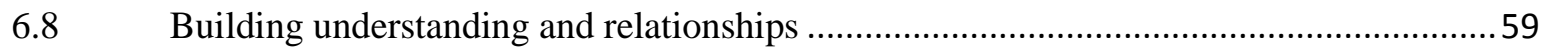

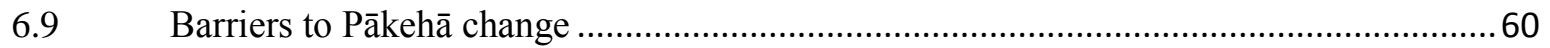

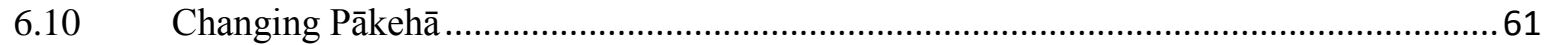

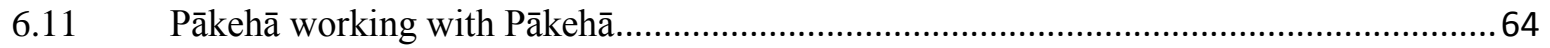

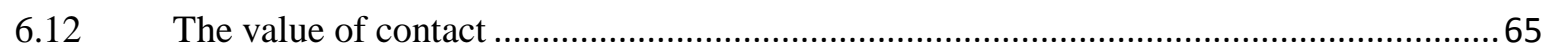

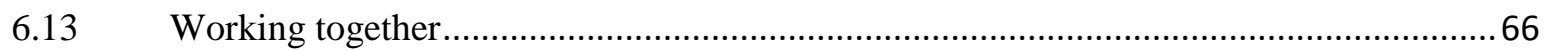

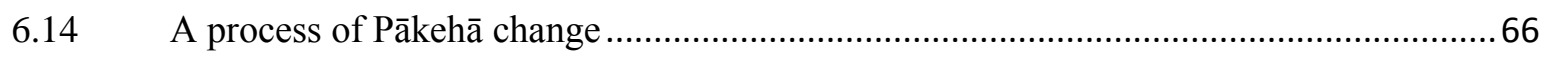

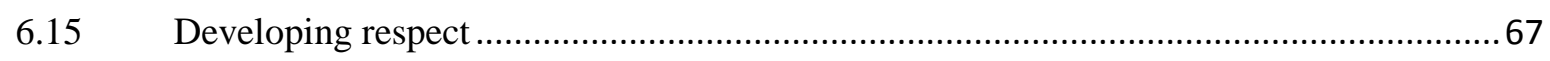

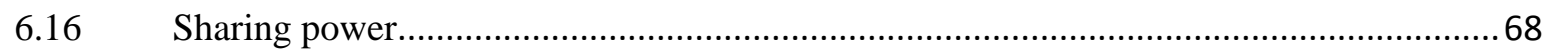

6.17 Understanding and Pākehā adoption of Māori practices ..................................................... 69

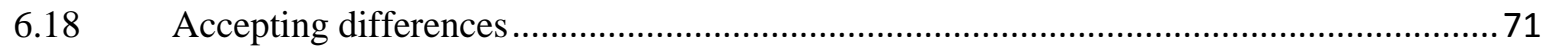

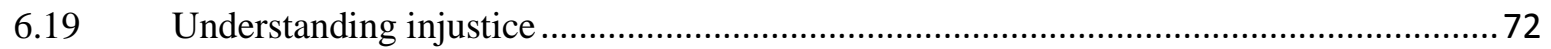

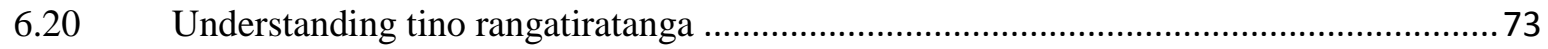

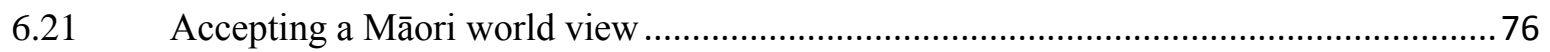

6.22 Why would Pākehā views change? ............................................................................ 77

7 Discussion - "In the end, no-one gets off the island" ........................................79

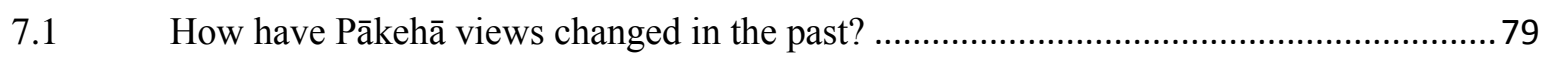

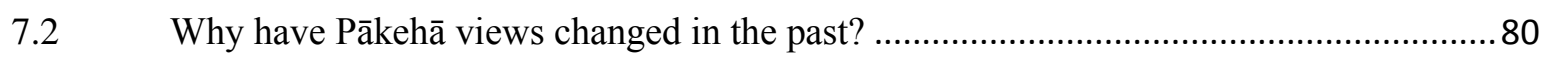

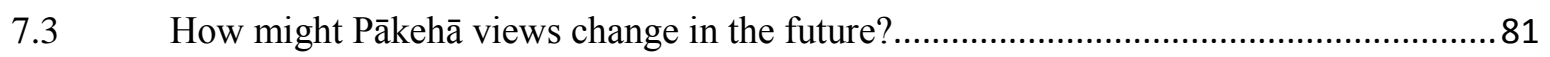

7.4 Why might Pākehā views change in the future? .......................................................... 82

7.5 Can transformative change to Pākehā views occur? ........................................................ 82

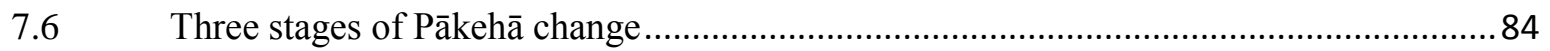

7.7 Who should decide Māori rights and interests in water?................................................. 89

7.8 Nobody owns water: what is behind the statement ...................................................90

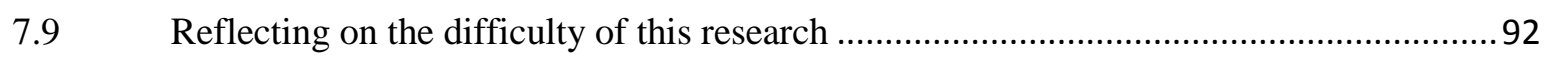

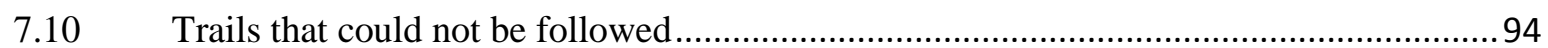


8 Conclusion - "We've got the potential to do something different and unique and special" 97 Appendices ..................................................................................................101

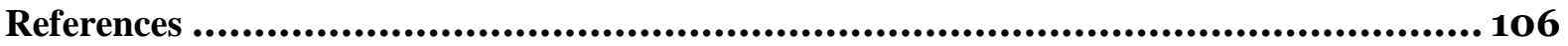




\section{Figures}

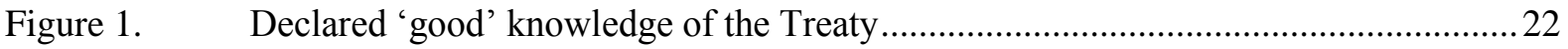

Figure 2. Declared 'reasonable' knowledge of the Treaty .........................................................23

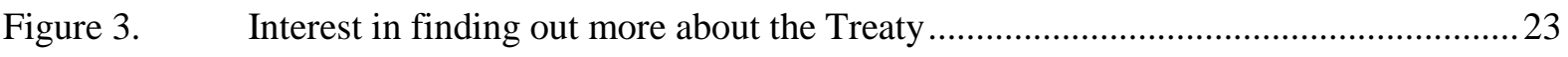

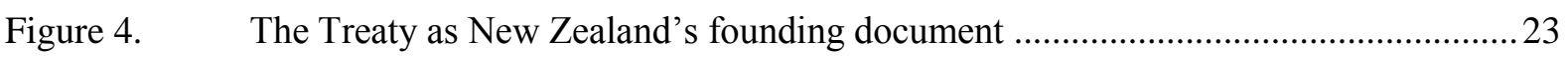

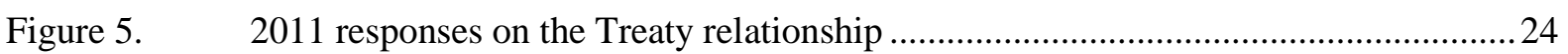




\section{Introduction}

Access to and control over fresh water resources in Aotearoa/New Zealand, is an area of considerable contest between Māori and the Crown (Ruru, 2012; Mikaere, 1997; Wikaira 2010). This was seen in 2012 when the Māori Council opposed the government programme of selling 49 per cent of the state owned enterprise Meridian Energy which uses fresh water resources to generate electricity. Contest over water resources is part of a wider assertion of Māori rights under te Tiriti o Waitangi (the Treaty of Waitangi) ${ }^{1}$, demonstrated recently in the release of the Waitangi Tribunal report, Stage 1 of the Te Paparahi o te Raki Inquiry (Waitangi Tribunal, 2014) which asserts that Treaty signatories did not cede sovereignty to the Crown in 1840. Responses to the report include assertions that it rewrites our history (de Graf \& Dinsdale, 2014), that it distorts our history (Bennett \& Quilliam, 2014a), and that it changes nothing (Bennett \& Quilliam, 2014b).

Iwi, hapū, whānau and diverse Māori communities have been urging governments to consider the question of Māori 'interests' in water for some time. The Ministry for the Environment report Wai Ora: Report of the Sustainable Water Programme of Action Consultation Hui (Ministry for the Environment [MfE], 2005), records clearly, Māori ${ }^{2}$ assertions that the issue of water ownership should be addressed before any changes to water management can occur.

Pākehā $\bar{a}^{3}$ responses to Māori interests in water are critical to future outcomes for both Pākehā and Māori. How Pākehā views about te Tiriti have changed and how they might change in the future will determine how Pākehā respond to Māori claims of rights and interests in water. The views of Pākehā are important because as the culturally and numerically dominant group in Aotearoa/New Zealand ${ }^{4}$ they exert considerable political power. Democratic governments are elected by majorities.

\footnotetext{
${ }^{1}$ Te Tiriti o Waitangi or te Tiriti is used in preference to the Treaty of Waitangi throughout the thesis as it privileges the Māori version of this document and seeks to counter the dominance of the English version. Where reference is made to authors who refer to the Treaty of Waitangi or the Treaty, their preference to use the English title is respected and repeated. The same applies to authors who use te Tiriti. Mikaere (2011) highlights significant differences between the English and Māori versions of te Tiriti and discusses the politics of referring to it in te reo or english.

${ }^{2}$ Use of the term Māori throughout this thesis is not intended to essentialise Māori views, but refers to the range of iwi, hapu, whanau and diverse Māori communities.

${ }^{3}$ The word Pākehā is used to refer to pale skinned New Zealanders of European descent.

${ }^{4}$ Aotearoa/New Zealand is used to refer the country of New Zealand except where an author is referenced, in which case the language of the author is used.
} 
This thesis explores changing Pākehā views about te Tiriti and water resources. It investigates how and why Pākehā views about te Tiriti o Waitangi, particularly in regard to water, have changed and how and why they may change in the future.

While researching topics for this thesis, I concluded that all fresh water topics are subordinate to the question of who has authority over water. In the end, questions of resource rentals, deteriorating water quality and access to water resources, cannot be resolved until the question of authority over water is resolved. Understanding changing Pākehā views I believe, can critically inform that question. 


\section{Research Topic}

This research investigates how Pākehā views have changed and may change further regarding fresh water resources and te Tiriti o Waitangi. A qualitative approach is taken, using semistructured interviews with purposively selected Pākehā interview participants as the primary data source. Review of relevant literature provides a secondary data source. The data has been analysed thematically to reveal any patterns, themes and contexts of the interview participants' views.

Exploring those changing views can provide guidance to those involved in education or policy that may affect Māori rights and interests in water. This research also seeks to contribute to the wider discourse of environmental studies by highlighting the importance of understanding those changing views and the implications they may have when investigations into human interactions with natural resources are undertaken.

\subsection{Research Question}

This thesis asks: how and why have Pākehā views of te Tiriti and Māori changed over time and how they might change in the future? The question is considered in relation to water resources, but necessarily considers a broader context.

In the 1980s the fourth Labour Government began a Treaty settlement process, one hundred and forty years after te Tiriti o Waitangi was signed. It seems apparent that the settlement process has only been politically achievable because of considerable changes in Pākehā attitudes to Māori, te Tiriti and a growing understanding of historic injustice.

If the Crown is to now negotiate Māori rights and interests in water resources, rights and interests that it has acknowledged, what further change might be required to Pākehā views, particularly in relation to te Tiriti and water resources.

This research seeks to consider these questions.

A significant challenge of this research is that the researcher is a member of the culturally dominant group that is being investigated. It considers the views of colonisers, but is undertaken by a member of the colonising group. The research takes place in an on-going colonial context. Tuhiwai Smith (2012) outlines the links between research, imperialism and colonialism and highlights that through research, Māori are still being colonised. Though this research is about Pākehā views and knowledge, and the subjects of the research are Pākehā, the topics of discussion include Māori aspirations, entitlements, control of fresh water 
resources and te Tiriti o Waitangi. Within the research, consideration is given to the implications of the researcher being a member of the culturally dominant group in Aotearoa/New Zealand and how this affects the research. For example, throughout the research process, an awareness was maintained of situations where culturally dominant assumptions were made. Those situations are considered and reported on within the discussion of the participants responses.

\subsection{Terminology}

I use the terms Māori and Pākehā throughout this research following comments from King (1999) that the words have meaning, appropriateness and relevance in an Aotearoa/New Zealand context and provide valid cultural options. However I am aware that O'Sullivan (2008) cautions that it is exclusionary and misleading to use the words Pākehā and Crown interchangeably because Māori, by virtue of their citizenship and political representation have a right to share in the collective sovereignty of the Crown, apart from any implications arising from their first occupancy status.

I also use the terms dominant group and dominant culture to define the culture-defining group or group whose culture constitutes the implicit norm for broader society. In Aotearoa/New Zealand this group is Pākehā, the white descendants of British settlers who maintain cultural dominance in virtually all government institutions and in many other aspects of society.

I have chosen to privilege Māori terms where I can. I do this because Māori words better express Māori ideas than English translations and because including Māori words into mainstream language use acknowledges the value and contribution of te reo to understanding the issues under discussion. The meaning of Māori words needs to be understood within a Māori knowledge context as Māori language meaning can easily be lost in translation. I also use Māori words because it is a small way in which I can support te reo.

\subsection{Thesis Structure}

This thesis has a relatively conventional structure but is exegetical, "building its ideas through the writing process itself" (Carter, Kelly, \& Brailsford, 2012, p.32). It seeks to build a story from quotes obtained through interviews with informed people and attempts to provide a voice for those interview participants.

There are eight chapters to the thesis. Chapter one broadly introduces the topic. Chapter two considers the research topic and question. Chapter three, provides some background to the 
research question, framing it in a historical context and arguing that colonialism is a contest for resources. It also provides a contemporary context, referring to a statement made in 2012 by the Prime Minister that, nobody owns water (Young, 2012). That statement provides an important touchstone throughout the thesis. This chapter then considers te Tiriti in relation to the thesis topic. In chapter four, I unpack the literature that informs this research. While there is not a great deal of literature specific to the topic, there is extensive writing that relates to the research and identifies the themes that emerge later in the interviews. Chapter five sets out the methodology for this qualitative research and explains why a constructionist approach using semi-structured interviews was chosen. Chapter six seeks to reveal the collective story that the interview participants tell. This chapter is extensive and relies heavily on direct quotes from the interviews in an attempt to allow the interviewees voices to be heard. The quotes are structured into the themes that emerge which in turn are organised to provide a coherent progression of thought. Chapter seven discusses the themes and links them to the literature review, picking up the key ideas and commenting on their significance. Further literature relevant to the discussion of the ideas is also introduced. Chapter eight provides a conclusion to the research . A list of references is then provided. 


\section{Background}

This chapter provides some background relevant to the research topic and considers the sale of shares in Meridian Energy and comments made by the Prime Minister in 2012 in relation to that sale. It also looks at the historic colonial context of the contest for water resources.

\subsection{Nobody owns water}

Māori frustration at the Crown's assumption of rights of power and control over water, expressed in the Crown's intention to partially privatise Meridian Energy resulted in an urgent claim by the Māori Council ${ }^{5}$ to the Waitangi Tribunal in 2012. The Waitangi Tribunal agreed to hear the claim that te Tiriti o Waitangi protected Māori commercial proprietary interests in water and that a breach would occur if the Crown proceeded with the share sales. The Tribunal decision supported the Māori claimants and found that Māori had rights and interests in water bodies for which the closest English equivalent in 1840, was ownership. It also found that these rights were confirmed, guaranteed, and protected by the Treaty of Waitangi, but that there was an expectation in the Treaty that water would be shared with settlers (Waitangi Tribunal, 2012). The government, in its defence, stated clearly that it acknowledged that Māori had interests and rights in freshwater resources, but claimed the sale of shares in the state owned enterprise would not compromise Māori compensation for any future claims they made over those resources (Ruru, 2012).

After a short consultation period with Māori, the government indicated an intention to proceed with the share sale. The Māori Council took their case to the High Court where their claims were rejected and an appeal was made to the Supreme Court. Again the Māori claims were rejected, the Supreme Court finding in favour of the Crown.

At the time, Prime Minister, the Right Honourable John Key, suggested that nobody owns water, that water is like air and cannot be owned. Water ownership would not be negotiated with Māori, Key indicated (Young, 2012).

As the process of Tiriti settlements nears an end, many people speak of entering a postsettlement era. It can be expected that matters will be raised through this next phase of te Tiriti process, which until now have not been issues. The actions of the Māori Council suggest that rights and interests in water may well be one of those matters.

\footnotetext{
${ }^{5}$ The New Zealand Māori Council, Te Kaunihera Māori o Aotearoa, is a statutory body established by the Māori which leads Māori policy development at the national level and community development at a local level and works with Iwi Leaders' and the Iwi Leadership Group.
} 
Prime Minister Key's view has been challenged by some Māori. Māori King Tuheitia responded emphatically, suggesting that Māori have always owned water (Bosselmann, 2012). At the Waitangi Tribunal hearing, Taipari Munro, a Whangarei kaumatua from Te Parawhau, clearly indicated that he did not accept the view that nobody owned water (Bennett, 2012).

Māori Council co-chairman, Sir Eddie Durie indicated where some misunderstanding may occur, outlining that particular streams, lakes, rivers, aquifers and springs that Māori claimants have used, have acquired a customary law interest for them. He suggested that there were prior interests in some fresh water resources, before they were to be allocated to private shareholders through the sale of Mighty River Power (Bennett, 2012).

One Tribunal submitter, Tony Hirapi of Te Arawa sub-tribe Tapuika Tiaki clearly illustrated Māori concern when he pointed out that rights where not asserted when water was used by the government to benefit the national interest, but when the water is used to benefit private individuals, there is disagreement (Bennett, 2012).

Though the current government's acknowledgement of Māori interests and rights in fresh water resources is far short of providing the authority over water that some Māori seek (Waitangi Tribunal, 2012) it highlights a change from the position of previous governments. In spite of this, the difference of position today has roots which pre-date the first contact between Pākehā and Māori.

\subsection{European 'discovery' of Aotearoa/New Zealand}

In his book about the global history of exploration, Fernandez-Armesto (2006) describes history as having two stories. The first is the story of divergence, the longest story, extending over more than 150,000 years since the emergence of Homo sapiens in Africa, almost to the present. Fernandez-Armesto (2006) suggests there is general agreement amongst historians and anthropologists that all extra-African humans are descendant from a single group of migrant Homo sapiens who were established in the Middle East about 70,000 years ago and who radiated rapidly across the globe.

The second story of history that Fernandez-Armesto (2006) describes is the story of convergence. The meeting of peoples from civilisations which had developed in different parts of the globe, after transport technology development facilitated exploration. Though limited convergence has occurred in some shape or form since divergence began, Fernandez-Armesto (2006) argues that convergence has become conspicuous in perhaps the last 500 years as 
European exploration provided routes for migration, trade and cultural exchange on a massive scale.

From about 1490 the age of exploration was motivated by a search for resources. FernandezArmesto (2006) describes European imperialism in the Americas as the exploitation of American resources for the benefit of European economies. In the Pacific, Abel Tasman reported that the parts of Australia that he saw offered no useful products (Fernandez-Armesto, 2006). James Cook journeyed to Aotearoa/New Zealand in 1768, in part to find and secure natural resources. Park (1995) writes that Cook's and Bank's interest in the Hauraki Plains was due to the sheer size of the kahikatea trees and the soil fertility that it demonstrated. It was the abundance of natural resources that led Cook and Joseph Banks, the botanist who travelled with him, to conclude that the Waihou River, the 'Thames' as they called it, would make an excellent site for a British settlement (Salmond, 2003). Park (1995) recalls Edward Wakefield's 1839 description of the Hutt Valley forests to within a mile and a half of the beach with swamps full of flax and William Wakefield's description of a grove of fine trees of the best description for boat and house building.

When Abel Tasman stumbled across New Zealand ${ }^{6}$ in 1642 , while searching for a sea route between Chile and Indonesia where the Dutch East India Company had interests (FernandezArmesto, 2006), he became probably the first European to encounter this land, a land only previously known to Pacific people. It was also the last significant inhabited land mass to become known to Europe and though convergence was far from complete, virtually the entire world geographically was now known to a greater or lesser degree to Europeans.

It may be that Tasman was preceded by earlier Europeans. Trickett (2007) argues that evidence suggests the Portuguese may have encountered and mapped Aotearoa/New Zealand as early as 1522, but eventually, in 1796, James Cook arrived in the Endeavour, linking Aotearoa New Zealand to England in a way that would ultimately have devastating outcomes for Māori (Belich, 1986).

The arrival of Europeans in Aotearoa/New Zealand, marked the convergence of cultures that had developed quite differently through being separated for thousands of years. That convergence of cultures resulted in the colonisation of Aotearoa/New Zealand primarily by the English though also by others. As part of the colonising process, but also for a variety of other reasons, in 1840 a treaty was signed between the British Crown and Māori chiefs. This

\footnotetext{
${ }^{6}$ New Zealand is used rather than Aotearoa/New Zealand as this is the form the referenced author uses
} 
occurred, initially at Waitangi and then at a number of locations throughout Aotearoa/ $\mathrm{New}$ Zealand (Orange, 2004). That treaty is Te Tiriti o Waitangi.

Colonisation then, is at least in part about securing and controlling natural resources. Kahn (1999) suggests that the history of relationships between indigenous people and subsequent settlers largely represents a battle for control over natural resources, a foundation for both economic and political self-sufficiency.

Kahn (1999) identifies that successive New Zealand government legal frameworks, institutionalised and systematically reflected an objective of controlling the natural resources that he considers were once wholly Māori property. He argues that from 1840, the Crown used legislation to deny Māori control over natural resources, particularly fresh water resources. Kahn (1999) identifies the 1903 Water Power Act which nationalised and monopolised water rights necessary for hydropower generation, a position maintained until 1987, the 1935 Geothermal Energy Act which nationalised geothermal resources and the Water and Soil Conservation Act 1967 which nationalised all water rights to all forms of water, as examples. None of these Acts made reference to the Treaty of Waitangi ${ }^{7}$ or Māori (Kahn, 1999).

The statement that nobody owns water, and the assertion of Māori views to the contrary, can be viewed in a wider colonial context and is consistent with Mikaere's assertion that colonialism continues today (Mikaere, 2011). The contest for control over water resources can be seen as a continuing desire by the Crown to appropriate natural resources, not unlike the intentions of the first colonisers of Aotearoa/New Zealand (Kahn, 1999). It is also consistent with the intentions of the Europeans who set out to 'discover' and appropriate the 'new' world (Fernandez-Armesto, 2006).

\subsection{Te Tiriti o Waitangi}

In part, te Tiriti o Waitangi can also be seen to be about determining access to and ownership of natural resources. The text shows this. Words selected by Henry Williams, asked by Hobson to translate the Treaty into Māori, included 'kawanatanga' for 'sovereignty' and were intended to grant governance of Aotearoa/New Zealand to the English (Orange, 2004). In Article Two of the Treaty, Williams used 'rangatiratanga' to indicate possession when referring to lands, forests, fisheries and other properties, guaranteed to Māori for as long as they wished to retain

\footnotetext{
${ }^{7}$ Reference to the Treaty of Waitangi is made in English where this is the language that the original author uses. This protocol is maintained throughout the thesis.
} 
them. This promise was included by Busby who redrafted the English version of the Treaty for Hobson and without which, Busby was sure Māori would not sign (Orange, 2004).

Subsequent to 1840 however, the history of te Tiriti identifies two very different responses to the on-going colonisation of Aotearoa/New Zealand. Māori views about te Tiriti have changed little. Since 1840, Māori have sought to have the promises of te Tiriti realised. Their struggle has been relentless. From early unsuccessful attempts to meet with English monarchs, approaches to the colonial government, marches, occupations, protests, a fisheries settlement and now a number of iwi settlements, the goal has remained the same. The pursuit of what Māori see as Treaty justice. For more than 170 years, the general Māori view has been that Te Tiriti o Waitangi made a series of commitments which remain only partially fulfilled by the colonising Crown (Orange, 2004).

Conversely, over 170 years, the Pākehā view of the Te Tiriti o Waitangi has changed considerably. Largely ignored by Pākehā from soon after 1840 until the 1950s Pākehā interest in Te Tiriti o Waitangi developed in the 1960s and 70s (Orange, 2004). Huygens (2007) describes this sudden interest as a 'resuscitation' of the Treaty and considers it an intriguing question arising in an Aotearoa/New Zealand social context. Intriguing because it highlights a dramatic change in Pākehā awareness. Waitangi Day became recognised as a day of national significance and eventually a public holiday. Protests and occupations at Whāingaroa (Raglan Golf Course), Takaparawhau (Bastion Point) and Pākaitore (Moutoa Gardens), though resulting in some backlash, appear to have contributed to a Pākehā acknowledgement of past injustices. Surveys show that Pākehā have an increasing knowledge of the Treaty (Human Rights Commission [HRC], 2011) and research shows that today Pākehā identify Māori motifs as symbols of Aotearoa/New Zealand nationhood (Sibley, Liu, \& Kahn, 2008). The Crown has now settled many claims for redress under the Te Tiriti o Waitangi and the Minister of Treaty Settlements has suggested that the settlement of historical claims will be completed within the next couple of years (Tahana, 2013).

\subsection{Māori and water rights}

It seems unlikely that the Crown will be able to continue to dismiss Māori assertion of Tiriti rights over fresh water resources. A national discussion may clarify the issues. Sonny Tau, Te Runanga-a-Iwi o Ngāpuhi Chairman, suggests that the ultimate solution will be a political one, a negotiated outcome that takes account of the rights of all of those who have an interest in water. Tau argues that talk of water ownership is confusing because ownership in a western 
sense is not what Māori seek. He claims that Māori seek to be recognised in the role of kaitiaki or guardians of water, giving them significant involvement in water allocation and the granting of allocation rights (Bennett, 2012).

Exactly how Māori rights and interests will be recognised, remains to be seen, but consideration of the history of Māori Treaty aspirations and changing Pākehā views, suggests that if this question is to be resolved, the views of the Crown and Pākehā will need to change. Such a change would be consistent with the changes in Pākehā views that have occurred since 1960. 


\section{Literature Review: Māori, Pākehā, te wai and te Tiriti}

Before gathering primary data, I undertook a review of literature which would inform the research. This chapter collates the literature and presents the ideas and themes that emerge. Untangling the many views about the relationship between Māori, Pākehā, water and te Tiriti uncovers perspectives based on position, power and world view. It reveals the influence of social and cultural dominance and action taken by both the oppressed group (Māori) and some groups within the dominant (Pākehā) group, to effect change toward Tiriti justice. As might be expected, there is a broad range of opinions and views, but the literature only provided part of a wider picture.

Locating my specific research question within the available literature was difficult, though literature that was relevant to or broadly informed the research question was more available. A number of authors consider changing Pākehā views about te Tiriti and the reasons for those changes, but little is written about the link to environmental resources in general or water resources in particular. In this chapter I consider the literature that had relevance to and provides background for my research question.

I began my literature review by searching the Victoria University Library catalogue, Te Waharoa. I used a mixture of search terms including "Treaty of Waitangi", "Pākehā attitudes", "water resources", "Māori entitlements" and "Treaty settlements". I undertook similar searches through the Google Scholar search engine and the Science Direct search engine. These searches produced a lot of material and it was necessary to constantly refine my searches to reduce the amount of material being identified. The searches revealed a number of academic papers, newspaper articles and other material. Where abstracts were provided, I surveyed them to determine if they contained material that was relevant to my research topic. If the material was available on-line it was downloaded. A number of books that were only available as hard copies in the Victoria University Library were borrowed. I also considered the reference lists of the material I had located, for clues to further relevant research not uncovered by my original search. I used the Victoria Library catalogue to locate a number of papers that others had referenced. I also visited a number of book shops, particularly Unity Books in Willis Street, Wellington and surveyed the section of New Zealand non-fiction. I purchased a number of books that were relevant to my research topic. When discussing my research topic with friends and colleagues, a number of book titles were mentioned, and some books were also loaned to me. 
I tried where possible to use academic papers or books written within the last ten years. Some material was older than this, but still provided useful points of view or information. This was particularly the case with books, some of which demonstrate critical or influential ideas or knowledge. I did not identify studies which specifically addressed my research question, but there were a number of studies both quantitative and qualitative which provided a picture of peoples' views relevant to my research.

The literature can be considered in a number of ways. One perspective is to take a chronological decade based approach, particularly from about 1960, and track changing attitudes and the underlying causes for change. Prior to the 1960s a myth of New Zealand racial harmony predominated amongst Pākehā (Orange, 2004), but during the 60s this view was exposed to a reality check as external influences like the US civil rights movement, womens' movement and issues raised by Māori, started a process of questioning amongst some Pākehā (Nairn, 1989). The 70s sees the emergence of Māori protests and activism, land marches and challenges to Pākehā racism and the 80s a developing mainstream recognition of Māori claims of injustice (Orange, 2004; Walker, 2005). Throughout the 90s the Treaty settlement process begins with a Fisheries agreement and settlements with Ngai Tahu and Tainui Waikato. But there is a Pākehā backlash against Māori claims during the 2000s (Orange, 2004). By 2010 it seems there is a level of acceptance amongst Pākehā about Māori claims and te Tiriti process.

Another approach is to consider the literature thematically and this is the approach I have taken. I chose this approach because I wanted to thematically analyse the data from the interviews and treating the literature in the same manner would provide some symmetry.

I have first investigated information that considers the historical changes in perceptions of te Tiriti. I then look at the question of indigeneity, relevant because the way in which Pākehā see themselves reflects how they view te Tiriti and Māori. After this I consider the empirical evidence about perceptions and attitudinal changes to te Tiriti followed by consideration of views about fresh water resources. These themes inevitably lead to consideration of literature about power relationships around te Tiriti and Pākehā opposition to the realisation of Māori rights. The review concludes by looking at some of the theory and research which underpins dominant group dynamics and the ideas of those who identify a need to find a harmonious way forward.

Either implicitly or explicitly, central to almost all of the literature I reviewed was te Tiriti o Waitangi. It seems from the literature that te Tiriti is regarded by many as a defining document 
in our history. Liu, Wilson, McClure, and Higgins (1999) investigated perceptions of history by Māori and Pākehā in the context of inter-group relations using sample groups of university students and the general public. They found that while there were significant differences in how Māori and Pākehā students believed historical events in Aotearoa/New Zealand should be described, an overwhelming consensus among study participants considered that the signing of the Treaty in 1840 stood above all other events in importance to Aotearoa/New Zealand history. It seems relevant to investigate that view from an historical perspective. Why is te Tiriti important to us and has that always been the case? The next section considers the source of Pākehā attitudes to te Tiriti o Waitangi and the factors that have influenced change to those views

\subsection{Historical changes in perceptions of te Tiriti}

Robinson (2010) provides an illuminating picture of Pākehā attitudes to the Treaty from 1877 to the 1970s and investigates the sources of those views. She identifies as critical, in the 1877 case of Wi Parata v Bishop of Wellington, dismissal of the Treaty in the decision comments of Prendergast CJ when he stated that the Treaty should be regarded as a simple nullity and that because Māori were without a body politic, their sovereignty of New Zealand did not exist and could not be ceded. Prendergast further stated that the title to New Zealand was acquired by the British Crown by discovery and priority of occupation, as the country, when the British arrived, was inhabited only by savages (Robinson, 2010). The writing of historian Lindsay Buick who in 1914 suggested that the signing of the Treaty was the foundation of nationhood, the birth of law and order in New Zealand and represented the benevolence of British colonisation, along with the comments of Prendergast CJ, provided ideas that would frame Pākehā views of the Treaty until the 1970s (Robinson, 2010).

Robinson (2010) identifies that though there were a range of Pākehā views about the Treaty from 1877 until the 1970s they fell into either of two categories. The first was the popular historians view that the Treaty was a valid symbol of British benevolence as the colonialists were good men who would not have taken control of a country without consent, that the Treaty had been adhered to and though there had been minor or technical breaches, Māori had complained little. This view argued that Pākehā could be proud of how governments had acted in the true partnership spirit of the Treaty. The second category was the legal and government position that the Treaty had no legal standing or authority in national or international law and while it imposed some moral responsibility on the Crown, it did not confer any legal authority or responsibility. Specifically, Māori did not have rights under the Treaty, particularly land 
rights, because sovereignty could not have passed from Māori to the Crown if Māori did not have sovereignty prior to British colonisation. Hence the courts and government need pay little attention to the Treaty (Robinson, 2010).

Orange (2004) suggests a different view was held by Māori. She shows the relentless but fruitless struggle for justice under the Treaty that Māori engaged in until the middle of the twentieth century. She recounts how Māori were dispossessed of land through the actions of the settler government, its agents and the Native Land Court and that their experience of the courts showed Māori that the Treaty afforded them no protection. She suggests that Māori shared a common bond in the Treaty, particularly because it established a relationship between them and the Crown. The Treaty may have had little relevance to Pākehā at this time but it remained a uniting issue for Māori (Orange, 2004).

Orange (2004) identifies newspapers printing the English version of the Treaty text and regular debate about the terms and application of Treaty based policies in the five years after the Treaty was signed. She suggests that most settlers knew about the terms of the Treaty, but by 1870 , after land confiscations and wars, politicians began to speak less of the Treaty and when they did it was mostly about Māori Treaty obligations. With increased immigration, the emergence of a new colonial society and the Māori population declining steadily, the significance of the Treaty to Pākehā diminished. New immigrants were less aware of the recent past and the Treaty seemed to them an irrelevant part of history (Orange, 2004).

Orange (2004) demonstrates the difference with a comparison in 1890 on the fiftieth anniversary of the signing of the Treaty, when Māori were planning Kotahitanga Māori parliaments which would bring tribes together in a spirit of unity under the Treaty, Pākehā focused on the first settler ships that arrived in Wellington. This she suggests, indicates that the implications of the Treaty were not important to Pākehā (Orange, 2004).

Robinson (2010) identifies a large gap in Treaty studies and understanding up to the 1970s, noting considerable scholarly literature since that time which focuses on either what the Treaty might have meant in 1840, or what it does or should mean over the past 40 years. Importantly, she notes that in all the literature, inquiry into what Pākehā thought about the Treaty is only considered in passing. Pākehā historians dominated the narrative until 1970 she suggests, writing for Pākehā, with Māori voices and perspectives almost entirely absent, even irrelevant, including from discussion about the Treaty itself. This she suggests reflects the location of power over this period (Robinson, 2010). 
Pākehā interest in the Treaty was stimulated, when in 1932 the Governor General gifted to the nation, the residence of James Busby and 800 hectares of land at Waitangi. Ngāpuhi then built a whare runanga, beside the residence. Later a flagpole was erected at the site where the Treaty was signed (Orange, 2004). Orange (2004) suggests that the government misunderstood the difference between Māori and Pākehā views of the Treaty and in setting up a national memorial at Waitangi was identifying a site for Māori challenge as much as celebration.

Other authors make reference to a lack of interest by the Crown in the first half of the twentieth century. Walker (2005) notes that the 1940 Treaty signing centennial was a symbolic gesture which preceded any legislative interest in the Treaty by 20 years. He suggests that while Ngāpuhi leaders for many years had been meeting each year on February $6^{\text {th }}$ at Waitangi, to discuss breaches of the Treaty by settler governments, the Crown's development of Treaty commemorations was unilateral, top-down and based on a sanitised view of colonial history in a social climate of historical amnesia (Walker, 2005). Walker (2005) provides a Māori context to the development of protest and action by Māori after 1960. He highlights the underground newspaper Te Hokio which appeared in 1968 and brought attention to contemporary rather than historic breaches of the Treaty and the Māori Organisation on Human Rights newspaper $M O O H R$ which advocated for the return to Māori of resources held by Pākehā. MOOHR also challenged the Education Department for its role in the loss of Māori language. Walker (2005) describes a number of protest groups and activities including Nga Tamatoa which emerged from the University of Auckland in the early 1970s, the 1975 land march which he suggests influenced the government to prepare proposals for legislation more in keeping with Māori needs rather than the needs of Pākehā voters and in 1977 the occupation of Takaparawhau (Bastian Point) by the Orakei Māori Action Group. Walker (2005) notes that television allowed the spectacular action at Takaparawhau to be viewed by the general populace, including the sobering clearance of the Point by 600 policemen after 506 days of occupation.

A turning point and demonstration of changing Pākehā views, described by Walker (2005), is the Waitangi Tribunal ruling that under the Treaty, the Crown had an obligation to protect Te Ati Awa fishing grounds from the discharge of sewage and untreated waste from the government's proposed synthetic fuel plant at Motunui. The Prime Minister, Rt. Hon. Robert Muldoon, overrode the decision on the basis that the discharge had planning tribunal and Cabinet approval. Walker (2005) suggests that Muldoon misread the public mood of considerable sympathy for Te Ati Awa principally because pollution of fisheries and the environment were a matter of public concern. The Waitangi decision had been widely reported 
in the press and newspaper editorials had criticised the government for failing to honour the Treaty.

However Walker (2005) also highlights reaction against Treaty claims and the fear that they could destabilise the political economy. He notes a vigorous attack on the government's Treaty policy by the National Party opposition in the lead-up to the 1990 election and the resultant government response of trying to determine the principles of the Treaty.

Five specific factors are identified by Robinson (2002) which have contributed to the post 1960s rediscovery of the Treaty's significance, the annual February $6^{\text {th }}$ televising of Waitangi Day events at Waitangi, a commitment by the fourth Labour Government to honour obligations to Māori and recognise the Treaty in legislation, the growth of Māori aspirations, external events including the United Nations recognition of the rights of indigenous people and increased contact between Pākehā and Māori resulting from the post war urbanisation of Māori. Nairn (1989) provides an illuminating personal view of the influences that changed Pākehā thinking about the Treaty including the writing of black psychiatrist Frantz Fanon of Martinique, Paulo Freire who visited Aotearoa/New Zealand in 1974 and the United States civil rights movement. She notes the influence of the liberal minority or left wing of many church organisations, Pākehā anti-racism groups and the effect of groups like Nga Tamatoa and the Polynesian Panther Party voicing that Pākehā were the problem rather than Māori. Nairn (1989) identifies the World Council of Churches, Programme to Combat Racism and the United Nations covenants and conventions on human rights as bringing new concepts and ideas on racism to Aotearoa/New Zealand.

Opposition to the 1981 Springbok tour is identified as a catalyst for many Pākehā who were challenged to reflect on domestic racism when protesting racism abroad. This prompted many Pākehā, particularly the Pākehā left, to discuss partnership, sovereignty, bi-culturalism and multi-culturalism. Critical to this discussion was an investigation of how Pākehā see themselves in relation to the Treaty and how they see their place in Aotearoa/New Zealand (Snedden, 2005). Central to this discussion is the question of indigeneity. Who is indigenous and what does it mean to be indigenous?

\subsection{Indigeneity: Who are we and who belongs?}

Establishing indigeneity is important because it has implications for the determination of rights as first occupants (O'Sullivan, 2008). Mikaere (2011) asserts this view, that in spite of te Tiriti, or the 1835 Declaration of Independence, Māori rights as tangata whenua derive from being 
the first people in Aotearoa and developing both an intimate connection to the environment and an intricate web of relationships to regulate their place in it.

Indigeneity is also important when considering how and why Pākehā may change. How Pākehā see themselves affects how they perceive Māori. In turn, Pākehā perceptions of Māori may influence whether Pākehā see a need to change their own position. A comparison of the views of Brash (2004), Round (2013), Sneddon (2005) and King (1999), illustrates this point.

In his largely autobiographical reflection Being Pākehā Now, King (1999) suggests a need for some recognition of Pākehā indigeneity and contends that Pākehā seek from Māori a mutuality of respect. King, who throughout his life and work had a lot of contact with Māori, expresses no doubts about the legitimacy of Pākehā to be in New Zealand, arguing that his Irish ancestors, like Māori came to New Zealand as immigrants from another place. He suggests that like Māori, Pākehā become indigenous when their focus of identity and commitment shifted to their home country and away from their countries of origin. Pākehā culture, he considers, was transformed by a relationship with the land, its flora, fauna, history, experiences and importantly interaction with Māori. He suggests that Pākehā who live in New Zealand by choice, are committed to its land and people and have a knowledge of both, are no less indigenous than Māori. King (1999) argues that many Pākehā, himself included, have a strong spiritual association with the rivers, lakes, coastline, land and history, rejecting as romantic the view that only Māori can have such a relationship with the whenua. He rejects the sweeping judgements that Pākehā are rapacious exploiters of natural resources and Māori kaitiaki, advancing that no culture has a monopoly on vice or virtue.

As a historian, King had researched our history and clearly acknowledges the injustices Pākehā were responsible for. He supports the investigation of those injustices and compensation to Māori because he considers that there was a treaty and it was violated, most frequently by the Crown. He acknowledges that the process compensates Māori for only a fraction of what was taken from them, unjustly and often illegally and states pride in a country that recognises historical debt and accepts responsibility for it.

But for King, to be Pākehā is not to be European, a stranger or alien in his own land. For him to be Pākehā is to be a non-Māori New Zealander, aware and proud of his antecedents but one who identifies intimately with this land as strongly as anybody who is Māori, another kind of indigenous New Zealander (King, 2003). 
Alternatively, Round (2013) contests even Māori indigeneity, suggesting that indigeneity refers only to something or someone who has been in a place since time immemorial. Because Māori came from Hawaiki a matter of hundreds of years prior to European arrival, he suggests that either Pākehā and Māori are indigenous, or neither are.

Maaka and Fleras (2005) highlight the diversity of indigenous people, from foraging groups in developing countries to urbanised communities in contemporary societies, but note a distinguishing feature of indigenous peoples is that they can make constitutional and territorial claims, rejecting the idea of Pākehā indigeneity.

There are only a small number of Pākehā authors who write about being Pākehā. Patrick Snedden and Michael King stand out as advancing a positive position for Pākehā in Aotearoa/New Zealand today. Snedden (2005) sensitively explores what it means to be Pākehā and considers some of the circumstances and points of view that cause Pākehā unease, including the relevance of the Treaty today, Treaty settlements, the foreshore and seabed debate and its subsequent legislation. But he goes further, exploring the idea that the Treaty gives Pākehā a right to belong in New Zealand and that a greater understanding by Pākehā of the Treaty will foster a Māori transformation which will benefit all New Zealanders. Snedden (2005) writes about his personal experience of both conservative and liberal views of the Pākehā/Māori relationship, his involvement with Ngati Whatua and his participation in organisations that respect Treaty based approaches to organisational development. He notes the importance to Māori of re-establishing manawhenua status over traditional tribal areas, the benefit of Māori having input to resource management issues and representation on government agencies. Snedden (2005) notes the events of our history that have changed our views including the occupation of Takaparawhau (Bastion Point) and the 1981 Springbok tour protests which highlighted the inconsistency of protesting against apartheid while ignoring racism in New Zealand. Importantly Snedden (2005) queries where the points of further progress in race relations might lie. He provides a vision of hope with Pākehā understanding of the Treaty at its centre.

It is a common argument, advanced by some Pākehā, that rather than considering Māori and Pākehā as separate groups, we should consider that we are all New Zealanders. This was a key theme of a speech by opposition leader Don Brash at Orewa in 2004 (Brash, 2004). Brash raised his concerns about what he described as racial separatism and a Treaty grievance industry. He suggested that bi-culturalism was being imposed on Pākehā and argued that it was unnecessary as we are becoming a homogenous race of South Seas New Zealanders. He looked 
forward to a day when the categories Pākehā and Māori are forgotten and advanced the argument that we are simply all New Zealanders. Brash questioned whether Māori are individuals with needs, or people with special rights (Brash, 2004). Mikaere (2011) strongly contests Brash's view. She suggests that such a position denies the power imbalance of the Māori/Pākehā relationship and the differing history of the coloniser and colonised. She suggests such a view indicates a deep rooted Pākehā insecurity about their identity and recognises a Pākehā search for cultural icons in such objects as gumboots, black singlets, pavlova, kiwifruit and buzzy bees as a search for national identity (Mikaere, 2011).

Research by Sibley et al. (2008) suggests a more complex relationship. They undertook a study which showed that Pākehā identified Māori cultural icons as being equally representative of Aotearoa/New Zealand nationhood as Pākehā icons. However Māori identified Māori icons as more representative of nationhood. The researchers suggested that Māori culture helps to promote national distinctiveness on a world stage and has considerable power to validate national identity for Pākehā. Interestingly, the results differed from theory and research in Australia and the United States of America where the majority white cultures did not recognise indigenous icons as representative of nationhood. This country difference is important because it suggests change has occurred in Aotearoa/New Zealand and that a similar change may be possible in Australia and the United States of America. The authors then asked how a symbolic acceptance of bi-culturalism could translate into resource specific claims against the Pākehā majority (Sibley et al., 2008).

Mikaere (2011) suggests it does not, that recognition of Māori culture provides some comfort for Pākehā when they are overseas, but upon their return they are critics of the assertion of Māori language and culture. Mikaere (2011) criticises the arguments for Pākehā indigeneity because they depend on forgetting the past, making Māori complicit in Pākehā myth-making and self-deception about their history. It also suggests equivalent fault when the vast majority of wrong-doing was on the Pākehā side. Mikaere (2011) however points out in the debate of Pākehā identity that there is a recognition, from some explicit and others implicit, that somehow te Tiriti is central to that identity.

Bell (2009a) when researching markers and rules in national identity construction amongst young adult Pākehā New Zealanders, identifies birth, blood and belonging as critical identity markers. She found a strong sense of attachment to New Zealand through birth and blood but difficulties arising in relation to establishing belonging, due to the migrant origins of the study participants' ancestors. She concluded that 'their claims to belonging can only ever come after 
those of Māori” (Bell, 2009a, p. 159), with residence and commitment not necessarily enough to secure belonging (Bell, 2009a).

Snedden (2005) answers the question of Pākehā indigeneity succinctly by suggesting Pākehā are emotionally indigenous but technically not. While Pākehā may have a connection to New Zealand, its landscape, culture, ways of being, and many have generations of history which can be a source of pride, it is not the same as the way in which Māori are indigenous. To equate Pākehā indigeneity with Māori indigeneity would negate 500 years of Māori occupation of New Zealand prior to Pākehā arrival, and importantly, as also stated by Mikaere (2011), would neglect the fact that Māori were the first people to settle here. Snedden suggests that for Pākehā to claim indigeneity in the same way that tangata whenua do, is not fair and not factual (Snedden, 2005).

It is interesting that Snedden (2005) and King (1999) deliberately use the term Pākehā to describe New Zealanders of European descent. King (1999) contends that the word is derived from 'pākepākehā' meaning people with fair skin, an indigenous expression to describe New Zealand people that are not Māori. Other suggestions that it is a pejorative term meaning 'white flea', 'turnip head' or 'long pork' are rejected by King as ignorant (King, 1999). Liu et al. (1999) identified that among the general population participants of their study, only 23 percent of Pākehā preferred that term, compared with 60 percent of Māori. Carlson (1998) identified a similar attitude with 38 of 322 respondents who identified as New Zealand European or Pākehā in a postal survey on attitudes to the Waitangi Tribunal, noting that the word Pākehā was derogatory or crossed it out (Carlson, 2007).

\subsection{What does the empirical evidence tell us about what we think?}

Since 2002, UMR Research has undertaken annual qualitative and quantitative research on human rights in New Zealand for the Human Rights Commission. The survey has a slightly different focus each year but includes investigation of how much people feel that they know about the Treaty, and records their reactions to a series of statements about the Treaty. The quantitative research uses a telephone survey of 750 people aged 18 years or over.

Some clear themes emerge from this research, particularly that knowledge of te Tiriti appears to be increasing. Figure 1. shows a declared 'good knowledge' of te Tiriti among survey participants increasing from 36 per cent in 2002, to 49 per cent in 2011 (HRC, 2002, 2006, 2010, 2011). 


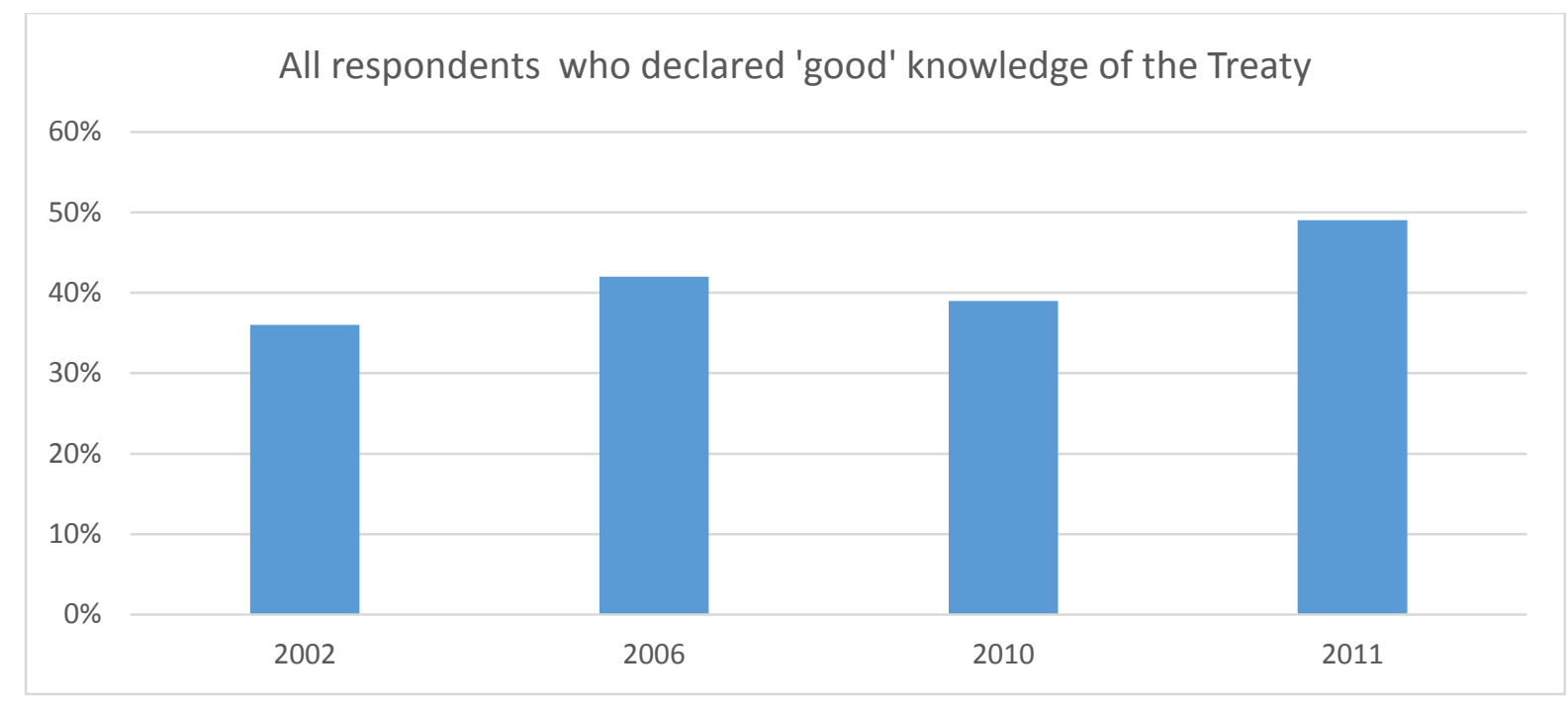

(Human Rights Commission, 2002, 2006, 2010, 2011).

Figure 1. Declared 'good' knowledge of the Treaty

However in 2004 further questions revealed that actual knowledge about three key Treaty facts was not as strong as the declared level of knowledge. 47 per cent of respondents knew that the Waitangi Tribunal heard Treaty claims and 34 per cent knew that the Treaty was signed in 1840 (HRC, 2004).

Carlson (1998) when investigating knowledge and attitudes to the Waitangi Tribunal through a postal survey of 440 randomly selected participants found that 67 percent of participants agreed that the Treaty was about partnership and co-existence but concluded that the general public had a poor knowledge of the Treaty, the Tribunal and the claims settlement process.

In 2006 a higher percentage of Māori than non-Māori, were shown to have a reasonable declared knowledge and interest in the Treaty (HRC, 2006) (Figure 2) and in 2004 nearly twice as many Māori than non- Māori research participants were interested in finding out more about the Treaty (HRC, 2004) (Figure 3). 


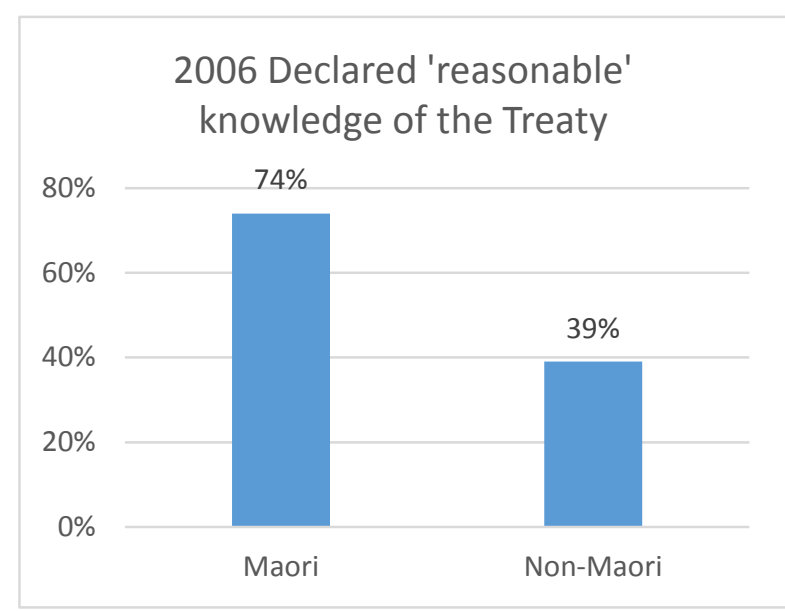

(Human Rights Commission, 2006).

Figure 2. Declared 'reasonable' knowledge of the Treaty

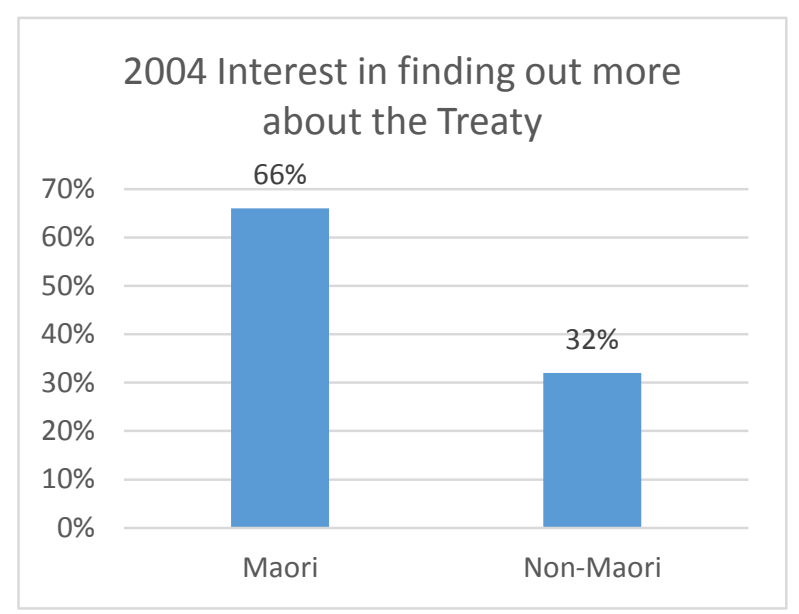

(Human Rights Commission, 2004).

Figure 3. Interest in finding out more about the Treaty

Regarding the perception that the Treaty is New Zealand's founding document and had a place in New Zealand's proposed constitution, almost twice as many Māori respondents than nonMāori `had this view in the 2006 survey (HRC, 2006). In 2009, The Race Relations Report, (HRC, 2009) identified fewer, though still high numbers of Māori research participants considered the Treaty to be New Zealand's founding document with a little over half of all respondents taking this view HRC, 2009).

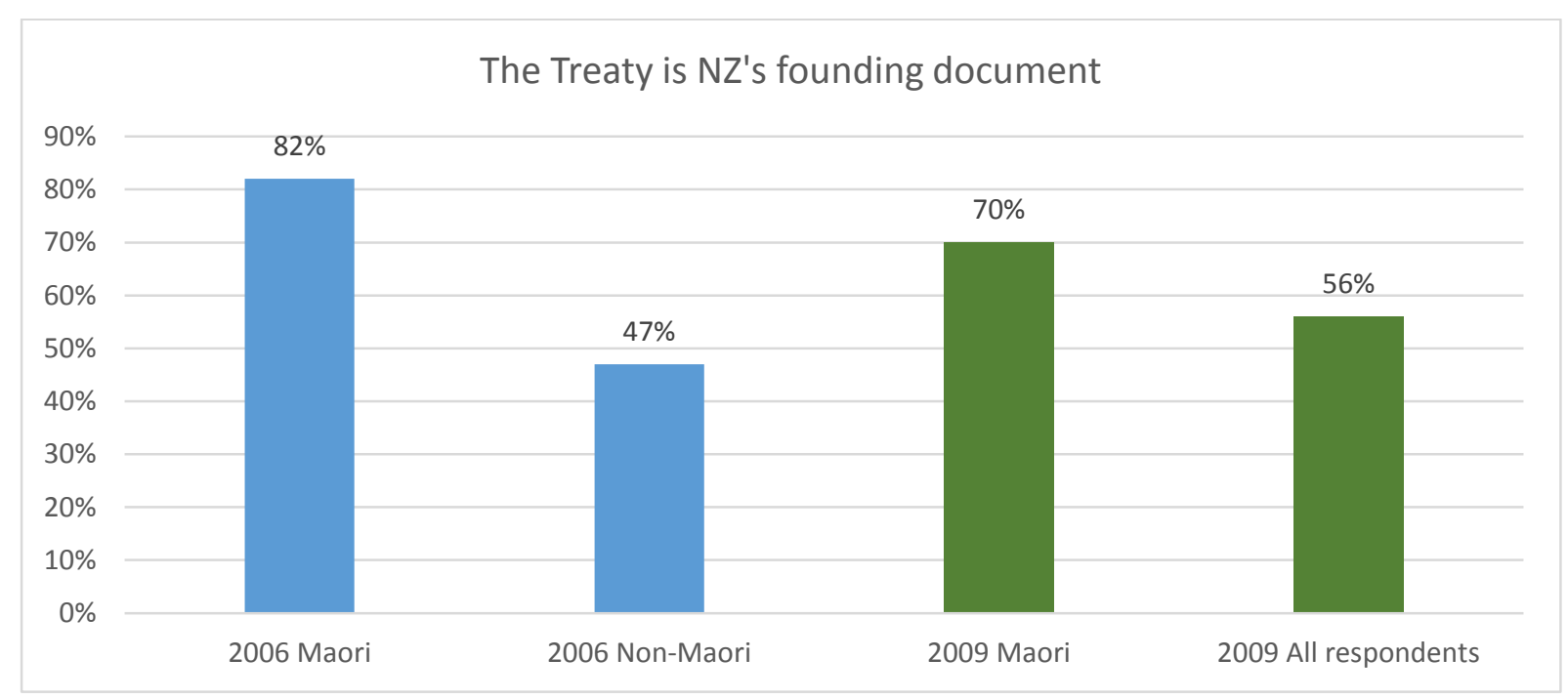

(Human Rights Commission, 2006 and Human Rights Commission, 2009)

Figure 4. The Treaty as New Zealand's founding document 
The 2011 study (HRC, 2011) found that similar levels of respondents agreed that the Treaty is New Zealand's founding document and half agreed that the Treaty was for all New Zealanders. But only a quarter of respondents considered that the Treaty relationship between the Crown and Māori was healthy.

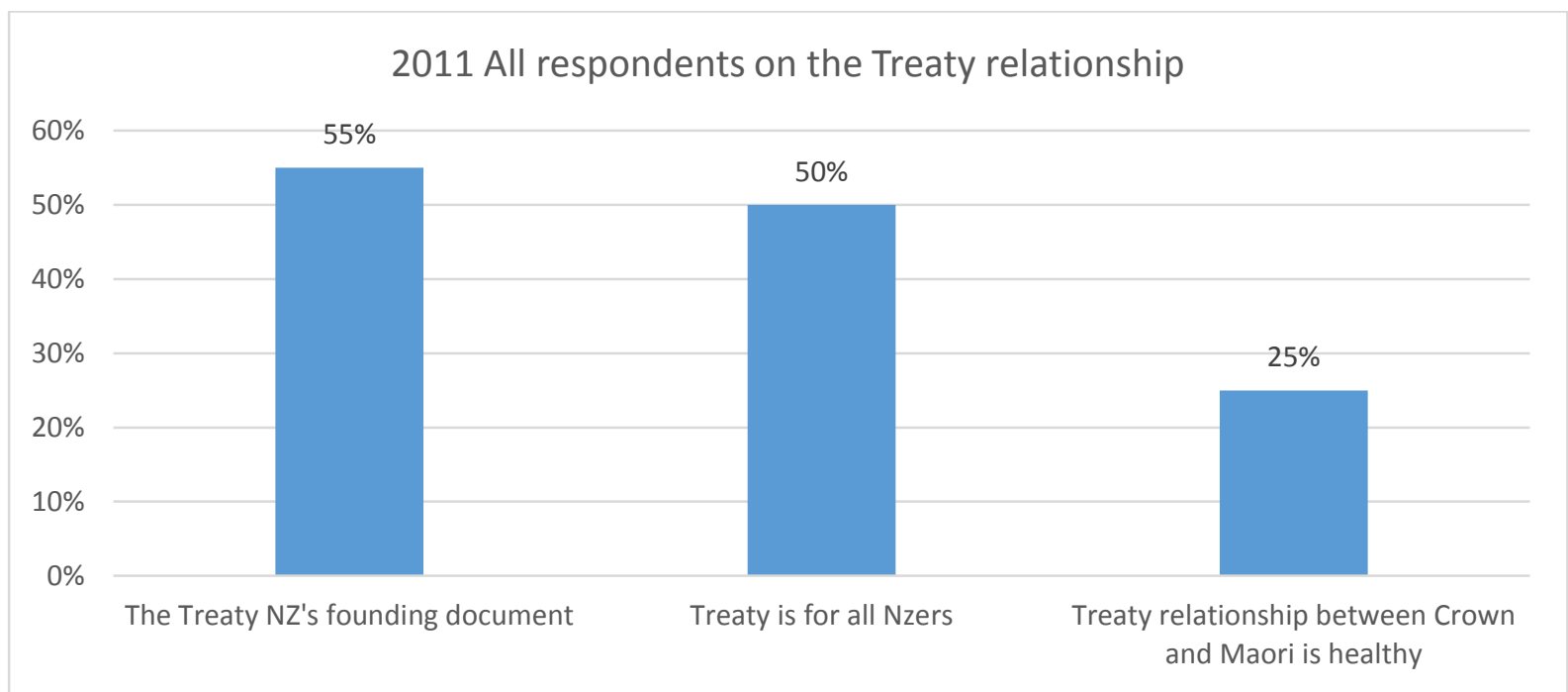

(Human Rights Commission, 2011).

Figure 5. 2011 responses on the Treaty relationship

The surveys also found a greater level of Treaty knowledge amongst younger people with those aged less than 30 having higher declared knowledge levels than other groups (HRC, 2006).

In 2004, more than half (57\%) of survey respondents thought that people having a greater knowledge about the Treaty would help them better understand our country and history (HRC, 2004).

When discussing why the government was trying to settle Treaty claims, people in focus groups suggested that it was to resolve issues and conclude on-going disputes but it was reported that there was a sense in the non-Māori groups that avoiding Māori unrest was the government's motivation (HRC, 2004).

In 2002 qualitative research undertaken with focus groups, one consisting of Māori, the other two non-Māori, over 45 years and under 45 years of age, reported that participants generally associated colonisation with events of the past and did not consider colonisation relevant to today, though some participants considered colonisation to be a dynamic and on-going process. Some participants reported that they were becoming tired of hearing about the Treaty in the media, but there was also a desire to know more about the Treaty. Participants both Māori and 
non-Māori considered that there needed to be more education about the treaty and it was reported that some older Māori participants considered that it had only been in the last 10 years (1992-2002) that people had really begun talking about the Treaty. Non-Māori participants felt that Pākehā would benefit from developing a deeper understanding of the Treaty (HRC, 2002). The 2006 survey found strong overall agreement (66 per cent) that Māori should have the same rights as all New Zealanders but should also have the right to live as Māori (HRC 2006).

This survey data needs however to be considered with some caution. The researchers suggest that results from Māori participants should be treated as indicative only because the Māori subsample is comparatively small (HRC 2002). This caution is explained by Robson (2002) who argues that social inequalities in health are a breach of tangata whenua rights and that one source of such inequalities is the unequal distribution of Māori and non-Māori, not just as researchers, but also as research participants. Robson argues that surveys based on random sampling of the population do not allow an equal depth of information about Māori because they include considerably larger numbers of non-Māori. Robson (2002) suggests that to improve research into Māori health outcomes it is necessary to include equal numbers of Māori and non-Māori as survey participants to ensure the surveys have equal explanatory power.

In spite of those cautions, the survey data is interesting, particularly in the way that it corroborates the findings of Liu et al. (1999) that the signing of the Treaty in 1840 is of critical importance to our history. It also supports the view of Orange (2004) that the Treaty has specific historic importance to Māori. O'Sullivan (2008) suggests that this is because, since 1840 it has been the predominant legal, political and moral framework for Māori discussion of rights.

This was the case with the Māori Council claim to the Waitangi Tribunal, High Court and Supreme Court over the government's proposal to sell shares in Mighty River Power. The issue was authority over water that was used for electricity generation and the rights of Māori to receive compensation or remuneration for use of that water. It demonstrated the importance of water to Māori and their assertion of Tiriti rights over water.

\subsection{Te Wai}

The current government's concern about the management of fresh water resources was made clear when, in 2009 it set up the Land and Water Forum, a diverse group of organisations considered by the Crown to have a stake in freshwater management. The objective was to develop a shared vision and common way forward for the management of fresh water 
resources. To date the forum has released three reports, intended to provide direction for future government initiatives in water resource management. The first report acknowledged that Māori have interests and rights in water resource management without clarifying what they may be or how they may be expressed (Land and Water Forum, 2010).

The second report focused on setting limits for water quality and quantity, reiterating that Māori have rights and interests in water and strongly promoting the need for iwi to be involved in decision making about fresh water resources, importantly noting that iwi values and interests should be addressed on a catchment-by-catchment and relationship specific basis. It noted the lack of a clear path for iwi involvement to occur and suggested mechanisms to address this, but stated clearly that the issues between the Crown and iwi concerning iwi rights and interests were not part of the brief of the Forum (Land and Water Forum, 2012a).

The third report focussing on managing water quality and allocation, clearly stated a need for Māori rights and interests in water to be identified and resolved, if an enduring management system is to be achieved. It notes that iwi have amongst other interests, an economic interest in water but clearly identifies that the most appropriate manner in which iwi rights and interest should be resolved, is through direct negotiations with the Crown (Land and Water Forum, 2012b) .

Though the reports of the Land and Water Forum strongly advocate for the acceptance of a Māori view of water resources, inclusion of Māori in the management of water resources and acknowledgment of the importance of Māori to the resolution of issues, they consider Māori as one of a number of stakeholders, all of whom have interests in fresh water resources.

Rights and interests in fresh water have long been expressed by Māori and many claims to the Waitangi Tribunal have a fresh water aspect to them. When commenting on a Wellington Regional Council proposal to export excess bulk water, Te Whiti Love (1996) points out that water, by its nature, is one of the most difficult resources to determine rights and interests for, particularly as it is difficult to characterise exactly what is sought in Māori claims to ownership. Local Tangata Whenua challenged the Wellington Regional Council's proposal because they claimed that ownership of the water had not been determined and the Council did not have rights of sale and export. According to Te Whiti Love (1996), differing concepts of ownership confuse the matter and he suggests a need to develop a set of common terms and understandings for rights and interests in water resources, including the right to allocate, the right to use, the 
right to regulate, the right to gain rent, the right to access, the right to conserve and the intrinsic rights of the resource itself.

This raises the question of property rights over water. Bruns and Meinzen-Dick (2005) and Meinzen-Dick and Mendoza (1996) identify access to water resources as a property right, but argue that the rights are only as strong as the institutions that stand behind them. They suggest three broad water property rights classifications as public, private and common property. They don't identify any specific indigenous water property rights.

In Australia where water shortages and over allocation have caused widespread concern the Council of Australian Government Agreement of 1994 allowed a water market and privatisation of water bodies (Alston \& Mason, 2008). The key elements of the agreement were to reform pricing, clarify water property rights, allocate water to the environment and adopt water transfer mechanisms. In response Baldwin (2008) who argues for treating water as a public good seeks a change from seeing water as a commodity to be exploited, often at the expense of the environment, to seeing water as a fragile shared resource that should be used for the benefit of all. Baldwin sees a need for governance approaches that are participatory, deliberative and take account of community values of justice and equity. She notes a lack of input in water debates from those who are not easily heard, including Aboriginal people, those who are not members of groups and those who are distant from major centres.

In New Zealand, the Resource Management Act (MfE, 1991) provides statutory rights to use water resources through water permits which have many of the characteristics of property rights (Hawke, 2006).

Williams (2006) comments on the relationship that Māori have to water, highlighting the importance of mauri, a vital essence which comes from the atua and provides each entity with its unique personality. He highlights the importance for Māori, of not altering the mauri when dealing with environmental issues. Importantly, Williams (2006) highlights that to some extent, Māori perspectives today are influenced by traditional views, including that water is a living thing with a mauri which differs from one water body, type of water and place, to another.

Pragmatic application of these views is described by Hsiao (2012) in her consideration of indigenous rights and the rights of nature relating to the Whanganui River agreement, recently signed, between Whanganui iwi and the government. The agreement recognises the Whanganui River as a living and legal entity with rights of its own, equivalent to human rights. The significance, Hsiao (2012) argues, is the rejection of a colonising view of nature as an 
uncivilised set of resources in need of commodification and conversion to colonial land preferences. As an alternative, the agreement acknowledges an indigenous cosmology, culture, identity and socio-political organisation which co-evolved from and with the natural environment. Hsiao (2012) draws an important link between reclaiming indigenous sovereignty and reclaiming environmental sovereignty, suggesting that by reclaiming environmental rights, indigenous sovereignty can also be restored.

The Waitangi Tribunal in its 1999 report recognised Māori authority (mana and rangatiratanga) under Te Tiriti o Waitangi over the whole of the river and the need for that authority to be properly acknowledged and provided for. The Tribunal found the 'Māori gift' of governance to the Crown was a qualified sovereignty which required the Crown to protect Māori rangatiratanga and taonga like the Whanganui River. Crown acts and omissions, including legislation, had the effect of denying Māori rights and interests in the river which had never been willingly ceded to the Crown (Waitangi Tribunal, 1999).

The salient point of the agreement was that the river bed was returned to the river itself, not the Whanganui Iwi. As a legal entity, the river has standing and cannot be owned. As an indivisible and living whole, the river has undergone a transformation from property interests to a legal being in its own right (Hsiao, 2012). Hsiao (2012) sees in this acceptance by the Crown of a Māori view of a natural resource, the emancipation of nature through a continuous process of decolonisation.

Ruru (2013) identifies water as a tough resource to settle because it is fundamentally important to all peoples and has an increasingly important economic value. She notes that the Crown acknowledges the importance and taonga status of water for Māori, and accepts the importance of water to Māori cultural identity and wellbeing. She also notes the government's conditional support for the United Nations Declaration of the Rights on Indigenous Peoples which specifically mentions indigenous rights to water, but points out that Māori have no constitutional rights to water (Ruru, 2013). Ruru (2013) suggests that the government is aware of general Māori dissatisfaction with water governance, acknowledges Māori interests as undefined and unresolved and highlights in the Fresh Start for Fresh Water policy programme, a need to negotiate with Māori and to address Māori interests in water. However Ruru (2013) identifies that the government refuses to address Māori water interests in terms of ownership of water. She notes that recent Treaty settlement statutes take a neutral position where parties claim ownership of water, instead finding agreement around co-management of water resources. These settlements Ruru (2013) suggests, focus on cultural redress but illustrate only 
partial reconciliation. The Whanganui River settlement Ruru (2013) points out, preserves public use and access to the river, existing private rights to the river and the final decisionmaking functions of local government. The on-going problem which Ruru (2013) sees is a government failure to address the issue of commercial and property redress with regards to water. As an alternative, government seeks to strengthen the role and authority of Māori in resource management (Ruru, 2013). Te Aho (2012) reiterates this position, identifying the Te Arawa Lakes Act, 2006, which vests ownership of lake beds with iwi but puts in place a comanagement arrangement for the lake water. Ruru (2013) argues that despite notable examples of cultural redress in water settlements, real decolonising reconciliation requires fair and complete restitution of propriety and commercial rights to water resources.

Mikaere (2011) provides instructive ideas on resolution of this issue, suggesting that in te Ao Māori (the Māori world), the tikanga is that the aggrieved party determines the redress when an injustice has been brought against them. Mikaere (2011) identifies this as a fundamentally important disconnect between the Pākehā and Māori world views that is seen in te Tiriti settlement process.

Te Aho (2012) identifies that the one-sided nature of Treaty negotiations which give the Crown the power to unilaterally set negotiating conditions, also allows the Crown to set bottom lines, This is seen particularly with water resources where the Crown maintains that there is no ownership of water and refuses to negotiate with Māori on that position. The power of the Crown's position also allows it to determine with whom it will negotiate, including some iwi, excluding others and in the process creating new Treaty grievances (Te Aho, 2012). Belgrave (2012) highlights that inequality of power overshadows all negotiations and suggests that in the context of Crown/Māori negotiations from 1860 until today, Māori have been constrained by that inequality. Belgrave (2012) also identifies that even if the Crown has wanted to negotiate with Māori, it has been limited by the demographic voting power of non-Māori.

The government's National Policy Statement, Freshwater Management Programme, illustrates this position (MfE, 2011). It first acknowledges water as an essential resource for our economic, environmental, cultural and social well-being which give primary production tourism and electricity generation a natural advantage. It then identifies the Treaty as the underlying foundation of the relationship between the Crown and iwi/hapu and notes the importance of addressing tangata whenua values in fresh water resource management. But objectives and policy relating to tangata whenua values and interests require only the 
identification of those values and interests in the management of fresh water and a requirement to take steps to involve iwi and hapu in that management.

The literature suggests that successive government positions on Māori rights and interests in fresh water resources, have prompted wider Māori concerns about their place in Aotearoa/New Zealand society, the power relationships under which they must participate, on-going prejudice and institutional racism.

\subsection{Inequality, power relationships and Treaty settlements.}

A simple context for the relationship between Māori and Pākehā is provided by Mikaere (2011), who highlights that Pākehā retain power in Aotearoa/New Zealand and in exercising that power seek to define Māori. She suggests that to provide real redress for past injustices, Pākehā will need to relinquish some of that power and entrust it to Māori.

A number of authors, in a collection of articles edited by Veronica Tawhai and Katarina GraySharp, identify specific areas where the Crown has failed to meet its obligations under the Treaty. Māori language is described as an indigenous taonga guaranteed to Māori by the Treaty (Black, 2011). Tomlins-Jahnke and Te Rina Warren (2011) describe continuing failures of the New Zealand education system as failures to honour the Treaty and suggest that the Treaty remained a critical reference for Māori because it was a key human rights instrument. They also comment on reactions against assertions of Treaty rights and suggest that the recognition of the Treaty in legislation and government policy is considered by some to represent Māori privilege. They describe how in 2004, Don Brash, then leader of the opposition appealed to Pākehā anxiety and called for an end to race based policy. The government of the day, fearful of a backlash against existing policy, requested the removal of the Treaty from the nine guiding principles of the education curriculum. Concerted efforts by Māori leaders and complaints from other community leaders reversed the government's decision.

Mikaere (2011) provides another example. In 1999 when a new Labour Government came to power it announced a commitment to spend $\$ 500$ million on specific programmes dubbed 'closing the gaps' which were intended to reduce inequalities between Māori and non-Māori. Some Pākehā resented the perceived 'special treatment' of Māori and considered the programmes to be inverse racism (Young, 2004). The government, though pointing out that the intention was to assist those who needed support, the largest numbers of whom were Māori, ceased referring to 'closing the gaps' and abandoned the specific focus on Māori (Mikaere, 2011). But Mikaere raises a further interesting point about this circumstance when she suggests 
"that the policy was in fact assimilative. While no-one would dispute the importance of improving the social and economic position of Māori, this policy was only ever couched in terms of measuring Māori against Pākehā” (Mikaere, 2011, p. 74). She points out that successful lives as Māori need to be measured against the level of participation in te ao Māori (Mikaere, 2011). The Human Rights survey that identified 66 per cent of respondents agreeing that Māori should have the right to live as Māori, suggests this view may be acknowledged by many Pākehā (HRC, 2006).

The question of whether Māori have rights or needs is important because the obligation for the state to assist the disadvantaged, has a different philosophical and moral basis to the obligation to facilitate indigenous rights. Māori should not be viewed as simply another disadvantaged minority without consideration of their indigeneity. Social status is irrelevant to the right to live as Māori as wealthy Māori have the same right to te reo and culture, for example, as poor Māori (O'Sullivan, 2008).

Reid (2011) considers the relationship between the Treaty and health, but first suggests that every citizen of New Zealand should have a thorough understanding of the Treaty as it heralded the transformation of Aotearoa to New Zealand and because it will allow each person to develop a personal position on the Treaty. A position that will reflect our demographics, histories, responsibilities and passions. Reid (2011) considers Māori health statistics and the right of people to enjoy the highest possible standard of physical and mental health. She focusses on Kāwanatanga, often loosely translated as governance and suggests that good governance will take account of equity, something that Māori health statistics suggest is missing in New Zealand.

\subsection{Te Tiriti settlement process}

Te Tiriti settlement process is intended to resolve past colonial injustices, including the $19^{\text {th }}$ century land confiscations, the loss of resources and a Crown failure to fulfil Treaty promises (Orange, 2004). A number of authors provide commentary on the outcomes and difficulties of the process. Mikaere (2011) criticises the assimilative nature of Treaty settlements and notes the inadequacy of the compensation that has been provided. Specifically she notes the 1995 Waikato Tainui settlement where land and money worth $\$ 170$ million was provided to Waikato Iwi, when the value of confiscated lands was $\$ 12$ billion and in 1998, when $\$ 170$ million was provided to Ngai Tahu for the loss of reserves and access to food resources in the South Island, when the 1988 value of the land was \$20 billion. Stone (2012) agrees noting that settlements 
provide less than one per cent of the value of what has been lost. Mikaere (2011) points out that cash has been used to compensate Māori for the loss of a profound relationship with the land, sea and natural resources. She notes that the settlements have resulted in the development of Māori corporate entities which prosper while the majority of Māori remain marginalised, a stratification of Māori society which recreates a class system similar to the Pākehā system and creates differing political agendas for Māori, depending on where they find themselves on the new class ladder (Mikaere, 2011).

Cowie (2012) considers the difficulties for both sides when settlements are negotiated, highlighting the need for compromise from Māori negotiators to accommodate what is realistically on offer from the Crown and the Crown task of balancing fairness, comparability and flexibility when reaching agreement. He notes however that it is rare for Māori to view settlement outcomes as fair and just. Te Aho (2012) reiterates this point, suggesting that the Crown has a bargaining advantage in negotiating Treaty settlements, allowing it to unilaterally decide the negotiation conditions. Cowie (2012) notes that settlements of historic claims are final, which prevents the adequacy of redress being challenged through the courts and prevents groups that have settled, making further claims against the Crown.

Vertongen (2012) discusses legal challenges to Treaty negotiations, processes or outcomes and describes how the mandate of negotiators can be challenged, how claims can overlap between claimant groups and how the settlement process can be challenged, including in some cases as a breach of Treaty rights. He notes that disputes can arise due to the Crown's policy of negotiating with large natural groupings of claimants which sometimes subsume small groups without their consent.

Vertongen (2012) also highlights that the settlement process is driven by the Crown with Ministers making key decisions as to who should be negotiated with and what redress should be offered. Though processes are formal and standardised, there is no statutory framework under which Treaty settlement processes are conducted, making the Treaty negotiations process essentially political.

Joseph (2012) elaborates on concerns of mandate, particularly ascertaining the identity of Māori claimant groups and hence the precision of settlement, and the establishment of Māori representative legal entities. He is concerned that the Crown's policies and laws seek to define Māori tribal identity and representation, considering Māori too much as a homogeneous group without giving due attention to the diverse varied and complex nature of Māori groups. He 
considers that the Crown's desire to negotiate with large natural groupings has advantages for the Crown, but does not accommodate the claimant needs of individuals, whānau and small hapū.

Joseph (2012) suggests that the Crown's determination that it will only negotiate and settle with large groups is motivated by its desire for settlements to be made to organisations which fit with the Crown's ideas of political organisation, representation and governance. He argues that the creation of corporatised iwi structures around Treaty settlements, means the Crown is defining what constitutes Māori tribal identity and is part of a wider government assimilationist, neo-liberal agenda that focuses primarily on Māori economic development.

That focus on economic development is seen in the way that the Crown provides redress to claimant groups. Stone (2012) considers the types of redress that has been provided in past settlements, focusing on the financial and commercial dimensions of settlements. Stone (2012) describes how these aspects generally comprise Crown-owned property and land made available to settling groups at market prices and cash which is referred to as quantum. He identifies the Waikato Tainui and Ngai Tahu settlements as examples where the financial part of the settlements has allowed those groups to strengthen their economic position, but suggests that claimant groups sometimes disagree with the way in which the Crown determines the severity of Treaty breaches and hence the quantity of the settlement. Stone (2012) suggests that when the return of land is part of a settlement, the Crown views it as being on a commercial rather than cultural basis and notes that private land is excluded from all settlements, making it impossible for claimants to recover some land that may have been originally occupied by them or is of special cultural significance to them.

Bargh (2012) considers the above themes in the context of the differing expectations that the Crown and Māori have of what Treaty settlements should deliver. She highlights the neo-liberal economic context under which settlements are agreed and the Crown view that if settlements improve the economic position of Māori through economic development, social improvements will follow.

These views reflect those of Kelsey (1989) more than 20 years earlier as the Treaty settlement process began, who identified a conflict between the government of the day's stated intention to honour the Treaty and its pursuit of a neo-liberal economic agenda of free-market policies. Kelsey (1989) identified that the return to Māori of the control of land and natural resources was in conflict with the corporatisation of government departments and selling of state owned 
assets which may have been the subject of claims. Māori opposition at the time, to the State Owned Enterprises Bill 1989, was evidence of this.

An examination of the concerns that Māori continue to raise about on-going disadvantage, te Tiriti processes, its outcomes and the reluctance of Pākehā to relinquish real power and control, might suggest support for a decolonising strategy. But a Pākehā counter argument is also expressed in the literature. These views seem to reflect those described by Robinson (2010) in her explanation of the 1877 comments of Prendergast CJ that the Treaty should be regarded as a simple nullity.

\subsection{Pākehā opposition to the realisation of Māori rights}

Views common to those who write in support of, but subsequent to the views expressed by Brash in his Orewa nationhood speech (Brash, 2004), include the belief that prior to the arrival of Europeans, Māori were a stone age, tribal, primitive people, among whom slavery and cannibalism were endemic and who benefitted considerably from the civilising arrival of Europeans. Many of those who write in opposition to claims for Tiriti justice consider that New Zealand had an excellent record of race relations prior to the 1960s when 'treatyism' (described as a Treaty grievance industry) perpetuated by those, both Pākehā and Māori, who benefit from it, began. They promote assimilation as the best option for indigenous people confronted with what is described as white dominance and promote a 'colour blind' state where there are the same legal rights for all and no special funding or privileges for one race.

Robinson (2013) argues that the Waitangi Tribunal is involved in a process of 'revisionist' history which reinterprets New Zealand's history in the light of present Treaty grievances, less concerned with past reality than it is with capturing present aspirations and presenting Māori as passive victims of massive British wrong-doing. He asserts that the problem stems from the legal aspect of the Tribunal process and the conflict between lawyers' duties to their clients and historians' desire to seek the truth and to see all aspects of an issue. Robinson (2013) cautions that a Treaty grievance industry promotes racial division which suits powerful interests who profit from special elite Māori privilege. He suggests that the current National Government is ruling against the interests of most New Zealanders by building Māori capitalism while struggling Māori protest and fight for Treaty rights. Settlements he suggests benefit a select few rather than improving the conditions for all Māori. Māori inequalities are a feature of class, not race, a problem that will not be solved by Treaty settlements (Robinson, 2013). 
Robinson (2013) assumes that traditionally historians have provided an objective and unbiased New Zealand history without taking account of the position or lens of the historian. Mikaere (2011), Tuhiwai Smith (2012), Walker (2005) and other writers might suggest that Robinson's 'revisionist' history is simply retelling events from a Māori reality and perspective.

Rata (2012) contests the popular perception that the Treaty is New Zealand's founding document and rejects the partnership principle of the Treaty. Partnership and co-governance arrangements she sees subverting democracy because Pākehā are denied input to iwi cogovernance decisions. One of the few authors to comment directly on the relationship between knowledge of the Treaty and its acceptance, Rata (2012) considers that an awareness of the undemocratic nature of political arrangements proposed by Treaty activists, particularly inclusion of the Treaty in a constitution, rather than ignorance of the Treaty, is the reason rights under the Treaty are not accepted by many.

Robinson (2013) contests the accepted history of a considerable reduction in the Mâori population due to illnesses introduced by European colonisation, but suggests the population reduction results from low fertility, female infanticide, societal disruption from four decades of inter-tribal wars and most significantly the introduction of the musket. Robinson and his coauthors are alone in rejecting illness as a cause of Māori population reduction and provide little evidence to support their view.

Cresswell (2013) contests that New Zealand was owned by Māori prior to European arrival, suggesting that because most of the country was not actively occupied by Māori, and because Māori did not have a European understanding of property rights, Māori cannot claim ownership of pre-European New Zealand. These views reflect the 1877 views of Prendergast CJ that title to New Zealand was acquired by the British Crown through discovery and priority of occupation (Robinson, 2010).

Cresswell (2013) suggests that when European settlers arrived, much of the country's natural resources had been stripped bare by slash and burn agriculture, that without secure property rights there was not an incentive to behave sustainably toward the environment, a true tragedy of the commons. This description is contrary to that presented by Evison (1993) who vividly describes Ngai Tahu mahinga kai areas and prosperous functioning societies in Te Wai Pounamu (South Island). He outlines the mahinga kai and reserve areas, schools and hospitals, promised but not delivered during land purchases and describes Banks Peninsula, before the bush was removed by Pākehā settlers, as a jewel with such bio-diversity, flowering trees and 
shrubs that seafarers, Māori and Pākehā could smell long before it emerged over the horizon. Cresswell (2013) suggests that the environmental damage Māori created, resulted in starvation, desperation and constant fighting over resources. He suggests that what saved Māori were the rights and privileges, particularly property rights of British subjects, guaranteed by the Treaty (Cresswell, 2013). Cresswell does not cite any research to support his views.

Round (2013) suggests that the Treaty makes no promises of special rights for Māori nor provides a foundation for racial privilege. Further he argues that it makes no suggestion that government was to be a partnership between Māori and the Crown. He suggests that tino rangatiratanga is merely tribal self-management, not dissimilar to local government and something which no longer has relevance as tribes as living entities have now disappeared (Round, 2013). Round (2013) contests the present day legitimacy of the Treaty because the Treaty partners, the Crown and Māori, no longer exist. The Crown in 1840 was Queen Victoria, an actively ruling Monarch when today the Crown refers to a government elected by a democratically elected parliament. Māori who signed the Treaty were 'full blooded' Māori, but today Māori are only 'part Māori' having mixed Māori and European descent. Past injustices, Round suggests, should only be compensated to those who suffered the injustice. Modern Māori, now part Māori and part European have ancestors who were both the instigators and recipients of injustice. Treaty settlements he argues compensate Māori for injustices that one group of their ancestors perpetrated against another group. On this basis he objects to any Treaty settlements (Round, 2013).

Round (2013) expresses concern that misrepresentation of what the Treaty provides to Māori, or Treaty mythology, is firmly entrenched in universities, teachers colleges and the public service, and the view that past wrongs at the hands of white oppressors entitles Māori to wealth and privilege will irreparably damage New Zealand. He warns that while Pākehā take that view, Māori demands will never end and the Treaty grievance industry will continue until the public coffers are empty (Round, 2013).

Butler (2013) reinterprets the accepted historical versions of events in Taranaki leading up to and including the 1860 war, the 1863 Waikato war and the controversial land purchases in the South Island in a way that presents Māori as savage and disorganised, and the British as reasonable peacemakers. He then describes the events that led to the formation of the Waitangi Tribunal and presents comment on the Taranaki, Waikato and Ngai Tahu Treaty settlements. He is critical of the Waitangi Tribunal for allowing the incorrect re-telling of history in a way that supports the Treaty settlement process and bemoans an ignorance of the true history of 
New Zealand, even at the highest levels of government. Finally he suggests that far from settling past grievances, the Waitangi Tribunal encourages more protest and racial ill feeling when most grievances had been settled by 1960 on a full and final basis (Butler, 2013).

There is an irony in the views of these writers. They accuse the Waitangi Tribunal of reinterpreting history to support a claims industry, but contest accepted history themselves, reinterpreting events in a way that moves fault from Europeans to Māori. It is notable that little of what they write has been referenced to recognised historians or is supported by independent, peer reviewed research. The conclusion drawn from this is that their views represent opinion above anything else. O'Sullivan (2008) identifies this type of discourse as promoting unequal power relations, allowing a dominant party to reconstruct history in its own terms, creating negative stereotypes of greed as popular mythology.

These views would be criticised by some as an attempt to impose a version of history which legitimises myths giving the dominant Pākehā group the right to sovereignty and a disproportionate share of resources as described by Pratto and Stewart. (2011).

It is unlikely that these views are widely and deeply held by Pākehā, as they are inconsistent with the Human Rights Commission's findings over several years which show a general acceptance of Treaty settlements and a desire to know more about the Treaty. It is more likely that the views expressed by this group of writers, represents what is now the more extreme end of a spectrum of Pākehā views and reflects what was the baseline of views commonly held by Pākehā up to the 1950s, views originating from Prendergast CJ in 1877 and early popular historians as described by Robinson (2010). The evidence suggests that while these views still exist amongst some, mainstream Pākehā attitudes have changed over time to be more accepting of Māori Treaty concerns.

In any case, given Aotearoa/New Zealand's parliamentary democracy and three year election cycle, it would not have been possible for three successive governments, each of which has been elected for multiple terms, to have continued te Tiriti settlement processes of the past twenty years, if the views expressed by this group of writers was deeply held and widespread.

\subsection{The psychology of social dominance}

It is clear from the literature that New Zealanders see themselves as an egalitarian nation, the emergence of biculturalism described as one of the most important social and political developments in the latter half of the twentieth century (Belich, 2007). How that self-perception manifests itself in attitudes to resource specific policies (affirmative action) has been the 
subject of research by Sibley and Liu (2004) who used two studies to investigate the relationship between social dominance orientation and support for positive action policy amongst undergraduate university students. Social dominance theory provides an explanation of how dominant groups attempt to impose a version of history to legitimise myths that give them the right to sovereignty and a disproportionate share of resources (Pratto \& Stewart, 2011). Sibley and Liu (2004) found that the majority of students in their study supported biculturalism in principle but were opposed (76 per cent) to resource specific biculturalism (affirmative action policies), identifying two forms of attitude to biculturalism and multiple possible motivations for intergroup attitudes across cultures. The study had a narrow sample group and the extent to which the results could be extrapolated is arguable. However a similar study by Sibley, Robertson, and Kirkwood (2005) which randomly selected Pākehā people seated in public places, found 66 per cent support for symbolic biculturalism and 37 per cent opposition to resource specific affirmative action policies. These studies considered the application of the existing models of Social Dominance Orientation and Right-Wing Authoritarianism as predictors of Pākehā attitudes to biculturalism. They found that Social Dominance Orientation was a significantly better predictor of support for symbolic biculturalism than resource specific biculturalism and considered that opposition to the general principles of biculturalism was driven by motivations for intergroup dominance and superiority and a failure to experience collective guilt (for past injustices). Significantly they found that those with high Social Dominance Orientation did not experience collective guilt (Sibley et al., 2005). This is an interesting counter to Mikaere (2011) who highlights collective guilt in Pākehā myth-making about history and its relevance to current Māori Tiriti claims.

Another study by Liu et al. (1999) examined the utility of a psychological framework in providing a set of theoretical lenses to view the perception of history, focusing on Māori and Pākehā when considering history making as a social activity. They identified a basic tenet of social identity theory, in-group favouritism, when Māori and Pākehā used words to describe the same events in history which not only favoured their own group, but provided verification of their own group's current position and desired future standing. The researchers also considered social dominance theory and identified a hegemonic representation of history produced by colonial power, however they identified that it was on the wane in New Zealand with the legitimising myth of history being actively challenged (Liu et al., 1999).

One of the key modes of social dominance theory are legitimising myths, ideas that are widely known in a society and linked to accepted cultural norms which make them seem self 
apparently true (Pratto \& Stewart, 2011). Legitimising myths "are beliefs (stereotypes) and attitudes (prejudice) suggesting that subordinate groups deserve their status" (Quist and Resendez, 2002, p. 287). Research by Quist and Resendez (2002) suggests that dominant groups have a heightened belief in legitimising myths when they perceive themselves to be under threat.

This may be seen in Brash's 2004 speech and others like it, which Sibley et al. (2005) suggest is based on legitimising myths and may alter representations of Māori/Pākehā relations by encouraging Pākehā to refute responsibilities for historical injustices while still adhering to discourses of equality.

These studies are important because they provide a social and psychological framework for understanding why people adhere to specific attitudes, a framework which may inform action to change attitudes in favour of those granting greater Treaty justice to Māori. However social dominance theory is contested with Schmitt and Branscombe (2003) arguing that social determination processes better explain inter-group inequality. Other theories include system justification theory and social identity theory (Sidanius, Pratto, van Laar, \& Levin, 2004).

\subsection{Society as an imagined reality}

Harari (2014) provides interesting comment on the maintenance of hierarchies in human societies. He explains that the difference between humans and animals is that animal behavior is determined by their DNA. Changes occur in animal behavior when there is a genetic mutation. If that change is beneficial to the species, then natural selection means that overtime, that DNA change and behavior becomes predominant within the species. Humans, he suggests underwent a cognitive revolution beginning about 70,000 years ago, allowing them to develop what he describes as imagined realities. Harari (2014) uses the example of a game of football. The rules of football are not real. They are an imagined set of information that instructs players on what they can and cannot do in a game. The game only works if the players collectively accept and play by the rules. A referee intervenes when the rules are not followed, but the player must accept the referee's ruling otherwise the game disintegrates into chaos. But the rules of football are only an imagined reality. Harari (2014) suggests that the only reason that humans can live together in large societal groups is because we accept similar if more complex imagined realities. He suggests that democracy, not a real thing like a tree or river, is an imagined reality that exists only in our minds and only works if people within a democratic society accept the imagined rules of democracy. Harari (2014) makes the point however that 
those who benefit from imagined realities go to considerable effort to ensure people think they are objective realities, rather than imagined ones. People are educated from birth with fairy tales, drama, song, painting, political propaganda and etiquette to believe that imagined realities are natural orders, embedded in the material world. Examples he provides are the suggestions that the capitalist free market economy is a natural market which finds its own balance and that some races of people are superior to others. He cites the views of Nazi Germany and the approaches of European explorers when they encountered indigenous people, as examples. The significant point that Harari (2014) makes is that social dominance, racism and colonialism are human constructs. While they can create prisons for some people, they are still ideas, attitudes and points of view that exist only in the human mind. While those imagined realities affect and influence the outcomes of some people's lives, determining standards of living or provoking acts of oppression, because they are imagined, they can be changed. If this is the case, then Pākehā views about te Tiriti can change.

\subsection{Te Tiriti relevance today}

Many Māori continue to believe that Te Tiriti gives them the right to access and manage natural resources, regardless of Crown management systems and laws, confirming Borrows (2006) assertion that Māori laws and customs create pre-existing constraints on the Crown.

Article One of Te Tiriti O Waitangi, in both the English and Māori versions, clearly cedes government over the land of Aotearoa/New Zealand to the British. Article Two just as clearly guarantees to Māori full exclusive and undisturbed possession of their land, estates, forests, fisheries and other properties (Orange, 2004). Kahn (1999) argues that the British objective of sovereignty was only gained through the absolute recognition of Māori natural resource rights, specifically water resource rights, evidenced by reference to full exclusive and undisturbed possession in the Treaty. He suggests that to gain government, the English conceded ownership of the natural resources. Durie (2005) argues that full exclusive undisturbed possession is translated as tino rangatiratanga, a phrase which comes close to the concept of sovereignty, something Māori have never abandoned.

Borrows (2006) highlights the importance of treaties between indigenous peoples and colonisers and suggests that they need to facilitate nation building and consent rather than violence. He suggests that treaties establish ground rules for future interactions and that honouring treaties involves taking responsibility for our history. He further identifies that one of the primary intentions of treaties, including the Treaty of Waitangi is to promote peace and 
order across cultures, but he notes that the signing of treaties is distinct from their implementation and that if the promises and obligations of treaties have not been honoured in the first hundred years after their signing, that does not mean they should be discarded. Borrows (2006) also suggests that the denial of human dignity and the impoverishment of many Māori is evidence that the assimilative laws and policies that followed the signing of the Treaty have not created a healthy nation and that more assimilation is not the answer. He argues that due to historic injustices and changing circumstances, treaties can become more relevant today than when they were signed. Borrows (2006) suggests that because Te Tiriti spoke of future relationships, it implied terms upon which subsequent agreements between the Crown and Māori would be made.

Certainly, te Tiriti is relevant to all in Aotearoa/New Zealand today, but settling the terms today of an 1840 agreement is far from straightforward. Crown assertions that settlements are full and final depend on the context and time of the settlements and may differ from the views of some Māori (Wheen \& Hayward, 2012). Those who suggest further and differing claims will be made, include both supporters and opponents of te Tiriti settlement process. Ani Mikaere (1997), when commenting on the value inadequacy of recent settlements, suggests that a settlement that seems fair at one time, may appear inadequate in hindsight and Crown insistence on the finality of settlements may not make them so. Round (2013) bluntly states that Māori demands will never end, noting particularly that claims to fresh water will continue after the current round of 'full and final' settlements.

Highlighting the importance of Te Tiriti to environmental management today, Borrows (2006) identifies that indigenous peoples are not the only beneficiaries of treaties and that nonindigenous peoples also have Treaty rights. Margaret (2010) reiterates this view, highlighting a need to challenge the perception that treaties benefit only indigenous people. As an example Borrows (2006) notes that the entitlements that non-indigenous peoples enjoy can often be traced to consent given to the Crown through a Treaty process. Justice Eddie Durie used the term tangata tiriti to refer to Pākehā who were in New Zealand by right of Te Tiriti (Durie, 1989, February 6).

It must then be important to find a way to progress which provides Māori, Pākehā and others with consent, dignity and honour. Snedden (2005) suggests that a Treaty based approach to managing our lives is both possible, practical and should not be feared by Pākehā. He argues that application of the Treaty creatively and energetically with Pākehā accepting and embracing its principles can provide a new basis for the relationship between Māori and Pākehā. 
However Gould (2012) suggests that many Pākehā see the Treaty as an exclusively Māori domain, and Māori politics as solely a Māori concern. He argues that we all have an interest in the success or otherwise of Māori and should not tolerate the poor Māori statistics in health, education and employment, suggesting that Pākehā indifference to what he describes as our defining constitutional document, the Treaty, makes our country weaker than it should be. O'Connor (2006) has similar views, suggesting the importance of Waitangi Day as a day when we can celebrate the Treaty, honouring Māori as tangata whenua. She laments that Pākehā have so little understanding of the Treaty and its meaning, advocating for participation in Treaty workshops as a powerful way to understanding our colonial history and Māori aspirations. Turia (2013) considers the Treaty represents inclusiveness and ensures a place in Aotearoa for both tangata whenua and tangata tiriti. She suggests that Pākehā have nothing to fear from the Treaty (Turia, 2013).

Given the government's acceptance of Māori rights and interests in fresh water resources and a need to continue the resolution of Māori claims under te Tiriti, changes in Pākehā attitudes to te Tiriti seem critical to success and could centre on the management of natural resources, with Te Tiriti as a central defining document.

\subsection{Making progress: Tiriti education and Pākehā as allies?}

For a small but growing group of Pākehā, action to create change in the views of other Pākehā has taken a priority in their lives. Identifying a link between Pākehā knowledge of te Tiriti, Pākehā acceptance of Tiriti claims, improved outcomes for Māori and the resultant benefits to all in Aotearoa/New Zealand has led to a Pākehā Treaty education network. Margaret (2013) identifies that te Tiriti gave Pākehā the opportunity to live in Aotearoa New Zealand, which if not honoured means Pākehā presence here is based on injustice. She suggests the focus of the Pākehā Treaty workers' movement is to shift Pākehā society towards social justice and selfdetermination or tino rangatiratanga for Māori by creating change within the dominant Pākehā culture. Margaret (2013) uses the term 'allies' to identify non-indigenous supporters of indigenous justice struggles.

There is a clear link between the work of allies and my research question. This thesis seeks to explore changes in Pākehā views in relation to te Tiriti and how those views may change in the future. Allies, like Treaty education workers, actively seek to create social change by educating Pākehā about te Tiriti and historic injustice. It seems evident that the work of allies can inform and illustrate my research questions. 
It also seems evident that the work of allies may have had an influence. The Minister for Treaty Settlements, Christopher Findlayson claims that the environment for Treaty settlements is now more benign than it ever has been. By June 2013, half of all Treaty claims had been settled and the government intended that the remaining claims would be settled by the end of 2014. Some disagreed with that timeframe (Tahana, 2013) and it has not occurred.

Margaret (2010) identifies the role of allies in creating social change in Aotearoa/New Zealand. She defines allies as people who understand the dominant/white/colonial mind-set and engage in specific work amongst their own people in support of the struggles of those they are in alliance with. Allies challenge a collective denial of colonial violence, white privilege and racism within the broader white settler populations (Margaret, 2010). Margaret (2013) suggests that working as allies gives people a powerful, active and positive role in opposing Pākehā dominance. She identifies the qualities that allies have and explores some of the challenges that allies face, but cautions that the term is meaningless without action.

Māori challenge to colonial and neo-colonial power relations in Aotearoa/New Zealand has produced recent local theories of Pākehā change. In general, these theories focus on collective or individual consciousness-raising processes which positively transform Pākehā understandings and awareness of colonial history, allowing Pākehā to participate in more informed relationships with Māori. Seminal research in this area was undertaken by Huygens (2007) who investigated how collective Pākehā consciousness can change in response to learning about te Tiriti o Waitangi. Huygens explored the social and psychological processes of change experienced by Pākehā responding to te Tiriti and reports a coherent and sustained alternative discourse of Pākehā honouring te Tiriti. This is described as an "anti-colonial discourse, affirming the Māori authority guaranteed in te Tiriti o Waitangi and aiming towards a mutually agreed relationship between Pākehā and Māori” (Huygens, 2007, p. 251). Huygens suggests that this pro-Tiriti discourse has been developed over the last 30 years of ongoing interaction with Māori. Theorising and changes implemented in non-government organisational settings has enabled Pākehā to have "non-resistant and coherent interaction with Māori who asserted te tino rangatiratanga" (Huygens, 2007, p. 252). Huygens (2007) argues that the antiracism/Treaty movement is a significant source of theorising of how a dominant colonial group may change in response to challenge and critique from indigenous people and that Treaty education has significantly contributed to the discourses Pākehā use in dialogue with Māori about a decolonised future. She challenges three meta theoretical assumptions of social science theory, the naturalising of dominance, the ideological homogeneity of dominant 
groups and the rational individual, suggesting that the Treaty gap is between those who know and support te Tiriti and those who don't, rather than between Pākehā and Māori. Huygens (2007) highlights the importance of Pākehā processes of change, as Pākehā remain the dominant, culture defining group in Aotearoa/New Zealand's public institutions and considers that efforts to educate Pākehā about te Tiriti o Waitangi, an explicit attempt to conscientise that dominant group, are consistent with Freire's argument that personal conscientisation, dialogue with others and permanent cultural action produce liberatory change.

The educative role of allies in informing Pākehā so that a greater understanding of te ao Māori can be achieved and seen as having relevance to Pākehā is, I believe, significant.

\subsection{Literature summary}

The review of relevant literature provides a context for examining changing Pākehā attitudes to te Tiriti. Where the literature covers changing Pākehā views, it tends to consider the past and the present rather than how views may change in the future. For example, it reveals the starting point of general Pākehā understanding of Māori and te Tiriti through the 'simple nullity' statement of Prendergast CJ (Robinson, 2010) and the view of early historian Lindsay Buick (Robinson, 2010) that colonialism was benevolent.

A large gap in Treaty studies and understanding up to the 1970s and the lack of Māori voices and perspectives outlined by Robinson (2010), identifies the location of power over this period. A number of authors, including Orange (2004), Walker (2005), Robinson (2002), Snedden (2005) and King (1999) provide an outline of the local influences and events that promoted changing Pākehā views from the 1960s including protests at Takaparawhau, the 1981 Springbok rugby tour and decisions of the Waitangi Tribunal. Walker (2005) also highlights reaction against Treaty claims which resulted in the government of the day trying to determine the principles of the Treaty. Nairn (1989) highlights external influences to change including Frantz Fanon, Paulo Freire, progressive churches and how they influenced Pākehā anti-racism groups. These authors describe the drivers of changing Pākehā views, but apart from Sneddon (2005), don't really discuss how and why there might be further change.

The small number of Pākehā authors who write about being Pākehā, principally Snedden (2005) and King (1999), advance a positive future position for Pākehā in Aotearoa/New Zealand, exploring what it means to be Pākehā and the idea that the Treaty gives Pākehā a right to belong in New Zealand, providing a vision of hope with Pākehā understanding of the Treaty at its centre. 
The alternative view, that we are all New Zealanders and that Māori and Pākehā should not be seen as separate groups, along with descriptions of a Treaty grievance industry and objections to Treaty settlements, is advanced by a number of authors. Apart from dire warnings about the future, they tend to contest views of the past rather than explore how and why change might occur for Pākehā.

Mikaere (2011) provides an illuminating view from a Māori perspective, highlighting the power imbalance of the Māori/Pākehā relationship. She does provide views of where Pākehā change could occur, without investigating how this might happen. To be fair to Mikaere, this is a question that Pākehā need to answer.

Research by Sibley et al. (2008) showed ways in which Māori have influenced Pākehā, particularly how Māori cultural icons validate national identity for Pākehā. Their results differ from theory and similar research in Australia and the United States of America

Empirical research undertaken for the Human Rights Commission shows changing Pākehā attitudes over time (HRC, 2004), particularly that knowledge of the Treaty appears to be increasing but with a higher percentage of Māori than non-Māori having a reasonable declared knowledge and interest in the Treaty (HRC, 2006). Nearly twice as many Māori than nonMāori are interested in finding out more about the Treaty (HRC, 2004), but the importance of the Treaty as New Zealand's founding document is clearly demonstrated (HRC, 2006, 2009, 2011).

A similar pattern is detected with regard to fresh water resources with the literature identifying government concern about the management of fresh water resources, and various bodies acknowledging Māori interests and rights in water resource management, but they fail to identify how and why change may occur in the future.

It is clear from the literature that water is one of the most difficult resources to determine rights and interests for, particularly because it is difficult to characterise exactly what is sought in Māori claims to ownership (Te Whiti Love, 1996). A number of authors discuss property rights in relation to water (Bruns and Meinzen-Dick, 2005) but again tend to deal with historic situations rather than outlining alternatives for the future

One author who does consider future options is Hsiao (2012) who identifies the recently signed Whanganui River agreement which recognises the Whanganui River as a living entity with rights of its own as a way forward. Co-management arrangements, also advanced as an 
alternative option are seen by some as a failure to address the issue of commercial and property redress with regards to water Ruru (2013).

A number of authors, in a collection of articles edited by Veronica Tawhai and Katarina GraySharp (Tawhai \& Gray-Sharp, 2011), identify specific areas where the Crown has failed to meet its obligations under the Treaty and while we can infer what change to Pākehā views might occur as a result, it is implicit rather than explicit. Similarly, a number of authors provide commentary on the outcomes and difficulties of the Treaty settlement process.

The literature provides some explanation for why dominant groups construct realities in an attempt to retain sovereignty and a disproportionate share of resources. Social dominance theory was provided as one explanation.

Some ideas of why changing the views of dominant groups was possible were explored and the ideas of Harari (2014) considered. Particularly it was suggested that social dominance, racism and colonialism are human constructs, ideas, attitudes and points of view that exist only in the human mind. The importance of literature on this topic is simply that it outlines why change is possible in dominant groups.

Literature from those actively working to change Pākehā views identifies the work of the Pākehā Treaty workers' movement to shift Pākehā society towards social justice and selfdetermination or tino rangatiratanga for Māori. Margaret (2013) uses the term 'allies' to identify non-indigenous supporters of indigenous justice struggles. Huygens (2007) describes how collective Pākehā consciousness can change in response to learning about te Tiriti o Waitangi and reports a coherent and sustained alternative discourse of Pākehā honouring te Tiriti.

The review of available literature provides a good understanding of the basis of Pākehā views about te Tiriti, the agents of change, the resisters of change, and the reasons why water remains a difficult location for that change to occur. It provides a sound basis upon which to consider the first part of the research question, how and why Pākehā change has occurred. It does not consider the second part, how or why Pākehā views about te Tiriti may change in the future, particularly in relation to water resources. This gap in the literature, the second part of the research question, is an important question to answer because it may provide guidance for educators and policy makers. The following chapter sets out the approach taken to finding answers to that question. 


\section{Methodology}

The goal of this research is to explore the views of a specific group of people. Subsequently, the primary source of data were Pākehā people who had demonstrated through their writing, action or position, an understanding of the history of Aotearoa/New Zealand in terms of the power relationship between Māori and Pākehā. They were people who had demonstrated an understanding of the Te Tiriti o Waitangi and the responsibilities that Pākehā people have under te Tiriti.

Ethics approval for the research was granted by Victoria University Human Ethics Committee on 13 January 2014 (Appendix A). Interviews were conducted with five people, each for a duration of about an hour. Each interviewee was provided with an information sheet about the research topic (Appendix B), in advance of the interview and signed a consent form (Appendix C) at the beginning of the interview.

\section{$5.1 \quad$ Secondary data}

The secondary data source was literature that considered the relationship between Māori, Pākehā and Te Tiriti o Waitangi and fresh water resources. We cannot know how Pākehā views might change in the future, but investigation of how they may have changed in the past, and the factors that influence change, can inform an investigation of the topic. Secondary data collection was used to:

- $\quad$ build an understanding of Pākehā views of te Tiriti and water resources, and how those views have changed,

- $\quad$ provide a context for those views in a wider social, psychological, economic, and environmental framework and

- Inform thinking about the issues which may influence changing Pākehā views.

\subsection{Primary data}

I chose to gather primary data by undertaking semi-structured interviews with purposively selected Pākehā New Zealanders. I was interested in how and why the views of a dominant group may change and to explore the perceptions and attitudes of the interview participants about this. I wanted to explore what, if any changes the interview participants thought might occur in Pākehā attitudes, or what they thought might need to occur and why, with respect to Māori rights and interests in fresh water resources. Semi-structured interviews were selected as the data gathering method because they would provide an opportunity to establish an 
understanding of the interview participants' views through questioning and listening. The semistructured interview approach included informal conversations which allowed me to provide a guide in terms of the topics to be covered, but allowed space for the participants to express their own views on their own terms. This approach reflected the view that "each one's way of making sense of the world is as valid and worthy of respect as any other..." (Crotty, 1998. p58). I considered that structured interviews might not allow the interview participants to express what was important to them, but that unstructured interviews might allow participants too much opportunity to diverge from the topic of my research.

I carefully selected interview participants choosing to interview Pākehā only. I wanted to explore the views of Pākehā who had been involved in protest, critique or education in support of increasing Pākehā awareness of te Tiriti and had demonstrated their established views on the topic because I considered that if there is to be change for Māori regarding fresh water resources, it is Pākehā views and attitudes that will need to change. There is a difficulty with this however as "Dominant groups in colonial settings typically maintain an ontological and epistemological hegemony to the detriment of indigenous peoples" (Huygens, 2007. p14). Huygens (2007) also argues that theories acknowledging structural oppression discount the dominant group as a site of change.

I could have selected Māori interview participants on the basis that critically aware members of an oppressed group may be considered experts on how social systems oppress them. Instead, I chose to interview Pākehā because as (Huygens, 2007) suggests, there is a need for dominant groups to undertake work to change themselves. I was also aware that Māori working for change, invest considerable time and energy on their own agenda with their own people and it did not seem appropriate to seek their assistance to investigate how Pākehā views might change. Māori may also be genuinely unaware of the internal workings of changing Pākehā attitudes (Huygens, 2007).

I could also have chosen to select Pākehā interview participants at random in an effort to obtain a cross-section of views, advancing an objective method. I rejected this approach because dominant groups typically maintain an epistemological and ontological hegemony which disadvantages indigenous people and advantages themselves (Huygens, 2007). Most Pākehā seem blind to their cultural dominance and do not see it as unjust. Insight into Pākehā views about Māori resource rights and interests, it seemed to me, would most likely be found with Pākehā people who were involved in trying to create change around Pākehā attitudes and views in that area. I selected interview participants who I believed had, as described by Freire (1972), 
been concientised or had developed a consciousness and knowledge that could have the power to change reality. They were people who were active in creating change in Aotearoa/New Zealand society. I considered that Pākehā who were active in supporting Te Tiriti would be most able to articulate an understanding of changing Pākehā views. The purposive selection of interview participants was critical and deliberate because it sought the views of people with specific characteristics, an approach which is consistent with the views of Tolich and Davidson (2011) who suggest that purposive samples deliberately seek certain types of people because they are typical of the case of interest to the researcher.

\subsection{Theoretical lens}

This research is qualitative in nature, uses a constructionist theoretical lens and follows a constructionist epistemology. I chose to take a constructionist approach because it is useful "to use constructionism where the focus includes 'the collective generation [and transmission] of meaning"” (Crotty, 1998.p58).

Social constructionism involves people working together to construct understanding, through the social interactions of a group. It suggests that meaning, significance and understanding are developed in coordination with other human beings. In the context of this research the constructed meaning is a collective understanding amongst Pākehā, of the significance of te Tiriti and its relationship to the management of water resources. The meaning and understanding has been formed over many years of social interaction amongst people in Aotearoa/New Zealand. The research then asks what further social construction in this area Pākehā may form in the future.

This lens is closely related to social constructivism which focuses on the learning of an individual due to their interactions in a group. But constructionism is more appropriate here because the focus is the collective change in Pākehā views rather than the specific change to individuals. Of course the two are linked.

I have chosen this approach because it not only looks at what is said, but considers also the surrounding social and historical contexts. It focuses on interaction and ongoing processes in actual settings and uses questions that involve description and evaluation of the critical theme of the research, in this case attitudes to te Tiriti and water. This approach was selected because it has the potential to reveal through the analysis of the interviewees words, the contexts and understandings that underpin the ideas that are expressed. 


\subsection{The interview and analysis process}

I sought to ensure that all voices in the research had a chance to be represented and have their views treated fairly and with balance. A list of reference questions were prepared and used to get the interviews started, but when underway the interviewees were allowed to discuss the topics that evolved from their responses. When the responses seemed to diverge from the topic, a return to the reference questions brought the interviews back to a discussion of the main themes of the research. Because the interviewees were permitted to determine to some extent the direction of the interview and the material discussed, each interview was different. Not all of the reference questions were asked of each interviewee and in some interviews, questions emerged in response to the discussion.

The intention of the interviews was to explore the topic in an open and thoughtful way, giving the interviewees an opportunity to express their views without critique or contest. Some participants picked up on particular topics that were important to them and spoke specifically about them. The attribution of quotes in the next section reflects this.

Responses to the Prime Ministers statement that nobody owns water (Young, 2012) was the first question that was asked of each interviewee. This was intended to anchor the interviews around water resources and te Tiriti o Waitangi. It also provided a context of Pākehā attitudes to these topics. The responses to that question served as an entry point to a wider discussion of changing Pākehā views. Interviewees were then asked if the Prime Ministers view represented a wider Pākehā view. This led to discussion of what views Pākehā held about water and te Tiriti and how they have changed over time. These questions were followed by asking what the interviewees thought Māori rights and interests in water might be. Responses to this question were very revealing, and with each interview, it was at this point that the interviewees really seemed to open up with what they thought. Discussion from this point varied depending on the interviewee and what they offered, but covered how Pākehā attitudes have changed to date, how they might change in the future, why they might change, what things might bring about change, and why they thought change in Pākehā views and attitudes might be important for the future of Aotearoa/New Zealand. Some interviewees were also asked about the role of Treaty settlements in changing Pākehā views.

I was surprised by the interest that the interviewees had in the topic and their willingness to openly discuss their views. Some of the views and ideas expressed were far from mainstream 
and I expect they would not have been discussed publically by the interviewees. A number indicated that they thought the topic was important and worthy of further research.

The interviews were audio taped and transcribed before being checked for accuracy by the interviewees. They were then analysed thematically using an essentially manual process. Each transcript was read through multiple times and common themes marked on the transcript. The interview responses that expressed ideas and views around common themes were then cut from the digital word documents and compiled together under theme headings. The quotes were then edited so that they were succinct and expressed the inherent ideas of the interviewee. Quotes from the interviews were then structured to tell a collective story relevant to the themes that emerged from the data. Further editing then re-organised the quotes to remove repetitions and focus on the views that were being expressed.

Often the responses, ideas and views expressed by the interviewees were consistent or in agreement. But sometimes differing views or views tangential to the predominant theme were expressed. Where this occurred all of the views have been included and comment made on how responses have differed.

The ideas and themes were considered in relation to the themes revealed in the literature review. Themes emerging from the interviews included conflict with te Tiriti and a process of exclusion inherent in the statement that 'nobody owns water'. The issues of water ownership and property rights and processes of Pākehā change, barriers to change and an understanding of how Pākehā can work toward power sharing relationships with Māori were explored. Critically, the contribution of Pākehā understanding of injustice, tino rangatiratanga and acceptance of a Māori world view emerged as a pathway that can provide a more equitable, positive and rewarding future for all in Aotearoa/New Zealand. 


\section{Results - "It's up to us to commit to the process"}

In this chapter, I have attempted to let the interview participants speak for themselves. I have done this by relying extensively on quotes, abridged where necessary to present the ideas that have been expressed. I have tried to limit my explanation of what has been said to signposting the quotes and constructing the themes. I have taken this approach for a simple reason. If you seek information from people on a topic about which they have considerable knowledge or expertise, you have a responsibility to let their words tell the story rather than interpreting what they have said. I have however organised the quotes to follow a logical progression that tells the collective story of all the interview participants.

Each quote is attributed to the interview participant who made it, by a letter from A to E. The participants remain anonymous but the letters link the quotes to each participant.

\subsection{A statement of exclusion}

The Prime Minister's statement that nobody owns water (Young, 2012) was attractive to many for its simplicity and egalitarianism. It suggests a public good, public benefit resource that we can all share, something that benefits all. But research participants saw in the statement a depth and expression of Pākehā views motivated by political, cultural, ownership and social dominance values. The statement provides a vehicle to explore Pākehā views.

... so right from the beginning, although it seemed an attractive statement, nobody owns water, I was cynical from the very beginning.- $C$

I like the idea that everyone owns water but if you say the Crown actually owns it and therefore the crown can sell it or trade it or deal with it commercially then you've got to have a debate about that.-E

It was suggested to participants that the Prime Ministers statement simply reflected the view that water was a public good, but they viewed this suggestion cynically. Their view was that the public good was promoted only for part of our society, excluding an alternative view point and setting aside Crown responsibilities under te Tiriti. This was seen in a framework of cultural dominance and a structure that favoured Pākehā at the expense of Māori.

... actually the public good is a Pākehā good and it... marginalises and takes out of the picture alternative ways of engaging and using water...-A 
...the public, as long as they are living a western lifestyle and have western beliefs, not the public if they live on a Marae and have a traditional relationship with a particular stream or with many streams and want to preserve that relationship.-C

Participants also felt that the statement specifically represented exclusion of Māori from a resource that was considered by them to be a toanga and subject to tino rangatiratanga under te Tiriti, putting Māori in a position of having to outline and justify their connection to water.

...what that's saying isn't that nobody owns the water it's that Màori don't own the water...-D

....so the statement that nobody owns the water.... contributes to the ongoing process of elimination and rendering diverse Māori invisible...-A

...Māori were put onto the back foot and immediately had to start describing their traditional relationship with the water, their claim to water and so on...

Interestingly, the participants identified customary Māori relationships specifically as being negated by the statement. The language used when participants expressed their views highlighted the deliberate selection of interview participants. It was clear early in the interviews that participants had a depth of knowledge about Pākehā/Māori relationships and the points of tension in those relationships.

...it wipes away all customary relationships ... it ignores the fact that tangata whenua as first nation have these customary responsibilities and relationships for looking after water, for managing their relationships, it wipes all that out.-B

These comments reflect the point made by Mikaere (2011) and O'Sullivan (2008) that in spite of te Tiriti, Māori rights are derived from being the first people to settle in Aotearoa/New Zealand. The also highlight the view that indigenous people "possess a unique and inalienable relationship with the state, along with a corresponding set of collective entitlements that flow from their constitutional status as descendants of the original occupants: (Maaka and Fleras, 2005, p.32).

\subsection{Conflict with te Tiriti o Waitangi}

Participants also raised te Tiriti and the message they felt implicit in the Prime Ministers statement about Treaty rights. They clearly saw framing a debate about water in a way that removed the question of Māori authority over water, as an attack on Māori Treaty rights and an attempt to position one side of the argument. 
.... [it] just isn't representing the intention of te Treaty (sic) in any way. So he's not honouring te Treaty (sic) in that statement ...-D

...he's making a very powerful statement to tangata whenua about their position in relation to water...-D

Participants identified a conflict between the statement and the government's intention at the time to sell shares in a hydro-electricity generation company that used extensive fresh water resources to generate electricity.

...it's highly contradictory, because it's being used in a context of the government exerting control over that resource, over water...... categorically no-one owns it, however we're gonna sell it.-D

But participants also identified that the statement had roots in historical Pākehā dominance, reflecting the view of Kahn (1999) that colonisation is a battle for control of natural resources. They saw in the statement, political motivations and a further act of colonisation, consistent with the view of Mikaere that colonialism continues today (Mikaere, 2011).

...it's asserting the power of the Crown and that is in conflict with Te Tiriti o Waitangi and the agreement that the Crown signed with .... hapu and tangata whenua around recognising.... that Māori have retained their own sovereignty.-A

...it's a deeply political thing to say in a colonised country...

In spite of this, one participant felt that the statement had benefits because it forced Pākehā to consider the question of water ownership

I acknowledge that the phrase nobody owns water in itself seemed to be quite consciousness raising for a lot of Pākehā and it was wonderful for them to think that through... ok, I always thought the government owned the water but actually I can see that Māori have their claims to it too.-C

\subsection{One claimant among many}

Participants were also concerned that the statement negated the special place that Māori have in Aotearoa/New Zealand as tangata whenua, placing Māori as one group amongst other groups that might have the same rights and interests to water. This way of marginalising Māori was considered to be widespread. 
...[the view that] Māori are just one interest group alongside farmers, alongside recreational user and others... none of those people own water and they're all equal, they all have equal interests...-A

...but there remains I suspect an ongoing view among Pākehā that Māori are not special and that having put right, in inverted commas, their situation then we go back to the Crown being the ruler with no particular reference to, or no particular special place for Māori.-E

An example of the situation identified by the participants is seen in the reports of the Land and Water Forum which strongly acknowledges the importance of Māori to the resolution of water issues but considers Māori as one of a number of stakeholders with competing interests (Land and Water Forum, 2012b).

Participants were clear that te Tiriti gave Māori as tangata whenua, specific rights in relation to water, rights that sometimes were inconsistent with predominant thinking or even with statutes.

...so I don't think that they're just another recreation user, I think that they have rights by virtue of being a Treaty partner, that usurp recreational rights...-A

...Māori are a recreational user but... they also have a right by virtue of their status as tangata whenua ... they have a long held relationship with the place and this is unique... and unique to Aotearoa and at times this unique position gets into conflict with statutory legislation...-A

\subsection{Water ownership}

Inherent in the statement is the question of water ownership and what ownership means in this context. The statement seems to privilege a western Pākehā view of ownership, favouring the concept of property rights and alienating other forms of authority over water. Framing of the statement in a Pākehā context, forces Māori to discuss water in ownership terms reflecting comments by Sonny Tau (Bennett, 2012) that talk of water ownership is confusing because ownership in a western sense is not what Māori seek. But cultural dominance has framed the debate with ownership only considered in a western sense.

I have learned from.... Kaumatua...that ownership is a slightly obscene way of describing the relationship between humans and the rest of the environment......it's almost like another way [in] which you can confiscate.-B 
...it's a tricky statement because in a sense I think that a lot of Māori would agree, nobody owns the water ... that word is a concept that is very Pākehā...., but it's a concept that has needed to be .... responded to... by the Mäori Council because of the way that the government has used it.... to take control and to exert power over water $\ldots-D$

...that's not a concept that Māori would use necessarily, but because they [Māori] are in this debate... then [their] response needs to be well actually... if you are gonna use that word of ownership then we do have proprietary rights, we do have ownership in a sense ...-D

\subsection{Property rights}

So who then does have a property right over water in Aotearoa/New Zealand? If ownership is to be considered in a Pākehā framework and access to water is to be effectively sold, then access becomes equivalent to a property right as described by Bruns and Meinzen-Dick (2005), Meinzen-Dick and Mendoza (1996) and Hawke (2006).

....any attempt to create a property right needs to be measured against the Treaty...-E ...if you are going to create a property right of water then you need to have a conversation about whose property right, who holds that property right and my understanding of the history of the Treaty and of the legal view of the Treaty is that it... is presumed to belong to Mãori unless it can be demonstrated that it was transferred by Māori with their knowledge and consent.-E

...unless the Crown can demonstrate that it had those rights transferred to it ... they can simply act as stewards of things like air and water on behalf of everyone.... and while they... continue to treat it as a common good... then I don't think there's a great problem, but the minute they say there is now a property right here, then they're in trouble.-E

\subsection{A general Pākehā view?}

In spite of their own views, participants recognised that the statement that nobody owns water probably represented a view held by many Pākehā.

...superficially yes, that would resonate with a lot of people, it's like no one owns the beach, no one owns water...-B 
Yes I think it is and I suspect it's held by many Māori as well, that nobody owns water, which means nobody is able to buy it and sell it... it's for the benefit of all.-E

It was significant though, that most participants considered that nobody having ownership of water was not an essential Pākehā view. They felt that many Pākehā would acknowledge that Māori have some authority over water, and critically identified this as a change in Pākehā views.

...there are many Pākehā views, so I would say that the majority of Pākehā would agree.... but there would be a portion of Pākehā that would disagree.-A

...change over the last 30 years has meant more Pākehā are more conscious.... about our relationship with Māori and our place here in Aotearoa and so I would ... think that there's.... a degree of Pākehā probably who might be questioning that statement-A

This comment reflects the view of Huygens (2007) who challenges the assumption that dominant groups have homogenous ideologies. The significance of the Prime Ministers statement about water is that it is a touch-stone for a range of Pākehā views. Whatever the motivations for the statement, it allows us to consider the range of Pākehā positions in relation to Māori interests or authority over water. It provides a kind of metric for assessing how far Pākehā views have changed and where they might go.

Most participants felt that the Prime Ministers statement curtailed an opportunity for dialogue on the subject of water rights and te Tiriti, an opportunity to advance Pākehā understanding of both common and diverse Māori positions in relation to water, an opportunity for education of Pākehā about another view of a resource of considerable value to us all.

...much as I do believe in my heart that water is important and all people need access to water... to meet their needs for life, I think that alongside that in Aotearoa we have to put the Treaty as the foundation for law making and for understanding our relationships with resources, so I don't think it's enough to just say no one owns water and leave it at that. $-B$

...it also means that non-Māori... Pākehā miss out on an important learning opportunity about... the way that Māori make sense of their relationship and [it] gets in the way of any type of dialogue or exchange of ideas, because... again it eliminates the possibility that there are different approaches...-A 


\subsection{Rights and interests in water}

Clearly there have been changes in Pākehā attitudes to Māori from the early twentieth century when legal frameworks institutionalised and systematically controlled natural resources, particularly fresh water resources (Kahn, 1999). The participant responses reflect the views of Orange (2004) that change has occurred amongst Pākehā such that they have a greater understanding that Māori have specific interests in water, interests that differ from Pākehā and which Māori have a right to express.

What then might Pākehā see as Māori rights and interests in water? Because the participants are people who have been involved in protest, critique or education in support of increasing Pākehā awareness of te Tiriti and had demonstrated their established views on the topic, it could be expected that they would be able to provide direction for what Māori rights and interests in water might be. But rather than specify those rights and interests, all of the participants expressed a view that it was not for Pākehā to decide what Māori rights and interests were. Rather, they thought that Māori had the right to do this for themselves under te Tiriti. This response was important because it represents a relinquishment of Pākehā power and control and acceptance that Māori have the right to determine their own interests in a natural resource. It provides a sign post to a position that perhaps Pākehā generally may be able to achieve in the future.

...when people are explaining rights and interests in a way that also has a determining aspect about what those rights and interests might be and [if] those people are Pākehā, then that to me is problematic.-D

The role of the state and Pākehā under the Treaty [is] not to second guess or define what Māori customary rights or interests are...-B

It was clearly expressed that whatever Māori indicated their rights and interests to be, the authority on which those rights were based, was te Tiriti o Waitangi. Te Tiriti was perceived as the document which enshrined for Māori a right of tino rangatiratanga over resources.

...Màori have a right that is again unique to them by virtue of the Treaty...-A

I'm of the belief that the Mãori text [of te Tiriti] is of precedence as opposed to the English text, in international law that's what it says... and within that, Māori retain their rangatiratanga, the mana of those resources, of the.... natural environment that they are engaging with. $-A$ 
It is now well established that it is the Māori version of te Tiriti that should be observed. The above comment is confirmed by the Waitangi Tribunal (2014).

Two participants were asked what they thought of te Tiriti settlement process, particularly whether the process was suitable for resolving Māori rights and interests in water. Their views reflected those of Vertongen (2012), Joseph (2012) and Cowie (2012).

...it's a start, but I think it needs to be refined and needs to change because... this idea of mandating particular iwi.... that brings up a whole lot of conflict within the collective about who has the mandate, who speaks for who, who has the power in this situation...$A$

...it's been kind of captured by a legal framework which doesn't necessarily engage with non-Māori...-A

I don't think the Treaty settlement process is actually suitable for the Treaty settlement process, let alone resolving water.... the Crown decided about larger natural groupings.... the Crown dictates and the Crown keeps control.-B

\subsection{Building understanding and relationships}

The key for Pākehā to develop an understanding of Māori rights under te Tiriti, an understanding of how tino rangatiratanga might be expressed, was seen as the development of a trusting relationship between Pākehā and Māori. A relationship that could lead to a conversation about not just the rights and interests in water, but also the responsibilities.

It's about a relationship so it's all about having an ability to have the conversation and if you haven't got trust, a relationship of trust you can't have the conversation in any of these relationships...-B

...without a good relationship we can't talk about how we might look at those interests and recognise those interests because... it's really about the ability of Pākehā and the Crown to build sufficient trust to be able to work with tangata whenua...-B

...there's a lot of, not only rights and interests but responsibilities in relation to water...-D

However it was expressed that any Pākehā/Māori relationship would only be successful if Pākehā came to the relationship with a respect for Māori connections to the natural world. Even the use of words like rights and interests, risked imposing Pākehā constructs onto discussions and outcomes. 
...ko au te awa ko te awa ko au - I am the river the river is me... for me that whakatauki... conveys some of the depth of the relationship... that language of rights and interests, again it's about defining and confining the relationship ...-D

...the process of colonisation and the defining by Pākehā of Māori rights has constrained their ability in certain circumstances to live the relationship with water in the way they might want to, but it doesn't mean that the relationship is not there, so those relationships hold, it makes it a more painful relationship in a way because they can't.... exercise what their responsibility is to water...-D

...things like co-management relationships coming out of Treaty settlements are still... structured under Pākehā models and determined by Pākehā models ...-D

\subsection{Barriers to Pākehā change}

When asked to identify contributors to Pākehā maintenance of the status quo, participants expressed frustration with mainstream media organisations which were identified as failing to provide a sufficiently wide range of information to assist Pākehā with a deepening understanding of a Māori world view.

...main stream media just cannot get their head around the idea that Pākehā take responsibility for the Treaty...-B

...we don't have good mechanisms for proper information around this, the way that the media operates doesn't allow for the depth of understanding or the views really to be shared or understandings shared...-D

The approach of the media was seen as important because participants perceived that if Pākehā were fully informed, it would promote change in their views.

...one of the things that really stood out for me [was that] the Tribunal had said .... in terms of that change .... most New Zealanders if properly informed as to the nature of Māori rights would not disagree that the owners of property rights should be paid for the commercial use of their property otherwise there would be no landlords and not tenants, no joint ventures, no leases, no commercial property arrangements of any kind, that seems to us to be absolutely basic to the way in which New Zealand society operates, and they go on further but the thing that seemed critical to me .... is ...about New Zealanders being properly informed as to the nature of Māori rights and for me the thing that [is] really critical to the type of change that we might have, is the 
information that people receive and that's something that's still hugely problematic...$D$

\subsection{Changing Pākehā}

Where then, in terms of understanding Māori rights and interests, particularly in regard to water, are Pākehā going? And in spite of the barriers, how will they get there? We know that considerable change has already occurred. Participants considered that there were no essential Pākehā views, but were positive that further change in Pākehā thinking would occur over the next five, ten or twenty year period.

...yes I do think things will change... I think we will make some... positive change and when I talk about positive change... I mean that Māori rights.... and Māori understandings, in their diversity will be given more weight over time...-A

...what I think is interesting is that there's a potential as change happens for some people who are threatened and fearful to become more entrenched in what I regard as negative racist positioning so in a sense there could be some backward steps, but I also do think there is the potential for positive change.-D

Interestingly, participants identified Pākehā as the ones who prevent change in themselves. The first issue identified was a deep seated and pervasive racism.

What we still have to grapple with is.... we Pākehà continue to carry a deep seated belief in white supremacy... just a fundamental belief by almost everyone that basically the western, Christian culture and civilisation was a superior one to other civilisations and cultures and I think that still exists today. $-E$

...it brings out that fundamentally quite racist view.... that Māori have no unique rights, so what we are really talking about is [a] dominant culture way of viewing the world...$B$

...this is often what happens when Pākehā are in control... we come to things with one view and we just assume that that's the way to do things. $-A$

Participants also noted that cultural dominance prevents the dominant group from finding out about the oppressed group, perpetuating the dominant position through control of ideas and information, an example of social dominance theory in action.

...cultural oppression completely blinds the dominant group for decades of an individual's life to the fact that there's anything else to learn. Because you get very 
complacent when you're in a culturally dominant group. You think ah we're the kings of creation ...-C

[The] culturally dominant group starts to control the.... conceptual resources that people think with and keeps them quite limited and quite self-serving ...-C

Another critical factor preventing Pākehā change was identified as the clash between working as a collective and working as an individual.

...Pākehā... individualism is.... our big... common experience... it's so difficult for us to actually recognise that what these people [Māori] are talking about is collaborative, collective, it's in their DNA to think about whānau whānaunatanga, o whānau whānaunatanga, rather than think about me and... my nuclear family...-B

Particularly, participants noted that a lot of Pākehā attitudes to Māori come from how Pākehā see themselves and their perceptions of how Pākehā historically have behaved, echoing research by Liu et al. (1999) which showed significant differences in how Māori and Pākehā students believed historical events in Aotearoa/New Zealand should be described. Participants also identified a Pākehā failure to see themselves as racist.

I think that a lot of the Pākehā positioning comes from our own understanding of what we have done as colonisers...-D

... a lot of Pākehā come to the conversation from a Pākehā understanding which is, it's all about taking stuff and using it...-D

...I mean nobody sees themselves as a racist oppressor, no-one defines themselves that way. Everybody thinks.... I'm not racist but... [it] is one of our favourite expressions...$B$

One specific idea that participants identified as a major hurdle for Pākehā is an understanding of tino rangatiratanga. It was expressed that an understanding of injustice and a greater need for equity was something that most Pākehā would accept, but a situation where Māori could be given authority or control was perceived as a considerable challenge for many Pākehā.

...I think there is Pākehā self-interest ... which for me means that the change over the next period is probably more change towards... hopefully more equitable relationships, but I think that in those equitable relationships Pākehā will still be challenged by a concept of tino rangatiratanga $\ldots-D$ 
...there'd be greater comfort with a more equitable relationship and co-management but the concept of tino rangatiratanga and that... Māori have proprietary rights and that Māori can exert those.... will be a greater challenge to ... Pākehā...-D

What seemed to be clearly expressed was that if there is to be change, it needs to come from Pākehā themselves. Participants discussed the things that they believed would motivate Pākehā to change their views about Māori and te Tiriti, providing a wide range of responses. However some clear themes emerged, the first demonstrating a simple understanding of the human condition.

...that's human nature, for people to change they have to see there's something in it for them[selves]. I don't think people.... change out of some sort of vague altruistic or politically induced ideals-B

...if [Pākehā] people have... some idea of how they're going to benefit from it [change] .... then it makes it.... easier for them- $A$

But it was stressed that Pākehā would need to understand that benefits would accrue wider than to the individual.

...people would have to recognise that it's good for all New Zealanders-B

...for people to actually see that Māori having greater engagement in control of something like water... actually, makes it better for everybody, is the stuff that will change things- $D$

...in terms of the process of change... finding ways to articulate to Pākehā that really, it'll be ok, that it might even be better-D

These views reflect the position of Gould (2012) that we all have an interest in the success or otherwise of Māori, as Māori success benefits Pākehā. Participants went further though indicating that water was an area where Pākehā needed to see how the benefits of Māori knowledge could improve circumstances for Pākehā.

I think Pākehā have to see the benefits for themselves in engaging [with Māori] and I think those benefits can be drawn out by.... saying...we're facing real challenges in how we manage things in our environment... how we engage with water resources and the oceans and biodiversity- $A$ 
...it's trying to show the benefits of Pākehā working across cultures.... moving beyond their own cultural frame and understanding Māori knowledge and practices and how [they] can support.... [the] sustainable use and enhancement of water resources. $A$

In a sense I think that.... there's a degree of self-interest.... if they can see that this is making... the local river or the local harbour... a healthier place to swim or a nicer place to have a picnic.... people might come to understand that .... actually Māori want that and we want that.... it's not just about them [Māori] doing it for themselves.-D

These views echo those of Gould (2012) that many Pākehā see the Treaty as an exclusively Māori domain and of Borrows (2006) and (Margaret, 2010) who suggest that treaties like te Tiriti don't only benefit indigenous people.

It was expressed however that there would be challenges for Pākehā in coming to see benefits for themselves.

...dissemination amongst non-Māori around the benefits of Māori knowledge and the challenges, I'm not blind to the challenges and the difficulties around... creating that common space. $-A$

...it's a slow process... there's no kind of magic bullet for Pākehā to let go their dominance.... dominant groups don't tend to want to. $-B$

\subsection{Pākehā working with Pākehā}

The question that arises then is one of how can change occur. Can action be taken by Pākehā to assist in changing the views of other Pākehā? It was very clear from the participants that they felt Pākehā could instigate and facilitate change to the attitudes and views of other Pākehā. It was even seen as a responsibility that Pākehā have, to work amongst their own to create change

...Pākehā do need more knowledge... they need to keep.... learning as students about what .... the Māori world say[s] about this.-C

...it's really important for us to be speaking to our own people... to be addressing some of the Pākehā fear of this unknown.... talking up the positives of what can come from Màori having.... greater power to determine what happens with water or with whatever it might be.-D

...there is the formal education......formal Treaty education which shifts people and that's very powerful.-B 
...if you've got the consciousness every opportunity's a Treaty opportunity.-B

These views reflect those of O'Connor (2006) who laments a Pākehā lack of understanding of te Tiriti and advocates participation in Treaty workshops to change this. When asked how changes in Pākehā attitudes could be facilitated, participants initially offered some general suggestions

...practical examples help, because they're grounded and they're applied.-A

...we do need to become more sophisticated to understand the processes that work inside our own culture... once we become a bit more critical of our own culture we tend to then open up and appreciate the things within an indigenous culture.-C

...there needs to be some strong Päkehā voices.... at a political level.... pushing the boundaries.... saying the stuff that might be quite unpopular... -D

\subsection{The value of contact}

Some participants were more specific, suggesting that contact around issues was a good way to promote Pākehā understanding of Māori positions. Reinstatement and protection of waterways was seen as an area where there were positive outcomes from groups engaging in practical activities.

...the involvement of local farmers alongside iwi representatives, say for instance.... doing work around Te Waihora Lake Ellesmere and then farming groups and local farmers working on creeks and waterways... the interaction that happens there, is the sort of thing that does shift people.-D

...working towards some shared objectives about having healthier waterways and I suppose if there hadn't been.... [a] Treaty settlement processes there wouldn't necessarily be the understanding that you can't have a lake trust without that being an iwi... mandated or represented, sort of process ...-D

...there's something about the desire for seeing better environmental practices and seeing healthier waterways and that sort of thing and then the engagement that... Pākehā might have along side Māori, to create that change, so that's one context where I can see... more change happening...-D

...through those processes there's learning... that happens along the way as Pākehā hear from Māori their stories of that water or their relationships to that water or [Pākehā] just see how they [Māori] relate to the water. $-D$ 
However it was expressed that this process doesn't work for everyone, as many Pākehā don't have access to this kind of contact.

...for the broader public.... so many people living urban lifestyles.... they are not going to have that kind of engagement... -D

... stream care and those sorts of initiatives.... aren't always alongside iwi but often are and so that's.... one area but it's a smaller sector ...-D

\subsection{Working together}

Working together was seen as being important because working collaboratively is a way to overcome fear and promote understanding.

...the more people get involved in issues where they work collaboratively alongside tangata whenua, the more the fear... dissipates...-B

...the interaction around things... in people's local communities, around water, caring for water, is one way into that and into the learning if that's happening alongside. $-D$

...it's not just about having a marae visit... I like the idea of integrated catchment management where all parties get together and talk about their interest...-B

...properly facilitated processes that are really inspiring.... get farmers... Māori and government agencies all on board with a common goal, and then sometimes... you do get that recognition by Pākehā [that] there's a depth and knowledge that we [need to understand $] \ldots-B$

\subsection{A process of Pākehā change}

The importance of Pākehā gaining greater knowledge of the Māori world was outlined by one of the participants as they set out a clear process by which Pākehā change their views. Knowledge of historic Māori/Pākehā relations and events and from this an acknowledgement of past injustice, was seen as necessary to provoke an emotional response. From the base of an emotional response, cultural work could proceed, leading to a new understanding and relationship with Māori. A process of Pākehā change.

We do need to have an emotional response and that's often to the sense of injustice, that's actually where our emotional response comes from.... we [get] to feel really uncomfortable feelings.... shame, shock, anger. Then [we can] ... do some cultural work among ourselves to open up our own views... -C 
...step one, knowledge. Step two, emotion. Step three, collective cultural work. Then step four we're ready for that conversation and that relationship. I see that playing out all over the place.-C

\subsection{Developing respect}

A key foundation of 'that conversation and that relationship' was identified as respect. Respect for the indigenous culture of Aotearoa/New Zealand and respect for the authority that Māori may have under te Tiriti.

Yeah it's basically giving due respect to... Māori history, knowledge of place and [the] existing relationship to the particular resource. $-A$

...basic Treaty education, that's needed to get people.... to be able to engage.... but we also need the conversations [about] what's needed for the change.... one of the cores to that change is respect, how we build in Pākehā, a respect for Māori authority.-D

One participant then gave examples of how such respect might be demonstrated

...if we take a spring or puna for example, it would be around looking at the history, the significance of that stream, of that puna to Māori historically and .... the significance of that to the settler Pākehā population....... but I think... the history of Māori and their particular relationship [to the puna] ...-A

... if there has been a long standing relationship then there is... a responsibility and an obligation for... the mana whenua... of that area.... to have their history valued and understood and to then enter into a negotiation about [the] use of that puna.... what the tangata whenua think should happen in relation to that water resource, so that there's a space for more negotiation and a sharing of power around how decisions get made...-A

...because Māori hold particular approaches to how.... our natural world can be looked after and... sustain us.... it's part of broadening... our understanding of our place, our location and our relationship to place by understanding the history and the.... relationship of tangata whenua to a particular place...-A

The conflict between indigenous views and the scientific world was seen to be significant, particularly by one participant.

...broadening our ideas around science and mataurangi Māori and putaio and becoming familiar with Māori notions, knowledge and practice and looking at the 
similarities and differences.... and becoming more sophisticated and nuanced about what counts as evidence, taking into account the multiple knowledges and value of the knowledge...-A

...there's some changes needed to happen at that kind of scientific end to show that.... the knowledge bases that we... draw from, they're both.... valid and they can complement each other... -A

\subsection{Sharing power}

But facilitating expression of a Māori world view was not seen as an easy process. A key however, was seen as resourcing Māori participation and for Pākehā to develop an understanding of power relationships and power sharing.

I do think it's complicated....Māori should be involved but then which Māori should be involved and .... how well resourced is that involvement...-A

If there's no sharing of resource or power to support that involvement then I don't think.... any real progress can be made. $-A$

...whenever we talk about resources, it throws up issues of power and how to share power in a more just way and I think that those issues are complex... and they change depending on area and.... on who's got the capacity and the ability to engage...-D

Suggestions were provided of how power sharing could be promoted when Pākehā organisations engage with Māori.

...but there are things that non-Mãori or statutory organisations can do to make that process easier.... thinking about... how they're resourcing tangata whenua to engage with them or how they're resourcing themselves to engage adequately with tangata whenua, are their staff trained, is there a training process that the Council might be using to understand Māori environmental values...-A

...when engaging with Māori.... thinking about how that relationship comes to be through the sharing of resource and power. $-C$

These views reflect the assertion of Mikaere (2011), who when discussing the relationship between Pākehā and Māori stated simply that Pākehā will need to relinquish some of their power and control and entrust it to Māori. Participants suggested that this would require that Pākehā and Māori work together. One participant expressed the following. 
...when Pākehà can understand where Māori are coming from through their history and through contact and through discussion, their thinking can change and their appreciation and willingness to engage increases once... that contact zone.... that inbetween space is created.-A

The common ground also means.... both groups giving up.... some of their hang ups and... a willingness that both groups can see the benefit and both groups learn from each other and... maintain their own sense of self in that process...-A

...by having people that are articulate and that can walk in either world and in both worlds.... can develop and be part of a change process for both groups...-A

\subsection{Understanding and Pākehā adoption of Māori practices}

Understanding and acceptance allows a relationship to be developed. Participants felt that developing a stronger relationship through understanding, between Māori and Pākehā was essential.

Māori have often said.... we must have a longer conversation about this... we need to have a conversation that goes on long enough [so that] we can start to understand each other's point of view... build a relationship.... understand each other, learn about the cultural values and then develop some specific... guidelines for the relationship we are going to have.-C

...it's important that as Pākehā we're clear.... about where we as Pākehā can stand to support the Māori position because... it's not our role to be determining or defining Màori positioning but... to do the work to understand that positioning and to learn about it...-D

One participant pointed out that despite the differences between Māori and Pākehā, there are many things that the two groups have in common. Many values that are common and many reasons for Pākehā not to see Māori as other.

Well part of it... is to take away the foreignness of it and part of that is because it is our relations, our work mates our neighbours, our team members that we're talking about rather than faceless strangers...-E

...but also it's by tapping.... into stuff within the Pākehā culture which says exactly the same thing, so the whole debate about the environment and climate change and so on has got a whole potential to tap into European understandings of the integrity of the 
natural world and the interconnectedness of the natural world, of our place in it... which is not inconsistent in any way with a Māori world view ...-E

...Pākehā notions of justice and fairness and integrity which are a strong part of our cultural tradition.... we're not talking about some weird, weird alien way of thinking about stuff...-E

...our culture can draw on traditions about a holistic view of life and.... it seems to me [to] become.... much more easy to reconcile with a Māori perspective on the nature of the universe and so on, so that's another way of doing it... to say actually this is not foreign to us to talk about this stuff.-E

Participants reflected that considerable change in Pākehā views and attitudes had already occurred.

There's an accompanying change in attitude in terms of acknowledgement [that] Māori .... have their place as tangata whenua, making New Zealand a unique nation, that's all changed. There is a greater acceptance of the fact that Māori tikanga and Mãori cultural values are not the same as Pākehā values, that's changing.-E

...I think we need to become more aware of what it is to be Pākehā, in relation to Mãori because I think we've changed quite a lot, particularly in the past 30 years but always actually since we've lived here around things like customs around death, customs around hospitality, customs around just that kind of stuff from working with Māori and from being influenced by Mãori...-B

Perhaps the part of the discussions with participants that was most revealing about the depth of Pākehā change that had already occurred, was about how and where Pākehā had already adopted Māori language, motifs or practices. It indicated a Pākehā acceptance of Māori ways of doing things. Everyone recognises the haka, and Pākehā see it as a symbol of nationhood (Sibley et al., 2008). Increasingly te reo is spoken on radio and television and more Māori words are commonly used by Pākehā. Participants identified areas where Pākehā are adopting Māori cultural practices or ways of doing things as a site of changing Pākehā behaviour. One participant gave the following examples.

...an American woman who was working with [us] was saying, oh my God you people, when you start a meeting you all talk about who you are and where you're from ... that's a completely Māori thing that we've adopted in our culture in some degree, whereas, the question..., I was brought up with [was] what do you do for a job, or what does 
your father do for a job, but the question for Māori is no hea koe.... where are you from .... I think that's had quite an influence on us in a really good way...-B

...I think tangihanga has a huge influence on Pākehā culture in a good way... people have started bringing their tupapaku home.... when family members die, we do that, and that would never ever have happened without having had all those experiences of tangihanga and, so we are.... hugely influenced ... -B

The contribution that institutions have made to normalising Māori tikanga was highlighted by one participant.

...I first got involved in all of this stuff in the 1970s, so that's 40 odd years ago and there's been a massive change in that time in the way that people are absolutely accepting of the status of Māori as tangata whenua and.... it's unthinkable for us now to do anything of an official nature without an acknowledgement of Māori tikanga for example... it's endured by some people, but by most people it's actually part of who we are as New Zealanders. $-E$

...part of who we are as a nation now does include...... that honouring of Māori, I've just come back from visiting.... in Canberra and we went to the national war memorial... every night at 5 o'clock they have a .... very moving simple little ceremony to honour people who have died in war and as I took part in that.... I thought in New Zealand that would have had a strong Mäori component, so that's who we are as a people now...-E

\subsection{Accepting differences}

In contrast, but not inconsistent to the identification of things that Pākehā and Māori have in common, one of the ideas that all participants expressed strongly was that Māori have views that are different to Pākehā, especially regarding the environment. Consequently they felt that Māori hold a special place in Aotearoa/New Zealand, a place determined by te Tiriti and a place unique as tangata whenua. Understanding and accepting this was seen as a key step in advancing change in Pākehā views of Māori and te Tiriti.

...because of the Māori history of a thousand years here and... a world view... of themselves as part of nature which is quite in contrast with the western world view...... it makes sense they [Māori] have a unique view.-C 
...we're not the same people, actually culturally we think really differently that's all right, there's lots of good things about the do it yourself Pākehā individual, but this culture over here.... whose country we settled and colonised, actually doesn't see it that way and....there is a lot of listening to do to understand that because it's not natural for $u s \ldots-B$

\subsection{Understanding injustice}

From the interviews, a pattern of Pākehā change in three stages seemed to emerge. The first stage of the pattern, evidenced by te Tiriti settlement process was a change in Pākehā views to an acceptance of historic injustice. This recognition of historical injustice and acceptance of a responsibility to compensate for it, was identified by King (1999) as a source of pride in being Pākehā. It seems evident that the action of Māori in asserting Treaty rights, as described by Walker (2005) has had the effect of raising Pākehā awareness and understanding and has been a driver for change. The participants expressed this view clearly

Most people really do believe that Māori have a legitimate claim about injustice in the past and therefore we should be listening to them more now.-C

I think there has been a massive change in terms of acceptance of wrong doing, of the importance... to put right that wrong doing and try and put something new in place...E

...Māori signed something... which said [they] will continue to have control over everything that's precious to [them] and so people slowly get that ...-C

However Māori have been raising claims of injustice since te Tiriti was signed. From that time until the 1950s, it seems there was little change in Pākehā views. The participants were asked why a Pākehā acceptance of injustice had only occurred since probably the 1970s.

...we've made massive steps in terms of just some basic historical knowledge... just straight factual information is different.-E

...it's occurred because Māori have made it irresistible. ... they have to [take] credit for their sustained and passionate and multi-faceted fight back for their rights.-B

...the work of the Waitangi Tribunal, the work that's gone on legally to say Māori do have claims against colonisation.... claims [about] their land.... claims about injustice.... it has percolated through to most people.-C 
Participants also identified the educational work that some Pākehā have carried out with organisations and individuals

...Treaty workshops generally... get... people to understand the Māori text of the Treaty and then ... into understanding the injustice of colonisation ... that Māori... never gave away their sovereignty of this country.-C

But participants felt that much more could be done, building on the opportunities provided by the Waitangi Tribunal.

...it's a lost opportunity that the Crown did not budget for an education process for communities alongside iwi when they did the [Treaty settlement] process, I think there needed to be a massive amount [of] regionally specific [education] ...-B

\subsection{Understanding tino rangatiratanga}

The second stage of change for Pākehā that seemed to emerge from the interviews was an understanding of tino rangatiratanga. Participants identified that the first steps toward this stage were being taken and were being expressed in the co-management arrangements in some Treaty settlements.

...for me positive change is change that is supportive of the exercise of tino rangatiratanga for Māori...-D

...so if there's Pākehā going 'well actually, very nice these co-management arrangements but it's not.... really about tino rangatiratanga, and that's really what Māori should be having in regards to water, so when's that going to happen?... people [are] starting to say that now ...-D

...they've set in place processes to try and give an expression to a permanent new relationship and a permanent new way of working between the Crown and Māori which honours their status as tangata whenua and which honours the fact that the Crown breached their duties and their obligations under the Treaty and so you get post settlement entities being created and post settlement processes... in Waikato they've got now a partnership process in relation to the river, which will be a permanent process... This is not going [to] just deal with something and then it will all disband and the Pākehā will take over, it will become always a co-management, co-governance arrangement...-E 
We have to normalise these ideas, and I mean, co-governance ... conceptually it's probably quite useful because... it recognises two bodies and... you do see these changes, you do see in local government... a few councils actually setting up genuine co-governance across the board relationship $[s] \ldots-B$

But there was some questioning from the participants about whether co-management or cogovernance were really expressions of tino rangatiratanga. Many argued that the power imbalance between Māori and Pākehā, particularly due to a lack of Māori resources, meant that the arrangements remained Pākehā dominated. These views reflect those of Ruru (2013) and Te Aho (2012) who consider co-management to be an inadequate expression of tino rangatiratanga.

...one of the things about co-governance is... it's not my understanding of rangatiratanga, it's already a compromise, and it's a compromise that involves one party, usually the regional authority with a lot of resources and a very strong world view and then the other party, the hapu of... a particular rohe, who are not at the table with the same amount of resource, trying to negotiate.-B

...what I see is that things like co-management relationships coming out of Treaty settlements are still... structured under Pākehā models and determined by Pākehā models and it's creating movement and change that might move more to Māori models but there's still constraints ...-D

...I would be sceptical that those types of arrangements while on the face looking like a partnership.... I'm yet to see how much control Māori will have in terms of influencing how decisions get made around water resources...-A

Central to the idea of tino rangatiratanga is the role of kaitiaki. Participants felt that recognising kaitiaki was an essential step toward accepting tino rangatiratanga

...it was interesting talking with different kaumatua about their customary fishing practices and the tension that can arise between what they believe is their role as kaitiaki, as people who are stewards of a place...-A

...I saw some conflict around the role of kaitiaki asserting their right to look after the resource... to ... provide for their people and to maintain their knowledge, to maintain their fishing practices and what the Crown.... through its structure of regional district and central government, how they try to control it...-A 
...these kaitiaki, we have to engage and support them and they have... prior rights, so for me that's what the Treaty means. Not everybody would agree, so... those are quite big things. $-B$

One participant questioned the practicality of implementing tino rangatiratanga today in the way the term was understood by Māori in 1840 when te Tiriti was signed. They felt that it would not be possible to implement tino rangatiratanga today, as it was understood in 1840 .

When the Treaty was being signed, the term tino rangatiratanga it seems to me was really really clear ... it was.... full sovereignty, absolute independence all of that notion. So in 1840 people who were signing the Treaty I believe understood what they were.... giving to the Crown.... kawanatanga as opposed to tino rangatiratanga which they held. In 2014 how you could give expression to that I have a huge problem, I simply don't think it's possible to say we will.... create....one or fifteen or twenty sovereign states ruled by the relevant hapu or iwi who will run everything it just doesn't seem to me to be realistic and therefore we are in the position where we need to draw on that history of.... co-habitation .... in this country to say let's find ways where we can run the country in a way that is for the common good and which does acknowledge the indigenous rights of... Māori people, but to talk about tino rangatiratanga in its literal sense I think is impossible and it would be futile for people who want to try and go down that path because I just don't think it's possible.-E

Given the concerns about co-management as an expression of tino rangatiratanga and the practicality of expressing tino rangatiratanga today, participants were asked where it was that Pākehā need to get to in their understanding of Māori particularly in relation to water. It was clear from the interviews that an understanding of injustice was not enough and acceptance of tino rangatiratanga through co-management arrangements would be insufficient to enable Pākehā to belong as tangata tiriti in Aotearoa/New Zealand.

The importance of Pākehā understanding tino rangatiratanga cannot be underestimated as has been made clear by the Report on Stage 1 of the Te Paparahi o Te Raki Inquiry (Waitangi Tribunal, 2014) and is highlighted by Professor Patu Hohepa who affiliates to Te Mahurehure, Ngāpuhi and Te Atiawa and is a former Professor of Māori Language at The University of Auckland. He says in relation to the Ngāpuhi Treaty settlement process, "There is no such thing as full and complete settlement until Tino Rangatiratanga is achieved", (Ihaka, 2014) 


\subsection{Accepting a Māori world view}

The third stage of Pākehā change identified by the participants, would require a Pākehā/Māori relationship in which Pākehā acknowledged indigenous norms and accepted a Māori world view, even if it would affect Pākehā lives in ways that they were not entirely comfortable with.

...when people understand and have a sense of injustice about something they can still remain completely within a mono-cultural view about that and they think, right we're going to fight for justice for Māori people, and yet they're not at all thinking that that means they might have to come under a different tikanga, a different law or set of practices, you know a different cultural set of how to treat their world...-C

...it's two different things going on, one is to have a sense of the injustice.... who should have retained their power, but the issue of.... which culture's practices should we follow.... then that's quite complex and yes.... it's a different story. $C$

...when you're dealing with.... resources, like.... water or oceans or mountains or whatever... the big conceptual step is that the other culture is not individually defined and I think that's quite difficult for us... -B

...you have a different relationship with water to us or to me and that's ok I respect that there's that difference so you might do different things in relation to... that but you do have a sovereign right to do that, that's your right,.... that's quite a challenge for Pākehà to get to that space...-D

...how can we take seriously the two world views .... te ao Māori and te ao Pākehāa, and acknowledge both have a hugely valuable contribution to make-E

...the settlement process is really about addressing the injustices of colonisation.... it's about dealing with equity.... it's not about exploring what the actual Treaty relationship's about.... when we get into the post settlement.... environment that's increasingly being talked about... and.... to move towards the power relationship of kawanatanga tino rangatiratanga that's.... inter-generational stuff and who knows in that process.... what calls Mãori will make about that ...-D

The participants were not asked specifically about how Māori might respond to changing Pākehā views of te Tiriti. All of the participants had considerable experience working with Māori, in te Tiriti justice movement, local bodies and other less formal groups. Most of the participants identified a willingness and generosity amongst Māori generally to work with 
Pākehā to assist a wider Pākehā understanding of taha Māori. A generosity that dates back to Pākehā arrival in Aotearoa/New Zealand.

...the stories of the early interaction between Māori and settlers and the relationships at those times when the power balance was very different... are really instructive to Pākehā around the generosity and the understanding that Māori had as hosts ...-D

...people don't see the generosity that ['s] been extended to them again and again as manuhiri, as tangata Treaty... the endless patience and generosity and willingness to share...-B

...there is so much good will, tangata whenua continually saying we need to do this for .... everyone's mokopuna... I hear that over and over again, everyone's mokopuna... $-B$

It is instructive that inter-generational change was seen in the mokopuna, considering the Human Rights Commission 2006 survey which found a greater level of Treaty knowledge in younger people and a higher declared knowledge of the Treaty in those aged less than 30 (HRC, 2006).

...I think there is an openness in younger people that wasn't in my generation. There's not quite the same overt racism...-B

\subsection{Why would Pākehā views change?}

As each of the interviews came to a close, I asked the participants why they thought Pākehā should change their views of Māori and te Tiriti. Given the complexity of the ideas expressed in the interviews up to that point, their responses were disarmingly simple.

...the mono-lingual, mono-cultural view is very damaging, not only to diversity but also to the Treaty...-B

...just the straight justice of the fact that Pākehā people came here knowing this was a land occupied by and run by Mäori people and a series of events happened where they [Pākehā] became the dominant culture... the courts and the tribunals and the governments are all acknowledging that in fact we have to do this in a way that's just and fair, so.... you've just got some fundamental justice and fairness at play there.-E ...the most obvious one is that humans do have a sense of morality and justice and.... actually some of this isn't fair... People's own, inborn sense of morality which ... comes 
from us being [a] social.... species... ultimately we do want to feel that we live in a world of harmony, in our family, in our relationships and in our society.-C

One participant noted that Pākehā can be confined by their dominant position and that sharing power was liberating for all parties.

...it's actually liberating to realise that dominance and power over [others] makes you sick as well as the other party.... that's the exciting thing for people who have had that experience and been on that journey... recognising that actually we're all better off by having these kind of relationships and that.... the country's going to be better off, we're all going to be better off if we can recognise that... dominance is not a [good] way... actually everything is a negotiation and that power shared with very different world views is enhancing...-B

Another participant identified an internal process which caused individuals to change .... as the culture around you.... starts to change its discourse .... the contradictions start to get too great.... [the] conceptual resources around somebody always trigger[s] them to.... search for some logic in their world.-C

As the conceptual resources change around Päkehā... people... start shifting their thinking...people don't wanna be left behind and thought of as the last living red neck on their street. $-C$

When the interviews were completed, I was left with a sense that each of the participants had a deep and overwhelming sense that there was a simple matter of right and wrong here. It was right that Pākehā views of Māori and te Tiriti should change to give Māori greater authority within Aotearoa/New Zealand over resources, their lives and their whenua. Wider Māori authority over water resources was just a part of a wider authority. While they accepted that in spite of considerable progress having been made to date, there was still a long way to go on a path that was not entirely clear and would present considerable obstacles to Pākehā. Participants equally felt deeply that it was wrong for Pākehā to stand in the way of Māori realisation of Tiriti rights, rather that Pākehā had a role to play that would have wide benefits for everyone in Aotearoa/New Zealand. 


\section{Discussion - "In the end, no-one gets off the island"}

In this chapter, the review of literature and the outcome of the interviews is discussed in relation to the research question. The question can be broken down into four parts:

1. How have Pākehā views changed in the past?

2. Why have Pākehā views changed in the past?

3. How might Pākehā views change in the future?

4. Why might Pākehā views change in the future?

When preparing the thesis topic the research question was considered in relation to water. As the research progressed, it became apparent that the question of authority over water and changing Pākehā views is inextricably woven into wider issues. It became necessary to canvas those wider issues.

The statement nobody owns water (Young, 2012) can be seen in this context. It implicates issues wider than water and ownership. As such it provides a touchstone for these questions. It is a barometer of the state of Pākehā views about te Tiriti, Māori and water resources. Behind those three words, lie 200 years of cultural relationship and a journey of cultural change. They represent at the same time an entrenched Pākehā position, the advances in understanding that Pākehā have made and the distance of cultural understanding that Pākehā must still travel. Additional to the statement is the attendant subtext that Māori have rights and interests in water. The State concedes this. But what that means and how it will be resolved will be determined by how far Pākehā have come and how far they will go in understanding, acknowledging and accepting the world view of indigenous Māori New Zealanders. Ultimately it will depend on how much Pākehā will allow an alternative world view to impact and change their own lives.

\subsection{How have Pākehā views changed in the past?}

The literature and the interviews were generally congruent on this question. Both outlined a considerable change in Pākehā views that has occurred since the 1950s. Critical to this changing view is the question of whether Māori hold a special place in Aotearoa/New Zealand or not. Despite some dissenting voices, notably Brash (2004) and Round (2013), both the literature and participants reported a growing acceptance that Māori have a special status as tangata whenua and that te Tiriti gives specific rights to Māori. This was reflected in a growing respect for Māori views and appreciation that Māori make this country unique. This is seen in the acceptance of Māori cultural practices at official functions, limited resourcing of Māori input to resource management decisions and increasing acceptance of te reo in the media. 
Participants provided examples of where Pākehā change had occurred with illuminating examples of widespread Pākehā adoption of Māori practices.

Perhaps the most significant demonstration of changing Pākehā views to date, has been the acceptance of historic injustice and Crown compensation to iwi through the Treaty settlement process. Both the literature and the participants identified the beginning of an understanding of tino rangatiratanga, mostly through the application of co-management arrangements in Treaty settlements as a critical next step for Pākehā.

The literature provides some good studies which support Pākehā identification of Māori icons as representations of nationhood. However it also shows that dominant group 'myth making' remains. Studies found support for symbolic biculturalism but opposition to resource specific affirmative action policies amongst Pākehā. In spite of this, empirical evidence from successive surveys by the Human Rights Commission indicate a growing general knowledge and interest in the Treaty of Waitangi.

There is no doubt that considerable further change could occur, and many authors continue to write about problems with, for example the Treaty settlement process and ongoing modern colonialism. Expression of these opinions and ideas continue to promote change in Pākehā views, reinforcing the activities that have promoted Pākehā change to this point.

\subsection{Why have Pākehā views changed in the past?}

Whether considering the past or the future, the relationship between how and why social change occurs is complex. One of the key factors at play is a feedback mechanism where change can create more change. How things change affects why things change and vice versa.

The literature is considerably more articulate in answering this question than the participants were, though the two remain consistent. A number of authors outline how external influences like the American civil rights movement, womens' movement, and progressive church antiracism ideas promoted changing attitudes amongst Pākehā.

Critical influences were Māori protests including the 1975 land march, Whāingaroa (Raglan Golf Course), Takaparawhau (Bastion Point) and Pākaitore (Moutoa Gardens). The widespread introduction of television to people's homes in the 1960s made these protests difficult for Pākehā to ignore. Additionally, from the 1950s many Māori moved from rural areas to cities, increasing contact between Pākehā and Māori. The Springbok rugby tour in 1981 confronted many Pākehā with racism at home when they were opposing racism abroad. 
The setting up of the Waitangi Tribunal in 1975 and the significant decisions it made from the 1970s along with government attempts to include the Treaty into policy and the development of Treaty education all contributed to changing Pākehā views.

But these changes have only occurred in the face of considerable opposition. Perhaps one of the most significant barriers to changing Pākehā views, identified in both the literature and interviews, was the unrecognised bias which derives from Pākehā values and position. Bell (2008) describes this as "an unconscious expectation borne of repeated experiences across lifetimes and generations of being centred and dominant... one that unconsciously reproduces relations of unequal power" (p. 862). The inability to see the effects of their cultural dominance, blinds Pākehā to a recognition that it is a Pākehā problem. As such, the subconscious nature of cultural dominance is perhaps the first barrier that Pākehā need to understand and overcome. As expressed by one participant:

...we are in such a powerful dominating position and.... we're not even aware of our own dominance in all these relationships...-B

Activities, identified by participants which broke down Pākehā dominance at a personal level, were those which involved personal contact and activities where Māori and Pākehā were working together. This was seen in environmental activities like stream care and environmental restoration. All of which leads us to the future. How and why might Pākehā views change in the years to come?

\subsection{How might Pākehā views change in the future?}

While the literature commented considerably on why and how Pākehā change had occurred in the past, very little has been written about this in relation to the future. Conversely, the participants provided considerable information about how things might change. The changes they saw built on the changes that had already occurred and were driven initially by the causes of change to date.

The participants foresaw a growing acknowledgement of a Māori view of water and increasing resourcing of Māori input to resource management decisions slowly devolving greater authority over resources to Māori authorities. They considered that Pākehā would become more informed, through ongoing contact with Māori and Māori organisations, leading to the development of conversations about issues, building of relationships and ultimately greater respect for a Māori world view. A key outcome would be a growing 
understanding that with water, as with many things, Māori have a different but legitimate view.

From this it was hoped that Pākehā might develop a greater understanding of the power relationship that exists between Pākehā and Māori and the sharing of that power.

The critical change seen by the participants as needing to occur, was a greater understanding and acceptance of tino rangatiratanga. They believed this was possible, but would not be easy for Pākehā. Water was seen as an area where this change might begin to take place.

\subsection{Why might Pākehā views change in the future?}

The interview participants provided answers to this question. They felt that if Pākehā could see the benefits that would accrue to them as a group and to Aotearoa/New Zealand as a whole, change could occur. They suggested that as Pākehā came to understand that, while there were significant differences between themselves and Māori, in many instances Māori want the same things as Pākehā. It was suggested that this could occur if Pākehā were properly and fully informed. The Pākehā media were identified as a barrier to this, and in need too, of being better informed. A driver for change was identified as a continuing recognition of historic injustice which could assist an understanding of contemporary injustice and discrimination. This it was suggested, would make Pākehā uncomfortable, opening them to changing their views. Particularly, the participants considered that Pākehā had a responsibility to work with Pākehā, recommending the importance of Treaty education. These things it was suggested would lead to greater acceptance of tikanga and Māori values, and a greater acceptance that Māori have a special place in Aotearoa/New Zealand.

It is a positive message, and the participants were very aware that such transformative change would be resisted and would be difficult. However they underscored the essential importance of such change.

\subsection{Can transformative change to Pākehā views occur?}

In spite of the changes that have occurred to date, the pace and extent of further change remains to be seen. There have been some spectacular changes in the widely held views of New Zealanders. Until the mid-1980s homosexual activity was illegal in Aotearoa/New Zealand, but in 1986 a private members bill was passed in the House of Representatives which changed that. Previous attempts to pass similar legislation had been unsuccessful in 1974, 1979 and 1980. While there was considerable opposition to the 1986 legislation, parliamentary support 
reflected changing public attitudes to homosexuality (Ministry for Culture and Heritage, 2014). In 2005 the Civil Union Act was passed in response to calls for the legalisation of gay marriage. The Act allowed couples of the same sex or different sexes to have their relationship solemnised as a civil union and officially registered in New Zealand. But it did not allow same sex marriage. By 2013 legislation was passed to make same-sex marriage legal. The bill was comprehensively passed by 77 votes to 44 and while there was some opposition, it was considerably less than in 1986. The legislative changes reflect the changing public view of homosexuality. This example demonstrates that views, widely held within a society can change and often over short periods of time.

Social change within a society becomes possible when a critical mass of people support that change. The important thing about social change is that it is a change to ideas, concepts and values, positions that people have internalised and adopted. Harari (2014) describes the rules or values under which society operates, as imagined realities, though he suggests that few people see them as such. His description provides a useful framework for understanding how change can occur. Harari (2014) suggests that three main factors are involved in preventing people from realising that the order which organises their lives, exists only in their imagination. The first is that the imagined order is woven into the material world. The second is that the imagined order shapes our desires. The third is that the imagined order is inter-subjective. This is described as something within the communication network that links the subjective consciousness of many individuals. If an individual changes their view, little in our society changes. But if most of the individuals in a society change their view, the inter-subjective phenomenon changes (Harari, 2014).

Views of the importance of te Tiriti are shared in the imaginations of millions of people in Aotearoa/New Zealand. The imagined order of Te Tiriti is inter-subjective, so to change it, will require changes in the consciousness of many people. Bell (2009b) articulates this succinctly, "Western universalism makes it difficult for peoples such as Pākehā to truly imagine a subjectivity and sensibility unlike their own. However if subjectivities are socially constituted, they may also always be otherwise." (p. 188) Harari (2014) suggests that this can only occur with the assistance of complex organisations, like ideological movements, political parties or governments. The success of these organisations requires the cooperation of large numbers of individuals. To create societal change then, it is necessary for a large number of people, unknown to each other, within that society to replace an existing imagined order with an 
alternative imagined order. If this can be achieved change can occur. One interview participant described the possibility as follows:

...we do tend to hit critical mass at surprising moments, which just shows you that every single little project and all the myriad things we could be doing even within our western world view... is worth it. Cos suddenly it all does hit critical mass. $-C$

Human Rights Commission surveys suggest that Pākehā are approaching that critical mass. They tell us that knowledge of the Treaty amongst Pākehā is increasing and that Pākehā want to learn more about the Treaty (HRC, 2004). The Human Rights Commission research also indicates that about half of the survey participants think the Treaty is for all New Zealanders and is the founding document of Aotearoa/New Zealand (HRC, 2011). A limitation of this empirical data is that while it presents a clear picture of the numbers of people with specific views, the statistical method of reporting the data suggests that the views of survey participants are homogenous. All of the participants I interviewed for this research, commented that the views of both Māori and Pākehā cover a wide spectrum. They suggested that while many attitudes and points of view may be held by the majority of these groups, there were no views that were essential to any group. In many respects, this difference in analysis of information, highlights the difference between examining the quality of peoples' views with qualitative research and representing those views through quantitative research (Tolich \& Davidson, 2011). The range of Pākehā views is possibly a factor that enables further change, providing examples that people can follow.

\subsection{Three stages of Pākehā change}

A clear three part pattern seemed to emerge from the interviews. The first was that to date, Pākehā views of Māori and te Tiriti have changed considerably, largely due to a growing Pākehā understanding and awareness of historic injustice particularly in relation to Māori alienation from historic lands. While there is continuing resistance to this view in some quarters, the participants expressed that the majority Pākehā view accepts this and it has resulted in te Tiriti settlement process. The next step in a process of Pākehā change was seen as developing an understanding of Māori tino rangatiratanga as expressed in Article Two of te Tiriti. While this was considered a more difficult concept for Pākehā to accept, the first stages are being seen in Tiriti settlements over natural resources with co-management or cogovernance provisions, particularly where they relate to water. The third step which emerged from the interviews, but not widely seen in Pākehā society is an acceptance within 
Aotearoa/New Zealand of a Māori world view. If the second and third steps are to follow the first, a lot must change in Pākehā thinking.

The participants clearly found grounds for Māori tino rangatiratanga in Article Two of te Tiriti. But many assumptions were made by the participants about what tino rangatiratanga meant. There was some suggestion that co-management or co-governance measures provided limited tino rangatiratanga in a number of Treaty settlements but the extent and value of this was viewed with some suspicion, particularly because such arrangements continue to be constructed under Pākehā models. These views were consistent with those of Orange (2004) who describes tino rangatiratanga as the right of Māori to be involved in resource management decisions under Māori terms. "Real participation in resource management will be difficult as long as the structures and culture remain essentially Pākehā” (Orange, 2004. p. 267). These views are reiterated by Ruru (2013) who argues that government seeks to provide for tino rangatiratanga by strengthening the role and authority of Māori in resource management and Te Aho (2012) who suggests that the co-management arrangement in the Te Arawa Lakes Act 2006 is less than the tino rangatiratanga sought.

Orange (2004) highlights the difficulties that successive governments have had in reconciling tino rangatiratanga with a Treaty relationship defined in 1975 as being akin to partnership. She suggests that in the 1990s, both National and Labour governments considered that Article One of the Treaty ceded sovereignty to the Crown, but that a number of Māori leaders and some Pākehā academics believed that use of the term kawanatanga in Article One ceded governance rather than sovereignty. Tino rangatiratanga was argued to be more than self-management. Orange (2004) reports that underlying the issues was the desire of many Māori for the restoration of mana and authority over resources to assist in the development of an economic base.

The importance of tino rangatiratanga cannot be overstated, especially with the recent release of the Waitangi tribunal report, Stage 1 of the Te Paparahi o te Raki Inquiry (Waitangi Tribunal, 2014). The report concludes that signatories to te Tiriti did not cede sovereignty to the British Crown. The conclusion described as inescapable. It finds that while the British entered Treaty negotiations intending to acquire sovereignty, it did not explain this to the rangatira they were negotiating with. Rangatira were told they would retain tino rangatiratanga, their independence and chiefly authority. The report found that the chiefs agreed to share power and authority with Britain and consented on the basis that the Governor and Chiefs would be equals. 
The report does not detail how effect should be given to the Treaty and tino rangatiratanga, but this is clearly a question of critical importance. One interview participant raised the difficulty of practically applying tino rangatiratanga in today's world, suggesting that the meaning of tino rangatiratanga was clear to those who signed the Treaty in 1840, but that meaning, if taken literally today, would give hapū authority over much of the environment. It was expressed that this situation was not realistic. A number of other participants had highlighted the issue of resourcing Māori input to existing processes.

Working out, how to apply an 1840 agreement in modern times is an essential part of the nation building and consent that Borrows (2006) sees as critical to avoid violence between indigenous people and colonisers. Partnership now seems to be the means by which the Crown intends to provide for tino rangatiratanga (Orange, 2004). Opponent of the Treaty process, David Round is correct when he states that te Tiriti makes no literal suggestion of a partnership between Māori and the Crown (Round, 2013), but Orange (2004) points out that the Labour Government of the mid 1980s while forging ahead with sweeping changes was repeatedly confronted with Treaty issues, particularly "how an agreement made in 1840 could be translated into modern terms of reference" (Orange, 2004, p.178). The partnership that Round (2013) rejects, came from three sources in the late 1980s, the Waitangi Tribunal, the Court of Appeal case on the State Owned Enterprises Act and to a lesser extent the Treaty principles prepared by the Treaty Unit of the Department of Justice (Orange, 2004). The term 'partnership' was beginning to be used widely in relation to te Tiriti, "to give contemporary meaning to the reciprocal nature of the Treaty's first and second articles" (Orange, 2004, p.196) and to recognise the relationship between Māori and Pākehā (Orange, 2004).

Borrows (2006) states that while treaties between indigenous people and colonisers set ground rules for future interactions, their signing is distinct from their implementation, indicating that a modern Tiriti solution can be agreed. The participants believed this was possible and the empirical evidence suggests that Pākehā are ready to take this step.

Though not asked directly what tino rangatiratanga would look like, it seems that participants would have responded as they did to the question of what Māori rights and interests in water might be, they would differ amongst Māori but would be something for Māori themselves to determine. The view of Orange is that "There is no unified Māori position on what might give effective expression to tino rangatiratanga" (Orange, 2004, p. 269). Durie (2005) comments extensively on tino rangatiratanga, but confirms "There is then no single definition of tino rangatiratanga and little comfort can be derived from linguistic origins or simplistic notions 
about an 1840 understanding of sovereignty" (Durie, 2005, p. 6). It seems clear however that understanding and expressing tino rangatiratanga will be critical to the future of Aotearoa/New Zealand. It may be appropriate that Māori tikanga is applied as discussed by Mikaere (2011), the injured party determining the redress. It may also be that water is the ideal area where ideas of tino rangatiratanga can be developed and expressed.

The third part of the pattern represented a considerable leap for Pākehā. Accepting indigenous norms and understanding a Māori world view would not only involve agreement that Māori had a right to live as Māori, as 66 percent of participants in the 2006 Human Rights Survey did (HRC, 2006), but accepting that a Māori world view could legitimately influence many aspects of Pākehā lives through the inclusion of that world view into the functioning of society. This would include where the impacts might sometimes negatively affect or disadvantage Pākehā. The key to this according to Bell (2009b) 'is acceptance that the cultures of indigenous peoples cannot be fully captured within Western epistemological frames, but remain distinctly at odds with their terms of reference" (p. 189). Understanding injustice would seem to be insufficient for Pākehā to concede authority over water to Māori. But because many Pākehā acknowledge that Māori have a different relationship to water than most Pākehā and because water is considered to be a under Article Two of te Tiriti, it may be a good place to begin that conversation.

The government has just completed a consultative process with the Land and Water Forum which, while limited in some respects strongly advocates for the acceptance of a Māori view of water resources, inclusion of Māori in the management of water resources and acknowledgment of the importance of Māori to the resolution of issues (Land, Water, Land, \& Water, 2012b). The government is aware of general Māori dissatisfaction with water governance and highlights in the Fresh Start for Fresh Water policy programme, a need to negotiate with Māori to address Māori interests in water (Ruru, 2013).

Unfortunately it seems that an opportunity to have this national discussion has been missed. Participants identified that cases brought to the Waitangi Tribunal provided an educational opportunity that was not taken. Information presented to the Tribunal which could have been used to educate and inform a national conversation, was not widely distributed and has not contributed to a wider national discussion.

The three-year constitutional review, announced by the government in December 2011 and intended to initiate a national conversation on a number of issues, including the role of the Te 
Tiriti o Waitangi (Bennet, 2011), has not achieved those aims. Failure in this task is not new. The National Party which leads the current government, included in its 1990 pre-election manifesto a commitment to establishing better public understanding of the Treaty and a consensus on its role (Orange, 2004), but when elected did little to expedite this commitment. It is probably optimistic to view opposition to the government's 2012 programme of selling shares in water dependent Meridian Energy as an opportunity to start a national conversation on tino rangatiratanga, but the government's refusal to address Māori water interests and authority over water at this time (Ruru, 2013) suggests a need for such a conversation.

More recently the release of Stage 1 of the Te Paparahi o te Raki Inquiry by the Waitangi Tribunal (Waitangi Tribunal, 2014) asserting that Treaty signatories did not cede sovereignty to the Crown, provided another opportunity for a national conversation. Unfortunately the Minister for Treaty Negotiations responded by stating that in spite of the findings, the Crown retained sovereignty in New Zealand and that would not change (Bennett \& Quilliam, 2014b). The reality is that the question of tino rangatiratanga will not go away. Māori will demand that the Crown, and by implication Pākehā, address this question, just as Māori demanded that the Crown and Pākehā addressed historic injustice. Māori have the right to do this under Article Two of te Tiriti. If te Tiriti gives Pākehā a right to belong in Aotearoa/New Zealand as Snedden (2005) suggests, then that opportunity is based on injustice if te Tiriti is not honoured (Margaret, 2013). Just as Pākehā came to accept colonising injustice and compensation for wrongs, they will need to understand and accept tino rangatiratanga. The need for a national conversation about this fits with the assertions of Borrows (2006) that where injustice has occurred, treaties can become more relevant and if obligations of treaties have not been honoured over time, they should not be discarded. Participants were clear that the starting point for such a conversation should be determined by Māori.

.... if you do the talking in a way that is truly respectful and responsive in fact you find a way through quite difficult situations, but that it's when people, particularly Māori feel ignored or trivialised or cast aside, then you will have problems...-E

...the last thing that Māori need is helpful Pākehā coming up with their position and asserting it when it's not the position that Māori want or need to have expressed so there needs to be some real care around what we speak and when we speak it.-D

...it's not up to us to have the blueprint for how this Treaty relationship is going to be... but it is up to us to commit to the process.... about building that relationship and doing 
some listening about... how would Māori like to see this issue resolved.... that's what we need to do.-B

I think that the Crown has to sit down and ask Māori how do you want to work this out.$B$

Ultimately, the participants were unequivocal that a wider and deeper conversation was needed. There was a clear suggestion that progress had been made, but that Pākehā have no option but to continue to learn about and understand the position of Māori.

...in the end no-one gets off the island, we're all here and we have to work it out...-B

\subsection{Who should decide Māori rights and interests in water?}

Perhaps the most interesting participant responses came from a question about what Māori rights and interests in water might be. After asking this question of the first two participants, I considered not asking it of the other participants. The first interview participant expressed a view that Māori rights and interests in water should be determined by Māori aspirations under the Māori text of the te Tiriti, particularly in regard to tino rangatiratanga, but did not specify what those rights and interests might be. The second interview participant expressed that they found the question challenging to answer but articulately identified that for a Pākehā to express what Māori rights and interests were, was to effectively define those rights and interests. It was conveyed that it was for Māori, not Pākehā to define what Māori rights and interests were. If Pākehā did this, it was another expression of Pākehā power and control in a colonial situation.

I sensed from the first two participants that the question was not a good one as it indicated a lack of understanding of the mechanisms of Pākehā dominance on the part of the interviewer. I considered removing the question from the subsequent interviews, but on reflection decided to retain it. My view was that there was benefit in a question that challenged participants and gave them the opportunity to examine their own position. It allowed the participants an opportunity to 'walk the talk', to identify a situation that invited them to take a culturally dominant position, or to identify that to do so was inconsistent with te Tiriti and the views they had already expressed about the right of Māori to determine these things for themselves. Ultimately each of the participants responded in a similar manner, an indication of the depth of their understanding of the issues the questions were asking them to explore. The following quote expresses the sentiment of all of the participants with some clarity 
I think that it's what they say it is, tangata whenua, hapu tanga... I have never met a Màori who would make claim to be able to define the interests and rights of another hapū or iwi... [and] I as a Pākehā have no intention of trying to define what Māori interests and rights are because that to me is what the hapu do, that is what Article Two rangatiratanga means, it's the self determination of the people in relation to their whakapapa based responsibilities... [it] is not for Pākehā to define.-B

The views expressed by the participants in response to this question, demonstrate that the relinquishing of some power and control, as suggested by Mikaere (2011) is possible, at least by some Pākehā.

\subsection{Nobody owns water: what is behind the statement}

Participants saw the Prime Minister's statement as retro-gressive and justifying the status quo with a public good argument that denied Māori a legitimate right of authority or co-governance over a part of the natural world that holds special significance for them.

...this kind of statement is an example of a logic of elimination.... used by settlers, by Pākehā.... [to] put above any other interests this idea that... we live in a democracy, we all have equal rights and we have responsibilities as individuals. [It] eliminates any possibility of an indigenous understanding and.... an indigenous way of being and any kind of recognition that prior to European settlement, Māori had developed sophisticated ways of.... engaging with the environment... the effects of colonisation have dismantled... the knowledge and practices of Màori... so the statement.... is in line with ... an invisibility that Māori actually have rights under the Treaty of Waitangi and have by virtue of their settlement of Aotearoa a thousand years ago.... deep connections with the water bodies throughout New Zealand and have developed an array of knowledge and an array of practices that speak to their connection that is unique internationally...-A

In many respects the Prime Minister's statement reflects the argument that we are all New Zealanders with equal rights (Brash, 2004), asserting that the government will administer resources like water, in everyone's interest. But participants were clear that it also asserts Pākehā colonial power by denying any Māori claim of ownership over water resources. It can be seen as an example of social dominance as described by Sidanius et al. (2004) because it uses the term ownership, defining the debate in Pākehā terms, and imposing a point of view 
that attempts to give Pākehā the right to sovereignty and disproportionate control over a resource.

The link that the participants made between the Prime Minister's statement, indigeneity, colonialism and te Tiriti was a reflection of the deliberate selection of interview participants. It is probably correct that Pākehā with a dissimilar background to the participants may not have made those links, but participants agreed that while the position represented by the statement reflected a wider Pākehā view, there would be many Pākehā who would question the statement. The Prime Minister's statement highlights the issues associated with changing Pākehā views. It is important to understand that there is no consciously deliberate intention in the statement to advance Pākehā cultural dominance. It is unlikely that the Prime Minister has contrived the statement with the conscious intention of asserting Pākehā colonial power and denying Māori access to water resources. It is more likely that the statement simply represents what the Prime Minister thinks. However it is an example of a social dominance theory legitimising myth in action. The Prime Minister has conceded that Māori have rights and interests in water and presumably is aware of Article Two of te Tiriti, but his dominant group roots give him a sense of entitlement, such that he can make a statement, which is in conflict with a reasonable interpretation of te Tiriti and clearly misunderstands Māori assertions of rights in relation to water. It also seeks to deny Māori and assert Pākehā control over a natural resource to justify the government benefiting from the sale of shares in hydro-electric power generation.

The statement represents a Pākehā position unchanged in over 100 years. One that is out of step with the changes of the last 50 years and with the future. But the sub text of the statement which concedes that Māori have rights and interests in water represents a changing Pākehā view and offers an opportunity for the future.

The interview participants were very clear that Pākehā would need to take responsibility for seizing those opportunities and making changes amongst themselves. Huygens (2007) in her doctoral thesis on processes of Pākehā change in response to te Tiriti found little evidence in published literature of theories about processes by which dominant groups change a social order. But she identified that dominant groups can facilitate change and explored how Pākehā create change amongst Pākehā. She highlighted the production of counter-hegemonic discourses and noted the crucial role of social movements in developing new, liberatory social constructions. The kind of organisations that Harari (2014) suggests change the consciousness of many people. 
But change may take time. While individuals may experience considerable change to their personal views, wider societal change around Pākehā views about te Tiriti may take longer.

...I don't think that sort of stuff is achievable in fifteen to twenty years necessarily, I think there's a longer horizon for that, because I've always seen this change around justice, te Tiriti justice and justice for Māori as intergenerational and it's often slow moving and you can have real kickbacks in the process as change is happening...... as settlements progress and the agreements are made.... on the ground things are working a bit differently...-D

\subsection{Reflecting on the difficulty of this research}

One of the difficulties I faced in undertaking this research was that it was Pākehā centred but investigated attitudes and points of view relating to Māori. As a researcher, I am Pākehā and the interview participants were also Pākehā. Researching specifically with Pākehā was deliberate, but by definition it meant that those from the dominant cultural group in Aotearoa/New Zealand were investigating themselves. While selecting a narrow group of participants is a legitimate research technique (Tolich \& Davidson, 2011), it risks the problems identified by Tuhiwai Smith (2012) that research by dominant groups into issues involving or affecting Māori can further colonise Māori. Despite being aware of this, situations arose where assumptions were made by the researcher or participants that demonstrated both their status as the dominant group and the blindness that dominant groups have to their position.

An example of this situation was found when one participant was asked if they thought it would be possible for Māori and Pākehā to find common ground around fresh water resources. The participant responded:

...I'm not blind to the challenges and the difficulties around, yeah of creating that common space. Common space doesn't quite do it for me, again the language is kind of tricky. $-A$

There may have been an assumption in the use of the term common ground which suggested that there was a need for Pākehā and Māori to meet somewhere around half way. But it may be that in this circumstance, half way wasn't a fair meeting place.

One participant also questioned use of the term resource in the questions. 
I just have to say at this point that I'm using resource in relation to water and I think that's potentially a problematic term because... it's quite a Pākehā term to use and it doesn't reflect really the depth of relationship for Māori with water...-D

This participants' depth of knowledge identified a situation of Pākehā (the researcher) defining water with a set of Pākehā values when for Māori the relationship with water was different.

...I'm Pākehā, I speak as Pākehā but when I use your term resource.... I just want to be acknowledging.... that it's more than that for Māori.-D

Highlighting use of the term resource in relation to water was important because it spoke to a relationship that participants clearly identified as being different for Pākehā and Māori.

...you have a very different relationship with a resource than you do... if you see it as a toanga and if you have a whakapapa relationship with water, you know, it's a very different thing than something we use how we want...-D

Perhaps at the other end of the scale though, is the risk that as Pākehā, we romanticise or essentialise Māori views. Not all Māori have a relationship with water that is deeper than the relationship that Pākehā have and many Pākehā have strong spiritual relationships with rivers lakes and the sea as described by King (1999) when he controversially suggested that some Pākehā are no less indigenous than Māori. Participants of course were very aware of the diversity of both Māori and Pākehā views and expressed this understanding throughout the interviews.

...I'd just like to acknowledge the scope of positions within Māoridom as within Pākehā society...-D

...but again Pākehā ... is [a] diverse category. $-A$

Choosing to use the term resource is significant however, because it reflects in $21^{\text {st }}$ century Pākehā the perception held by the first European explorers who came to Aotearoa/New Zealand and assertions by Kahn (1999) and Fernandez-Armesto (2006) that colonisation was a contest for resources. It also recalls James Cook's description of Aotearoa/New Zealand as a land with an abundance of valuable natural resources (Park, 1995; Salmond, 2003).

Certainly, it is clear that we all make assumptions and many times those assumptions come from a mono-cultural, socially dominant position. This is often seen, as described above, in language which privileges a western Pākehā view. Sometimes the word itself privileges the view and other times it is the meaning of the word that privileges the view. Reference to 
ownership in the Prime Minister's statement is an example of both, where a role of kaitiaki, as described by Sonny Tau (Bennett, 2012), is sought by Māori rather than the western meaning of ownership that was taken from the statement by many Pākehā.

Many times throughout the interviews, the participants raised the problem of language that expressed solely a Pākehā view, underscoring the importance of language as both a site of cultural dominance and potentially as a decolonising tool.

The ubiquitous nature of expressions of cultural dominance became more apparent to me as the research progressed. Even though I was aware of this from the beginning of the research, I was inevitably drawn to express information in a way that privileged my own background. This highlighted for me the seeming limitless and pervasive extent of a culturally privileged viewpoint. One often obscured by that very same privilege. From a personal point of view, I could only resolve to remain vigilant, as were the participants, of how my own background pre-disposed me to a set of prejudices, many sub-conscious, which reinforced my position as part of the dominant culture in Aotearoa/New Zealand. I felt that the participants had been brave in being so open about their views, as in so doing, they risked exposing their own prejudices, conscious or sub-conscious.

At another extreme, Pākehā who openly express views that are counter to the mainstream, face a wider risk. One participant expressed it in this way:

...the truth is that for a very long time I've experienced that Pākehā who stand up on the Treaty are not automatically trusted by Māori and neither they should be, but they're also not trusted by their own as well, so it is an uncomfortable place to sit...-B

Bearing all of this in mind, I sought to make sense of the information the participants had generously provided.

\subsection{Trails that could not be followed}

Invariably, research of this nature highlights areas where further research would be beneficial. One of the frustrations with this, as I suspect with any research, was having to stop pursuing trails of information which, while interesting, would broaden the research beyond its focus. Research by its very nature uncovers information which provides fertile routes for further inquiry. During the interview process, rapid decisions needed to be made on whether questions, supplementary to the prepared questions, assisted the focus of the research or broadened the 
topic beyond what was manageable. During the analysis of the interviews, questions also arose which in hindsight might have been useful to ask during the interviews.

One question which would have provided further useful inquiry of the interview participants' views, is how public conversations on tino rangatiratanga could be started and conducted? Unfortunately the importance of examining views about tino rangatiratanga did not become apparent until the analysis of the interviews was in progress. Given the importance that Orange (2004) places on tino rangatiratanga as a discussion within government departments and amongst Māori, it seems that the acceptance by Pākehā of this concept and how its importance may be progressed with Pākehā, is an area that would benefit from further research.

Another area that the research touched but could not pursue is bi-culturalism. Considerable research has already occurred in this area and much can still be undertaken. It was considered that asking participants about bi-culturalism would have broadened the research extensively. I considered that investigating bi-culturalism would provide good parallel research, but may have complicated and diffused the focus of this research.

During the interviews, participants were not asked to make comparisons between New Zealand and other countries. Yet a couple of participants volunteered interesting anecdotes and opinions on how Pākehā had accepted taha Māori compared with other similar countries. This recalled observations by Sibley et al. (2008) who found that Pākehā identification of Māori cultural icons as representations of nationhood was different to the theory and research in Australia and the United States of America. Research into how views about indigenous cultures had changed amongst majority white populations in Australia and the United States of America, compared with New Zealand is another area where useful research could be undertaken.

Theories of change amongst dominant cultures, expanding on the work of Huygens (2007) and non-dominating cultural relationships would have supported this research but could not be pursued. Equally, investigation of what motivates allies to work for change within their own culture is another area where useful research could be undertaken.

Another interesting area of research which was touched upon was Pākehā romanticising of Māori and the underpinnings of those views. The theories of Pākehā identity and perceptions of indigeneity were explored a little with reference to King (2003), Snedden (2005) and Bell (2009a) and provide a topic for further useful research related to the topic of this thesis. 
Social dominance theory was explored as an explanation for Pākehā resistance to change, but it is contested and other ideas and theories could have been examined including system justification theory and social identity theory. It was not possible to explore this very relevant area in the depth it deserved. 


\section{Conclusion - "We've got the potential to do something different and unique and special"}

...we are now a very strongly integrated nation and population... we've got the potential to do something different and unique and special, so it's actually ... a really creative contribution that we make ... this ability to do things differently in terms of the indigenous population... so I always felt really positive and excited about it rather than frightened and threatened.-E

The above quote provides a positive response to the research question, how and why have Pākehā views of te Tiriti and Māori changed over time? They have changed such that we are now a strongly integrated nation and population, bringing us to a position where we can do something unique and special.

The reviewed literature provided answers to the question of whether Pākehā views of te Tiriti and Māori have changed over time. It showed the foundation of entrenched Pākehā views that te Tiriti was a simple nullity and did not need to be honoured, that colonisation was benevolent and brought civilisation to Māori. How a myth of New Zealand racial harmony predominated amongst Pākehā and how these views became entrenched in Pākehā thinking. But Pākehā views began to change from the late 1950s.

Primarily, Pākehā began to accept that historic treatment of Māori had been unjust. Pākehā acceptance of injustice was a response to a growing political and cultural Māori voice. Each decade brought more change to Pākehā thinking. External influences like the US civil rights movement and womens' movement raised Pākehā awareness. Issues raised by Māori started a process of questioning amongst many Pākehā. Māori protest, activism, land marches and challenges to Pākehā racism in the 1970s confronted Pākehā, forcing mainstream recognition of Māori claims of injustice. The setting up of the Waitangi Tribunal and some significant court cases resulted in the beginning of a Treaty settlement process, a fisheries agreement and major settlements with Ngai Tahu and Tainui Waikato in the 1990s. In many respects, Māori made this process impossible for Pākehā to resist.

Government departments, since the 1980s have been required to take account of the Treaty when preparing policy and 'the Crown's commitment to the principles of the Treaty is now well established in legislation and throughout the entire fabric of government" (Orange, 2004, p. 265), a change that has been described as a quiet revolution which may eventually have as much impact on Māori as the Treaty settlement process (Orange, 2004). 
In spite of a Pākehā backlash against Māori claims during the 2000s, today there is acceptance amongst Pākehā of Māori rights and te Tiriti process. Successive surveys by the Human Rights Commission provide empirical evidence which supports this view.

The literature, including from significant authors like Orange (2004) and Walker (2005) is supported by the results of interviews undertaken for this thesis. There is a strong level of congruence between the primary and secondary data sources on how and why change in Pākehā views has occurred.

There was little comment in the literature on changing Pākehā views in relation to water resources, though a number of authors identified the difficulties in finding common understanding around water due to differing values and ideas between Māori and Pākehā. Interview participants clearly identified that contact between Pākehā and Māori around water projects, stream-care and resource management processes had been a factor in changing Pākehā views in this area.

Answers to the second part of the research question, how and why Pākehā views might change in the future, were not identified in the literature. The interviewees however were enlightening on this part of the research question, identifying that the changes that have occurred in the past give hope for the future

...we also have to hold on to the fact that there have been big changes and keep hopeful, keep talking, keep listening.-B

Though none of the participants expressed it as such, three phases of change emerged from the interviews. The first, accepting injustice is described above. The second, understanding and accepting tino rangatiratanga was seen clearly as the next change that Pākehā need to make. While exactly how tino rangatiratanga would be expressed today is not clear, but it was seen as being something that Pākehā should determine for Māori. Pākehā acceptance of this was linked to Pākehā acceptance of themselves as tangata tiriti. Such a significant change was considered possible, though difficult. Further contact between Pākehā and Māori, and education about te Tiriti that would lead to the development of respect for taha Māori and Māori values, was seen as critical to developing an understanding of differences and an acceptance of a Māori world view, the third phase of Pākehā change.

Participants believe that this could happen because Pākehā would eventually come to see that there would be benefits to themselves and because a basic Pākehā understanding of justice would prevail. They provided a number of examples of where this was happening, particularly 
in practices like powhiri where Māori traditions were accepted and engaged in, by Pākehā. It was suggested that water could be a site for further transformative change.

But this level of change will require trust on both sides. If Pākehā accept themselves as tangata tiriti, they will be able to build a relationship with Māori that is based on mutual trust.

...we as Pākehā have to trust that there has been the provision of a place for us, that there has been huge generosity in that relationship... and to have a bit of trust... for what's possible in the relationship. $-D$

The importance of Pākehā continuing to change was seen as being not just about today, much more than that.

...the Treaty relationship, being an ongoing discussion, ongoing conversation that isn't just about history, isn't about settlement, but is about the future of Aotearoa New Zealand....-A

If Pākehā can take that second step, it will set Aotearoa/New Zealand apart from other colonised countries. Greater Pākehā understanding of indigenous New Zealanders will confirm that already there are significant differences between Aotearoa/New Zealand and other similar countries. Research participants were very aware of those differences.

...one of the interesting phenomenon that I've watched in New Zealand and particularly in comparison to other countries is the intimacy of our country, so that when we talk about Māori and Pākehā, for most of us we are not talking about otherness to anything like the degree that they do in many countries... we're not talking about some other people somewhere else that we don't really know or have any dealings with... we're talking about a much more intimate connection ...-E

In many respects, that difference has been the subject of this research. While the research has not investigated the difference itself, the progress that Pākehā have made, the path that Pākehā can take in their understanding of te Tiriti and Māori and its importance to our future, builds on an aspect of Aotearoa/New Zealand that sets us apart from many countries that were colonised.

It would be incorrect to say that Pākehā and the Crown have responded to the issues of dominance and two hundred years of colonisation in an adequate manner. But in recent years, some Pākehā have provided an example to others, of how a start to reconciling historic injustice can be made. Pākehā have also demonstrated how dominant groups can change their views in 
a way that benefits indigenous people, and while those changes are not universal amongst Pākehā, where they occur, they are significant. Acknowledging the start that Pākehā have made, identifying how far Pākehā have come, and having an indication of where they could go, provides some hope for building a more tolerant and just society and nation. The potential that Pākehā have to progress to a mutually trustworthy and respectful relationship with Māori, after many years of discomfort has finally developed something of a foundation from which further transformational progress can occur. Pākehā are now in a position to do things differently, different from the past, and different to others. 
Appendices 


\section{Appendix A. Ethics Approval}

From: researchmaster-help@vuw.ac.nz [mailto:researchmaster-help@vuw.ac.nz] Sent: Monday, 13 January 2014 9:35 p.m.

To: Jim Graham

Cc: louise.grenside@vuw.ac.nz; Jessica.Hutchings@vuw.ac.nz

Subject: Human ethics application approval

Dear James,

Thank you for your application for ethical approval (Nobody owns water: How and why might Pakeha

attitudes change regarding the Treaty of Waitangi and fresh water resources, reference 0000020391),

which has now been considered by the Standing Committee of the Human Ethics Committee.

Your application is approved as of today. You will receive an approval memo in the near future.

Best wishes with the research.

Allison Kirkman

Human Ethics Committee

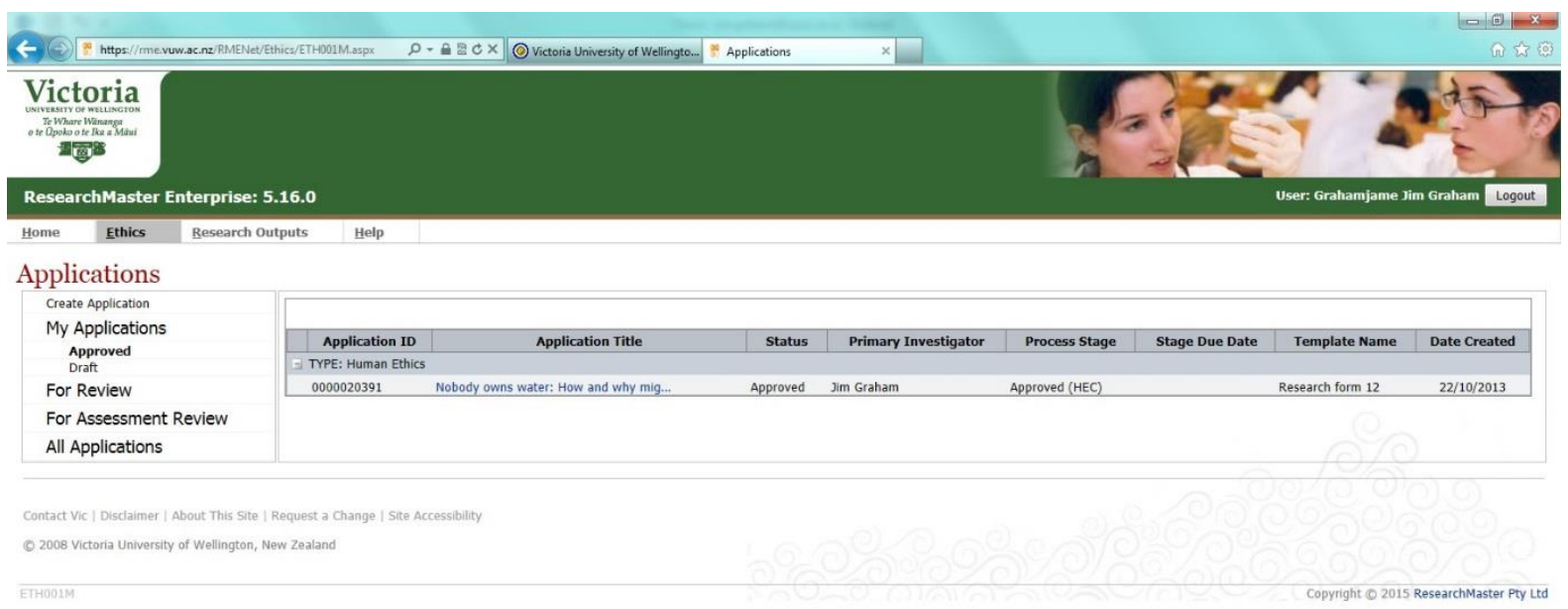




\section{Appendix B. Interview Participant Information Sheet}

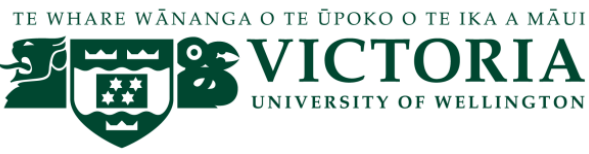

\section{Nobody owns water: How and why might Pākehā attitudes change regarding the Treaty of Waitangi and fresh water resources.}

\section{Information Sheet for Participants}

My name is Jim Graham and I am a post graduate student at Victoria University. As part of my Masters of Environmental Studies, I am undertaking a research project for my thesis. I am interested in how and why Pākehā attitudes about the Treaty of Waitangi and water resources have changed over time, how those attitudes may change in the future and how these things may affected Māori aspirations for Treaty justice regarding access to fresh water resources. You are invited to participate in this research study.

This project has been granted ethical approval by the Victoria University Human Ethics Committee.

I wish to undertake semi structured interviews with a number of people who have demonstrated an understanding of the importance of the Treaty of Waitangi to both Pākehā and Māori and have some insight into Pākehā views of the Treaty and how those views affect outcomes for Māori.

Conversations from the interviews will be digitally recorded, transcribed and analysed thematically. Participation in the study will be confidential. Any statements that you make will not be identifiable when the study results are written up. Transcripts of the interview will be provided to you for checking accuracy and you will have the option to withdraw any data until such time as the analysis is complete which will be by 31 July 2014. You will have the option of being appraised of the outcomes of the research and a copy of the final research assignment will be provided to you upon request.

Only my supervisor and I will have access to the digital recordings or written transcripts. The digital recordings will be deleted on completion of the thesis examination. Results may be published in a relevant journal or used as part of a conference presentation.

My supervisor for this research is Dr Jessica Hutchings and you may contact her at Victoria University on phone 021406 226, or Email, Jessica.Hutchings@ vuw.ac.nz if you have any queries about this research.

If you are interested in participating in this study, please sign and date the consent form enclosed and return it to me by Email (or hand it to me when the interview is conducted). I will then contact you to discuss a suitable time and place to meet for an interview. I anticipate that the interviews will take no longer than an hour.

I can be contacted by Email, grahamjame@ myvuw .ac.nz or by phone 0272313445.

Your participation in my research will be much appreciated.

Regards

Jim Graham 


\section{Appendix C. Interview Participant Consent Form}

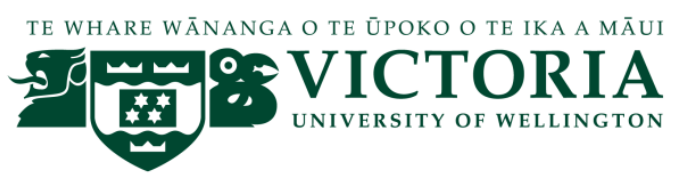

\section{Consent Form for Research Study Participants \\ Nobody owns water: How and why might Pākehā attitudes change regarding the Treaty of Waitangi and fresh water resources.}

\section{Researcher: Jim Graham}

I have been provided with and understand an explanation of this research project. I have had an opportunity to ask questions about the research and have had them answered satisfactorily.

I understand that I am being asked to participate in a semi-structured interview of about 60 minutes duration and that the interview will be digitally recorded.

I understand that the interviews are confidential and my privacy will be protected. Any comments that may be made by me that are reported in the published research findings will not identify me.

I will have the opportunity to check a transcript of my interview for accuracy and I will have the option to withdraw any data until such time as the analysis is complete which will be by 31 July 2014 .

I understand that only Jim Graham and his supervisor Dr Jessica Hutchings will have access to the data provided by me.

I am aware that this project has been granted ethical approval by the Victoria University Human Ethics Committee.

I would like to receive a summary of the findings.

yes / no

I agree to participate in the research.

yes / no

Name of Participant

Signed

Date

Contact phone number 


\section{References}

Alston, M., \& Mason, R. (2008). Who turns the taps off? Introducing social flow to the Australian water debate. Rural Society, 18(2), 131-139.

Baldwin, C. (2008). Governance and justice in water. Social Alternatives, 27(3), 3-7.

Bargh, M. (2012). The Post -settlement world (so far) Impacts for Māori. In N. R. Wheen \& J. Hayward (Eds.), Treaty of Waitangi settlements (pp. 166-181). Wellington, New Zealand: Bridget Williams Books.

Belgrave, M. (2012). Negotiations and settlements. In N. R. Wheen \& J. Hayward (Eds.), Treaty of Waitangi settlements (pp. 29-47). Wellington, New Zealand: Bridget Williams Books.

Belich, J. (1986). The New Zealand wars and the Victorian interpretation of racial conflict. Auckland, New Zealand: Auckland University Press.

Belich, J. (2007). Making peoples: A History of the New Zealanders : From Polynesian settlement to the end of the nineteenth century. Auckland, New Zealand: Penguin.

Bell, A. (2008). Recognition or ethics? Cultural Studies, 22(6), 850.

Bell, A. (2009a). Dilemmas of settler belonging: Roots, routes and redemption in New Zealand national identity claims. The Sociological Review, 57(1), 145.

Bell, A. (2009b). A Conversation through history: Towards postcolonial coexistence. Journal of Intercultural Studies, 30(2), 173-191. 
Bennet, A. (2011, date?). Twelve named to pilot constitutional review, New Zealand Herald. Retrieved from http://www.nzherald.co.nz.

Bennett, A. (2012, July 14). John Key: Waking the taniwha, NZ Herald. Retrieved from http://www.nzherald.co.nz.

Bennett, A., \& Quilliam, R. (2014a, 14 November). Expert: Treaty ruling 'distorts NZ history', New Zealand Herald. Retrieved from http://www.nzherald.co.nz/.

Bennett, A., \& Quilliam, R. (2014b, 14 November). Crown still in charge: Minister Chris Findlayson on Waitangi Treaty ruling, New Zealand Herald. Retrieved from http://www.nzherald.co.nz/.

Black, T. (2011). 'Ko te mana Tuatahi': The Treaty of Waitangi. In V. M. H. Tawhai \& K. Gray-Sharp (Eds.), Always speaking: The Treaty of Waitangi and public policy (pp. 920). Wellington, New Zealand: Huia Publishers.

Borrows, J. (2006). Ground rules: Indigenous treaties in Canada and New Zealand. New Zealand Universities Law Review, 22, 188-212.

Bosselmann, K. (2012, September,26). Debate: Who owns the water, New Zealand Herald. Retrieved from http://www.nzherald.co.nz.

Brash, D. (2004, January 27). [Speech] Nationhood speech presented at Orewa Rotary Club. Retrieved from http://www.scoop.co.nz/stories.

Bruns, B. R., \& Meinzen-Dick, R. S. (2005). Water rights reform: Lessons for institutional design. Washington DC, USA: International Food Policy Institute. 
Butler, D. (2013). Twisted history, Treaty settlements criticised. In Robinson, B. Moon, D. Round, D. Butler, H. Barr \& P. Cresswell, Twisting the Treaty: A Tribal grab for wealth and power ( $3^{\text {rd }}$ ed) (pp.123- 173). Wellington, New Zealand: Tross Publishing.

Carlson, K. S. M. (1998). Placing the Waitangi Tribunal: Attitudes Towards the Claims Settlement Process in New Zealand. Paper presented at the Critic \& Conscience: 5th National Postgraduate Conference. Wellington.

Carter, S., Kelly, F., \& Brailsford, I. (2012). Structuring your research thesis. New York; Houndmills, Basingstoke: Palgrave Macmillan.

Cowie, D. (2012). The Treaty settlement process. In N. R. Wheen \& J. Hayward (Eds.), Treaty of Waitangi settlements (pp. 48-64). Wellington, New Zealand: Bridget Williams Books.

Cresswell, P. (2013). Property rights - A blessing for Māori New Zealand. In Robinson, B. Moon, D. Round, D. Butler, H. Barr \& P. Cresswell, Twisting the Treaty: A tribal grab for wealth and power ( $3^{\text {rd }}$ ed.) (pp. 52- 58). Wellington, New Zealand : Tross Publishing.

Crotty, M. (1998). The Foundations of social research: Meaning and perspective in the research process. London: Sage.

de Graf, P., \& Dinsdale, M. (2014, 15 November). Ruling rewrites our history, Northern Advocate. Retrieved from http://www.nzherald.co.nz/northern-advocate/.

Diamond, J. M. (1998). Guns, germs and steel: A short history of everybody for the last 13,000 years. London: Vintage. 
Druett, J. (2011). Tupaia: The Remarkable story of Captain Cook's Polynesian navigator. Auckland, New Zealand: Random House.

Durie, E. T. (1989, February 6). Waitangi Day address. Waitangi, NZ.

Durie, M. (2005). Tino Rangatiratanga. In M. Belgrave, M. Kawharu \& D. V. Williams (Eds.), Waitangi revisited: Perspectives on the Treaty of Waitangi. (pp.3-19). Auckland, New Zealand: Oxford University Press.

Evison, H. (1993). Te Wai Pounamu, the greenstone island: A History of the southern Mãori during the European colonization of New Zealand. Christchurch, N.Z: Aoraki Press in association with the Ngāi Tahu Māori Trust Board \& Te Runanganui o Tahu.

Fernandez-Armesto, F. (2006). Pathfinders: A Global history of exploration. New York: WW Norton and Company.

Freire, P. (1972). Pedagogy of the oppressed. Harmondsworth, UK: Penguin.

Gould, B. (2012, December 10). Māori issues matter to Pākehā too, New Zealand Herald. Retrieved from http://www.nzherald.co.nz/

Harari, Y. N. (2014). Sapiens: A Brief history of humankind. London: Random House.

Hawke, R. (2006). Improving the water allocation framework in New Zealand: Enhanced transfer (MED OP 06/09). Wellington: Ministry of Economic Development. 
Howe, K. R. (2006). The Last frontier. In K. R. Howe (Ed.) Vaka moana: Voyages of the ancestors : The Discovery and settlement of the Pacific (pp. 14-21).Auckland, New Zealand: David Bateman.

Hsiao, E. C. (2012). New Zealand: Whanganui river agreement - Indigenous rights and rights of nature. Environmental Policy and Law, 42(6), 371.

Human Rights Commission. (2002). Human rights and the Treaty of Waitangi. Wellington, New Zealand: Human Rights Commission. Retrieved from http://www.hrc.co.nz/.

Human Rights Commission. (2004). Treaty of Waitangi awareness research. Wellington, New Zealand: Human Rights Commission. Retrieved from http://www.hrc.co.nz/.

Human Rights Commission. (2006). Treaty of Waitangi and related issues omnibus results. Wellington, New Zealand: Human Rights Commission. Retrieved from http://www.hrc.co.nz/.

Human Rights Commission. (2009). 2009 Race Relations Report. Wellington, New Zealand: Human Rights Commission. Retrieved from http://www.hrc.co.nz/.

Human Rights Commission. (2011). Treaty of Waitangi UMR omnibus results. Wellington, New Zealand: Human Rights Commission. . Retrieved from http://www.hrc.co.nz/.

Huygens, I. (2007). Processes of Pākehā change in response to the Treaty of Waitangi. (Doctoral thesis), University of Waikato, Hamilton.

Ihaka, J. (2014, 21 March 2014). Treaty wrangle tearing iwi apart New Zealand Herald. Retrieved from http://www.nzherald.co.nz/ 
Joseph, R. (2012). Unsettling Treaty settlements. In N. R. Wheen \& J. Hayward (Eds.), Treaty of Waitangi settlements (pp. 151-165). Wellington, New Zealand: Bridget Williams Books.

Kahn, B. A. (1999). The legal framework surrounding Māori claims to water resources in New Zealand: In contrast to the American Indian experience. Stanford Journal of International Law, 35(1), 49.

Kelsey, J. (1989). Rogernomics and the Treaty. In H. Yensen, K. Hague \& T. McCreanor (Eds.), Honouring the Treaty: An Introduction for Pākehā to the Treaty of Waitangi (pp. 126 -140). Auckland, New Zealand: Penguin Books.

King, M. (1999). Being Pākehā now: Reflections and recollections of a white native. Auckland, New Zealand: Penguin.

King, M. (2003). The Penguin history of New Zealand. Auckland, New Zealand: Penguin Books.

Land and Water Forum. (2010). Report of the Land and Water Forum: A Fresh start for freshwater. Wellington, New Zealand.: The Land and Water Trust. Retrieved from http://mfe.govt.nz/issues/water/freshwater/land-and-water-forum/.

Land and Water Forum. (2012a). Second report of the Land and Water Forum: Setting limits for water quality and quantity freshwater policy and plan-making through collaboration. Wellington, New Zealand.: The Land and Water Trust. Retrieved from http://mfe.govt.nz/issues/water/freshwater/land-and-water-forum/. 
Land and Water Forum. (2012b). Third report of the Land and Water Forum: Managing water quality and allocating water. Wellington, New Zealand.: The Land and Water Trust. Retrieved from http://mfe.govt.nz/issues/water/freshwater/land-and-water-forum/.

Liu, J. H., Wilson, M. S., McClure, J., \& Higgins, T. R. (1999). Social identity and the perception of history: Cultural representations of Aotearoa/New Zealand. European Journal of Social Psychology, 29(8), 1021-1047.

Maaka, R., \& Fleras, A. (2005). The politics of indigeneity: Challenging the state in Canada and Aotearoa New Zealand. Dunedin, New Zealand: University of Otago Press.

Margaret, J. (2010). Working as allies: Winston Churchill Fellowship report. Wellington, New Zealand.

Margaret, J. (2013). Working as allies: Supporters of indigenous justice reflect. Auckland, New Zealand: Auckland Workers Education Association.

Meinzen-Dick, R., \& Mendoza, M. (1996). Alternative water allocation mechanisms: Indian and international experiences. Economic and Political Weekly, 31(13), 25-30.

Mikaere, A. (1997). Settlement of Treaty claims: Full and final, or fatally flawed? New Zealand Universities Law Review, 17(4), 425.

Mikaere, A. (2011). Colonising myths--Māori realities: He rukuruku whakaaro. Wellington, New Zealand: Huia Publishers and Te Wānanga o Raukawa.

Ministry for Culture and Heritage. (2014). Birth of the gay movement. Retrieved from http://www.nzhistory.net.nz/. 
Ministry for the Environment. (1991). Resource Management Act 1991. Wellington, New Zealand: Ministry for the Environment.

Ministry for the Environment. (2005). Wai Ora: Report of the Sustainable Water Programme of Action Consultation Hui. Wellington, New Zealand: Ministry for the Environment.

Minsitry for the Environment. (2011). National Policy Statement for Freshwater Management 2011. Wellington, New Zealand: Ministry for the Environment.

Nairn, M. (1989). Changing my mind - transitions in Pākehā thinking. In H. Yensen, K. Hague \& T. McCreanor (Eds.), Honouring the Treaty: an introduction for Pākehā to the Treaty of Waitangi (pp. 75-89). Auckland, New Zealand: Penguin Books.

O'Connor, T. (2006). There's still a long road to travel. The Nelson Mail, Retrieved from http://www.stuff.co.nz/nelson-mail/.

O'Sullivan, D. (2008). The Treaty of Waitangi in contemporary New Zealand politics. Australian Journal of Political Science, 43(2), 317-331.

Orange, C. (2004). An Illustrated history of the Treaty of Waitangi. Wellington, New Zealand: Bridget Williams Books.

Park, G. (1995). The Groves of life: Nga uruora : Ecology and history in a New Zealand landscape. Wellington, New Zealand: Victoria University Press.

Pawson, E., \& Brooking, T. (Eds.). (2002). Environmental histories of New Zealand.Environmental histories of New Zealand. Auckland, New Zealand: Oxford University Press. 
Pratto, F., \& Stewart, A. L. (2011). Social dominance theory. The Encyclopedia of Peace Psychology. Put url retrieval statement.

Quist, R. M., \& Resendez, M. G. (2002). Social dominance threat: Examining social dominance theory's explanation of prejudice as legitimizing myths. Basic and Applied Social Psychology, 24(4), 287-293.

Rata, E. (2012, 13 Dec, 2012). Treaty no longer symbol of national unity, The New Zealand Herald, Retrieved from http://vuw.summon.serialssolutions.com/.

Reid, P. (2011). Good governance: The Case of health equity. In V. M. H. Tawhai \& K. GraySharp (Eds.), Always speaking: The Treaty of Waitangi and public policy (pp. 35-48). Wellington, New Zealand: Huia Publishers.

Robinson, G. M. (2002). Treaty and tribunal: Redressing longstanding grievances in Aotearoa/New Zealand. The Round Table, 91(367), 613-624.

Robinson, H. (2010). Simple nullity or birth of law and order? The Treaty of Waitangi in legal and historiographical discourse from 1877 to 1970. New Zealand Universities Law Review, 24(2), 259.

Robinson, J. (2013). Why theTreaty?. In Robinson, B. Moon, D. Round, D. Butler, H. Barr \& P. Cresswell, Twisting the Treaty: A Tribal grab for wealth and power (pp. 17-26). Wellington, New Zealand: Tross Publishing.

Robinson, J., Moon, B., Round, D., Butler, M., Barr, H., \& Cresswell, P. (2013). Twisting the Treaty: A Tribal grab for wealth and power. Wellington, New Zealand: Tross Publishing. 
Robson, B. (2002). Mana Whakamārama. - Equal explanatory power: Māori and non-Māori sample size in national health surveys. Wellington, New Zealand: Te Rōpū Rangahau Hauora a Eru Pōmare, Wellington School of Medicine and Health Sciences, University of Otago.

Round, D. (2013). The law made simple. In Robinson, B. Moon, D. Round, D. Butler, H. Barr \& P. Cresswell, Twisting the Treaty: A Tribal grab for wealth and power (pp. 59-114). Wellington, New Zealand: Tross Publishing.

Ruru, J. (2012). Māori rights in water - the Waitangi Tribunal's interim report. Mãori Law Review (Sept), 8-18.

Ruru, J. (2013). Indigenous restitution in settling water claims: The Developing cultural and commercial redress opportunities in Aotearoa, New Zealand. Pacific Rim Law \& Policy Journal, 22(2), 311.

Salmond, A. (2003). The Trial of the cannibal dog: Captain Cook in the south seas. London: Allen Lane.

Salmond, A. (2006). Two worlds. In K. R. Howe (Ed.) Vaka moana: Voyages of the ancestors : The Discovery and settlement of the Pacific (pp. 246-269) Auckland, New Zealand: David Bateman.

Salmond, A. (2011). Bligh, William Bligh in the south seas. Auckland, New Zealand: Penguin.

Schmitt, M. T., \& Branscombe, N. R. (2003). Will the real social dominance theory please stand up? The British Journal of Social Psychology, 42, 215. 
Sibley, C. G., \& Liu, J. H. (2004). Attitudes towards biculturalism in New Zealand: Social dominance and Pākehā attitudes towards the general principles and resource-specific aspects of bicultural policy. New Zealand Journal of Psychology, 33(2), 88.

Sibley, C. G., Liu, J. H., \& Kahn, S. S. (2008). Who are 'we'? Implicit associations between ethnic and national symbols for Māori and Pākehā in New Zealand. New Zealand Journal of Psychology, 37(2), 38.

Sibley, C. G., Robertson, A., \& Kirkwood, S. (2005). Pākehā attitudes toward the symbolic and resource-specific aspects of bicultural policy in New Zealand: The Legitimizing role of collective guilt for historical injustices. New Zealand Journal of Psychology, 34(3), 171.

Sidanius, J., Pratto, F., van Laar, C., \& Levin, S. (2004). Social dominance theory: Its Agenda and method. Political Psychology, 25(6), 845-880.

Snedden, P. (2005). Pākehā and the Treaty: Why it's our Treaty too. Auckland, New Zealand: Random House.

Stone, D. (2012). The Financial and commercial dimensions. In N. R. Wheen \& J. Hayward (Eds.), Treaty of Waitangi settlements (pp. 138-148). Wellington, New Zealand: Bridget Williams Books.

Tahana, Y. (2013, June 04). Treaty Settlements: Long and winding road to resolving the past, The New Zealand Herald. Retrieved from www.nzherald.co.nz/.

Turia, T. (2013, February 15). We're here by virtue of the Treaty, embrace it, Wanganui Chronicle. Retrieved from www.nzherald.co.nz/wanganui-chronicle/ 
Tawhai, V. M. H., \& Gray-Sharp, K. (Eds.). (2011). Always speaking: The Treaty of Waitangi and public policy. Wellington, New Zealand: Huia Publishers.

Te Aho, L. (2012). Ngā Whakataunga waimāori: Freshwater settlements. In N. R. Wheen \& J. Hayward (Eds.), Treaty of Waitangi settlements (pp. 102-113). Wellington, New Zealand: Bridget Williams.

Te Whiti Love, M. (1996). Private rights to water: A Treaty issue. New Zealand Engineering, $51(11)$.

Tolich, M., \& Davidson, C. (2011). Getting started. An Introduction to reseach methods. Auckland, New Zealand: Pearson.

Tomlins-Jahnke, H., \& Te Rina Warren, K. (2011). Full exclusive and undisturbed possession: Māori education and the Treaty. In V. M. H. Tawhai \& K. Gray-Sharp (Eds.), Always speaking: the Treaty of Waitangi and public policy (pp. 21-34). Wellington, New Zealand: Huia Publishers.

Trickett, P. (2007). Beyond Capricorn: How Portuguese adventurers secretly discovered and mapped Australia and New Zealand 250 years before Captain Cook. Bowden, S. Aust: East Street Publications.

Tuhiwai Smith, L. (2012). Decolonizing methodologies: Research and indigenous peoples. Dunedin, New Zealand: Zed Books.

Vertongen, B. (2012). Legal challenges to the treaty settlement process. In N. R. Wheen \& J. Hayward (Eds.), Treaty of Waitangi settlements (pp. 65-78). Wellington, New Zealand: Bridget Williams Books. 
Waitangi Tribunal, (1999). The Whanganui River Report. Wellington: Ministry of Justice. Retrieved from http://www.justice.govt.nz/tribunals/waitangi-tribunal/.

Waitangi Tribunal, (2012). Stage 1 Report on the National Freshwater and Geothermal Resources Claim. Wai 2358. Wellington: Mininstry of Justice Retrieved from http://www.justice.govt.nz/tribunals/waitangi-tribunal/.

Waitangi Tribunal, (2014). Report on Stage 1 of the Te Paparahi o Te Raki Inquiry. Wellington: Ministry of Justice Retrieved from http://www.justice.govt.nz/tribunals/waitangi-tribunal/.

Walker, R. (2005). The Treaty of Waitangi in the post colonial era. In M. Belgrave, M. Kawharu \& D. V. Williams (Eds.), Waitangi revisited: Perspectives on the Treaty of Waitangi. (pp. 56-80). Auckland, New Zealand: Oxford University Press.

Wheen, N. R., \& Hayward, J. (2012). The Meaning of Treaty of Waitangi settlements and the evolution of the settlement process. In N. R. Wheen \& J. Hayward (Eds.), Treaty of Waitangi settlements (pp. 13-28). Wellington, N.Z: Bridget Williams Books.

Wikaira, M. (2010). Māori ownership of freshwater: Legal paradox or potential. (Batchelor of Laws Dissertation), University of Otago, Otago.

Williams, J. (2006). Resource management and Māori attitudes to water in southern New Zealand. New Zealand Geographer, 62(1), 73-80.

Young, A. (2004, October, 02). A time to let sleeping treaty concerns lie, New Zealand Herald. Retrieved from http://www.nzherald.co.nz/. 
Young, A. (2012, February, 7). Key on Waitangi claim: 'No one owns water', New Zealand Herald. Retrieved from http://www.nzherald.co.nz/. 